\title{
Un établissement agricole et artisanal de la fin du haut Moyen Âge au 22 de la rue Bourg-les-Bourgs à Quimper (Finistère)
}

Excavation on an early medieval rural settlement and workshop at 22 rue Bourgles-Bourgs, Quimper (Finistère)

Jean-François Villard

\section{OpenEdition Journals}

Édition électronique

URL : https://journals.openedition.org/rao/1522

DOI : 10.4000/rao.1522

ISBN : 978-2-7535-1846-9

ISSN : 1775-3732

Éditeur

Presses universitaires de Rennes

\section{Édition imprimée}

Date de publication : 31 décembre 2011

Pagination : 183-218

ISBN : 978-2-7535-1844-5

ISSN : 0767-709X

\section{Référence électronique}

Jean-François Villard, « Un établissement agricole et artisanal de la fin du haut Moyen Âge au 22 de la rue Bourg-les-Bourgs à Quimper (Finistère) », Revue archéologique de l'Ouest [En ligne], 28 | 2011, mis en ligne le 30 mars 2014, consulté le 23 août 2022. URL : http://journals.openedition.org/rao/1522 DOI : https://doi.org/10.4000/rao.1522 


\title{
Un établissement agricole et artisanal de la fin du haut Moyen Âge au 22 de la rue Bourg-les-Bourgs à Quimper (Finistère)
}

\author{
Excavation on an early medieval rural settlement and workshop \\ at 22 rue Bourg-les-Bourgs, Quimper (Finistère)
}

Jean-François VILLARD*

\begin{abstract}
Résumé : Une opération de fouille préventive réalisée rue Bourg-les-Bourgs à Quimper, dans un contexte antique bien connu, met au jour les structures inédites d'un petit établissement rural daté de la fin du haut Moyen Âge, entre le $\mathrm{Ix}^{\mathrm{e}}$ et le milieu du XI ${ }^{\mathrm{e}}$ siècle. Celui-ci, appréhendé partiellement par l'emprise des fouilles, se caractérise par la présence de fossés d'enclos, de structures de stockage et de combustion, ainsi que de fosses aux fonctions diverses. Parmi ces vestiges, se distingue un secteur artisanal stratifié dédié à la métallurgie (activités de réduction de fer). L'analyse des structures, alliée à l'étude céramique, permet de définir l'évolution chronologique et spatiale de l'établissement. Ce dernier peut être mis en relation avec des sites contemporains situés autour du bassin de l'Odet et s'intégrer à l'Histoire quimpéroise.
\end{abstract}

Abstract: Excavations in advance of development at rue Bourg-les-Bourgs, Quimper, in the heart of the Roman settlement, revealed for the first time the remains of a small rural site dating, from the early medieval period, between the $9^{\text {th }}$ and the middle of the $11^{\text {th }}$ century. The settlement, only partially excavated, is defined by enclosure ditches, storage pits and also pits of varied usage. Other features were identified as corn-drying kiln, earth or oven and furnace. Among these features, an area for iron smelting was identified. Combined analysis of the features and the pottery assemblage allow the spatial and chronological evolution of the settlement to be defined. The settlement can be compared to contemporaneous sites located in the Odet basin and will take its place in the history of Quimper. (Trad. J.-Y. Robic)

Mots clé : haut Moyen Âge, habitat rural, métallurgie du fer, silo, fosse, foyer, four à grain, bas fourneau, typologie, céramique, scorie, analyse spatiale.

Keywords : early medieval, rural settlement, iron metallurgy, storage pit, pit, hearth, corn-drying kiln, furnace, typology, pottery, slag, spatial analysis.

\section{INTRODUCTION}

\section{Le site et son contexte géographique}

Le site du 22 de la rue Bourg-les Bourgs est localisé (fig. 1) sur la rive droite de l'Odet, en zone urbanisée à $700 \mathrm{~m}$ au sud-ouest du confluent de l'Odet et du Steiir. Celui-ci correspond à l'angle sud-ouest de l'espace intra-muros du bas
Moyen Âge. Les parcelles cadastrales concernées (BX n 283 et 444) sont implantées sur un rebord de plateau (altitude entre 15 et $21 \mathrm{~m}$ ) exposé au sud-est et dominant la rivière dans le prolongement oriental du plateau de la Terre Noire, lui-même orienté nord-ouest/sud-est (altitude $65 \mathrm{~m}$ ) et encadré par deux ruisseaux. Le plus septentrional est un affluent du Steïr (ruisseau de Kermabeuzen) et le plus méridional est un affluent, aujourd'hui canalisé, de l'Odet. Le

* Responsable d'opération INRAP; Centre de Recherche archéologique du Finistère, 2 rue du Stivel, 29000 Quimper. 


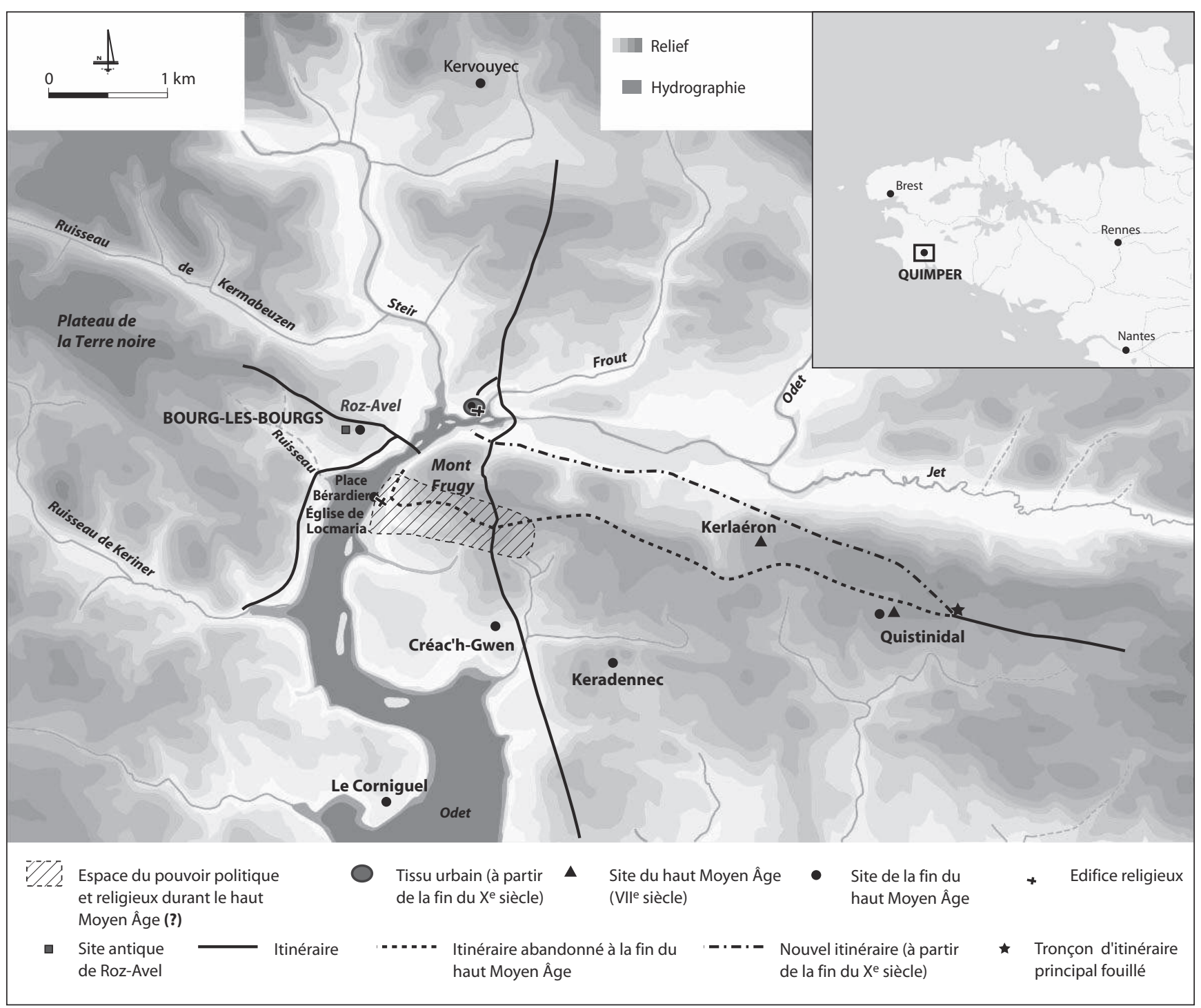

Figure 1: Quimper durant le haut Moyen Âge.

Figure 1: Early medieval Quimper.

site offre, vers le sud, un point de vue sur la vallée de l'Odet, tandis qu'à l'est et au sud-est, au-delà de la rivière, domine le mont Frugy (altitude $72 \mathrm{~m}$ ) au pied duquel est implanté le quartier antique et médiéval de Locmaria.

Le terrain présente un profil en pente douce, en direction du sud-est. Le centre de l'espace fouillé est marqué par un léger replat. Le pendage s'accentue ensuite fortement au sud de la zone décapée en direction de la rue Bourg-lesBourgs, taillée en contrebas, en pied de colline. Le substrat est relativement varié, notamment en fonction de l'altitude. Dans la partie haute, le sol est composé d'arène granitique. Celle-ci, grossière au nord où elle est au contact d'un filon de granite, s'affine vers le sud. Au-delà de la limite du replat, le substrat devient argileux (argile fine gris-jaune à gris-vert).
Enfin, en bas de pente, l'argile se charge en graviers roulés et petits galets, correspondant à d'anciennes plages du Tertiaire. C'est sur cette partie basse qu'est implanté l'établissement du haut Moyen Âge. Le substrat graveleux souligne l'étroite relation entre ce terrain, le réseau hydrographique proche et le contexte de fond de ria. Les travaux menés par le Centre de Recherche archéologique du Finistère sur la topographie (courbes de niveau en fonction des données fournies par les fouilles archéologiques) et sur l'hydrographie de Quimper (en intégrant des notions de géomorphologie et de variations du niveau marin) ont permis de proposer une cartographie du paysage quimpérois entre le Néolithique et le $\mathrm{XIII}^{\mathrm{e}}$ siècle de notre ère (Le Bihan et Villard, 2005). Cette étude montre que, dans le cas de la rue Bourg-les-Bourgs, à 
l'époque gallo-romaine et autour de l'année 1000 (périodes de niveau marin élevé, proche du niveau actuel, sans urbanisation massive contraignante), les terrains surplombaient une large baie distante d'environ soixante-dix mètres, tandis qu'au début du haut Moyen Âge ( $v^{\mathrm{e}}-\mathrm{VIII}^{\mathrm{e}}$ siècle), puis aux $\mathrm{XII}^{\mathrm{e}}-\mathrm{XIV}^{\mathrm{e}}$ siècles, des régressions asséchaient le fond de ria, déconnectant le site de la rivière, éloignée alors d'environ deux cents mètres.

\section{Le contexte archéologique}

Le site de la rue Bourg-les-Bourgs est inclus dans la zone archéologique sensible entourant l'établissement antique de Roz-Avel, situé à $75 \mathrm{~m}$ en direction du nord-ouest. Étudié sur une superficie d'environ $1200 \mathrm{~m}^{2}$ entre 1975 et 1977 par Jean-Paul Le Bihan (Sanquer, 1975, 1976, 1977a et b; Le Bihan, 1986), le site de Roz-Avel livra les vestiges de plusieurs constructions gallo-romaines en pierre, de belle facture (bâtiments d'habitation, thermes, murs et galerie), ainsi que des traces d'artisanat et un abondant mobilier archéologique. L'histoire de l'établissement se décompose en quatre phases. Un ensemble de la fin du ${ }^{\text {er }}$ siècle après J.-C. pouvant être interprété comme une villa avec cour et édifice thermal succède à des petits bâtiments individuels (première moitié du $\mathrm{I}^{\mathrm{er}}$ siècle après J.-C.). L'ensemble évolue entre les $\mathrm{II}^{\mathrm{e}}$ et $\mathrm{III}^{\mathrm{e}}$ siècles. Des thermes plus importants sont construits (salle de chauffe, hypocaustes et piscine froide). L'établissement est détruit vers 275. Celui-ci, implanté à flanc de coteau, domine au nord-ouest les vestiges de la rue Bourg-les-Bourgs. Au pied du coteau, longeant la rive approximativement à hauteur de la rue Bourg-les-Bourgs, passait l'itinéraire quittant Quimper antique en direction de Pont-l'Abbé et Tronoën, tandis qu'au nord de Roz-Avel se dessinait un second tracé, allant vers Douarnenez. Ces voies se rejoignaient vers l'est, au point de passage à gué le plus proche. En face, de l'autre côté de la baie, s'érigeait la ville gallo-romaine de Locmaria, dominée par le mont Frugy avec sa nécropole et son sanctuaire.

Cet environnement laissait augurer la présence de vestiges antiques sur les parcelles de la rue Bourg-les-Bourgs (cf. infra), cependant la découverte du site de la fin du haut Moyen Âge fut une surprise.

\section{Historique de l'intervention et principales découvertes}

Le projet d'implantation d'habitations collectives dans le parc et dans les bâtiments restaurés d'un ancien foyer pour enfants (fig. 2) déclencha en 2004 un diagnostic archéologique dont le résultat fut positif (Roy, 2004). Une occupation gallo-romaine, datée du $\mathrm{I}^{\mathrm{er}}$ siècle de notre ère fut mise

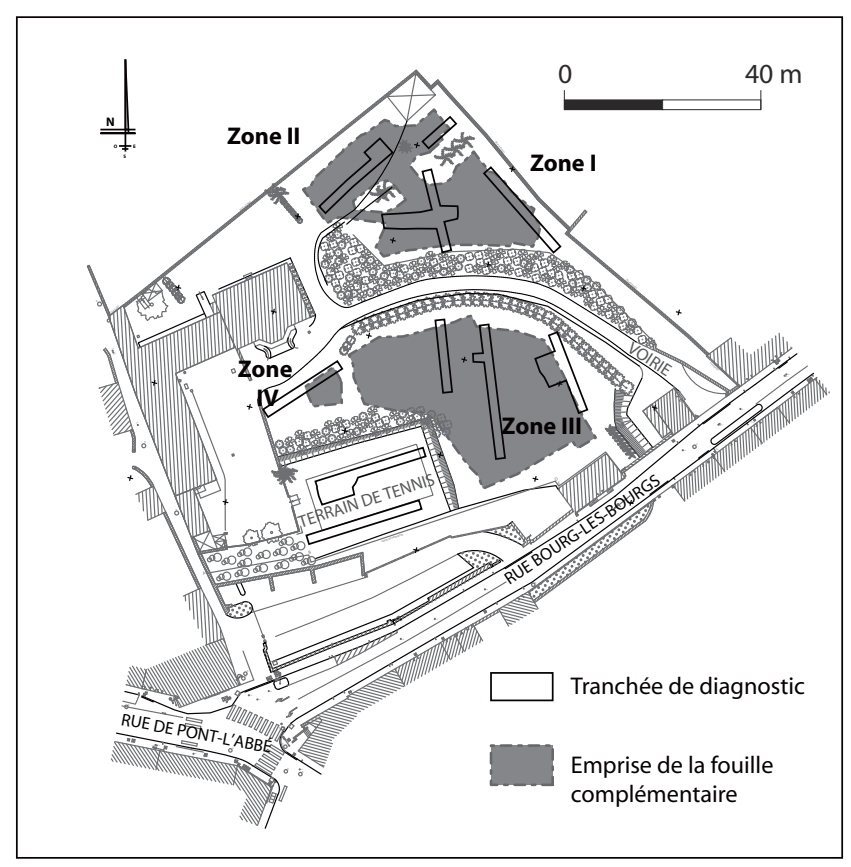

Figure 2 : Le site de la rue Bourg-les-Bourgs, localisation des zones étudiées.

Figure 2: Rue Bourg-les-Bourgs, location of the excavated areas.

au jour, probablement liée à l'établissement voisin antique de Roz-Avel (fig. 1). Compte tenu de la densité des vestiges, seuls quelques uns furent sondés, validant la datation. Ce fut suffisant pour entraîner la prescription d'une fouille de sauvetage par le Service régional de l'Archéologie, sur les espaces accessibles menacés par le projet immobilier. C'est cette fouille, effectuée en 2005, qui révéla l'établissement médiéval.

Du fait de la complexité d'aménagement des $7400 \mathrm{~m}^{2}$ de terrains cadastrés (bâtiments, espaces excavés, terrain de tennis, parking et voirie), la fouille dû se plier à certains impératifs, seuls $2650 \mathrm{~m}^{2}$ étant réellement accessibles. Sur ces espaces libres, une surface de $1900 \mathrm{~m}^{2}$ put être étudiée (zones I à IV).

Cette fouille (Villard, 2005a) précisa la nature des vestiges gallo-romains repérés en 2004 (fig. 3). Il s'agissait d'un établissement basé sur des systèmes structurés d'enclos fossoyés (enclos principal et amorce de limites d'espaces périphériques), mis en place dans les premières décennies du $\mathrm{I}^{\text {er }}$ siècle de notre ère et occupés jusqu'à la fin de la période julio-claudienne. À partir de l'époque flavienne, le paysage se modifie. La trame fossoyée, dense, disparait au profit d'un système plus lâche et à l'orientation décalée, s'appuyant perpendiculairement sur un axe de circulation nouvellement créé. Ce dernier gravit la colline, reliant entre elles les grandes voies de Douarnenez et de Pont-l'Abbé. Ce chan- 


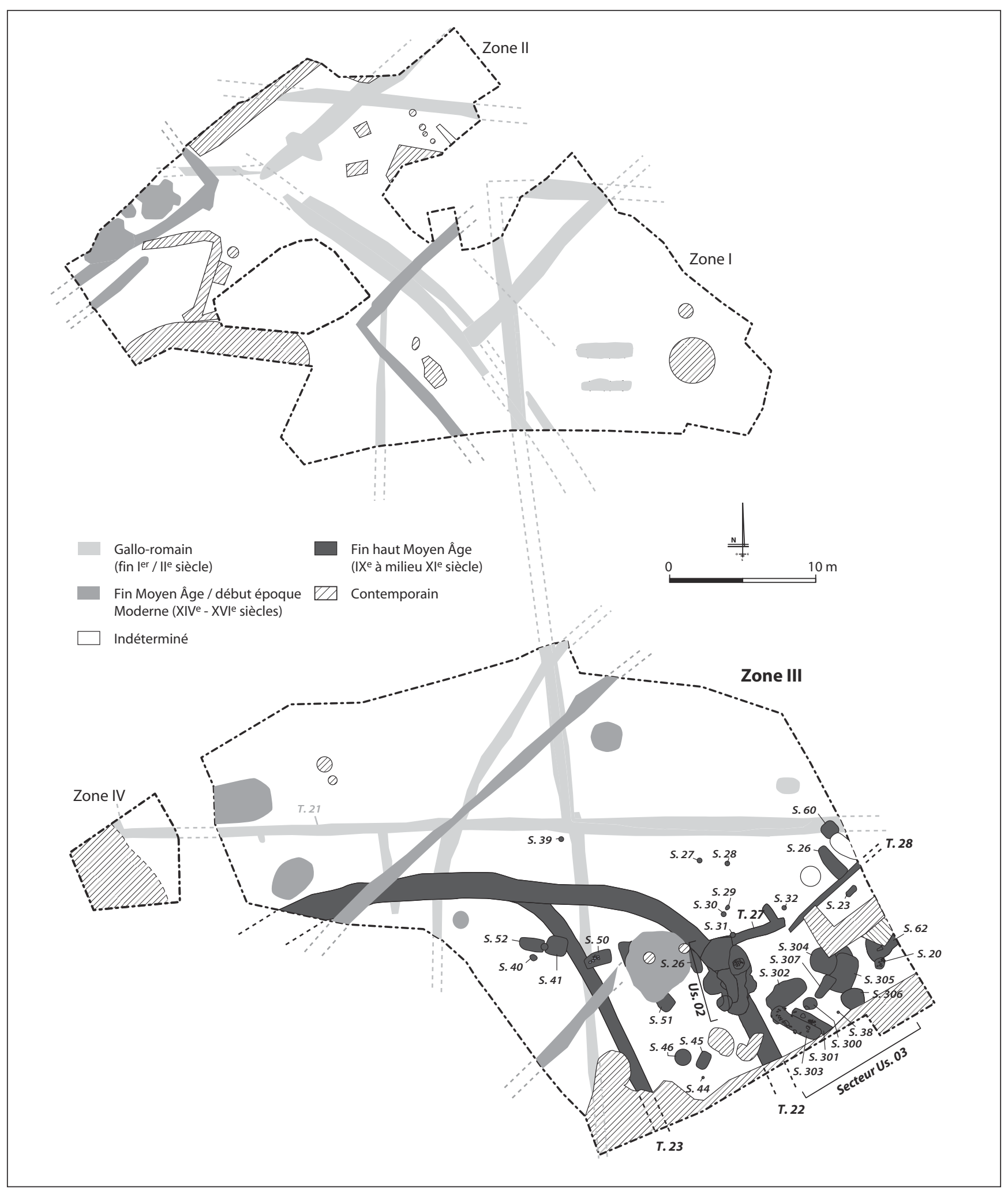

Figure 3 : Plan général diachronique des vestiges.

Figure 3: General chronological plan. 
gement semble contemporain de l'édification de la villa de Roz-Avel qui matérialise la seconde phase d'occupation de ce site (Le Bihan et Villard, en préparation).

En dehors de l'établissement de la fin du haut Moyen Âge, le site livra quelques vestiges ruraux du bas Moyen Âge et du début de l'Époque moderne (carrière d'arène granitique et parcellaire).

\section{Les vestiges de la fin du haut Moyen Âge}

Contrairement aux vestiges antiques et du bas Moyen Âge répartis sur l'ensemble de l'espace fouillé, les structures du haut Moyen Âge se concentrent au sud de la zone III, au-delà du replat topographique, sur l'amorce de la pente dominant la vallée de l'Odet (fig. 3). L'établissement n'a été étudié que partiellement car il s'étend, en direction du sud, de l'est et de l'ouest, au-delà des limites du terrain. Par ailleurs, des destructions consécutives à l'urbanisation du secteur l'affectent profondément.

Deux fossés au tracé circulaire, un secteur artisanal (Us. 02) caractérisé par des structures de traitement des minerais de fer associées à des niveaux de sol, des silos, des structures de combustion, des séries de fosses et quelques trous de poteaux matérialisent le site (fig. 4 et 5). Tous ces vestiges livrent du mobilier céramique typique, à Quimper et en Cornouaille, d'une période couvrant les $\mathrm{IX}^{\mathrm{e}}-\mathrm{XI}^{\mathrm{e}}$ siècles de notre ère. Ces vestiges, centrés sur l'époque carolingienne, étaient jusqu'ici inédits. Ils s'inscrivent dans un contexte particulier de l'histoire de Quimper, qui voit dans un premier temps la construction de la première église de Locmaria et la mise en place de son cimetière ( $\mathrm{IX}^{\mathrm{e}}-\mathrm{X}^{\mathrm{e}}$ siècles), ainsi que le montre la récente fouille de la place Bérardier (Le Bihan et Villard, 2007); puis la création du noyau urbain de Quimper intra-muros (fin du $\mathrm{x}^{\mathrm{e}}$ siècle), au confluent de l'Odet et du Frout, autour de la cathédrale primitive et de son cimetière. Cette fondation, ainsi que le déplacement du siège épiscopal entre ces deux centres religieux, prouve, si besoin était, la présence, dans le bassin de l'Odet, d'une certaine densité de population et ce en dépit d'une documentation historique et archéologique discrète. Cette population est surtout appréhendée au travers de six établissements ruraux, disséminés sur le territoire de la commune (Créac'h-Gwen, Keradennec, Kerlaéron, Kervouyec, Le Corniguel et Quistinidal). Tous ces sites présentent des caractéristiques similaires à celles de la rue Bourg-les-Bourgs (structures à vocation agricole et artisanale). Ils sont réunis par les réseaux de voie antiques toujours partiellement en fonctionnement, ainsi que cela fut démontré à Quistinidal (fig. 1). La présente étude complète ce corpus d'établissements.

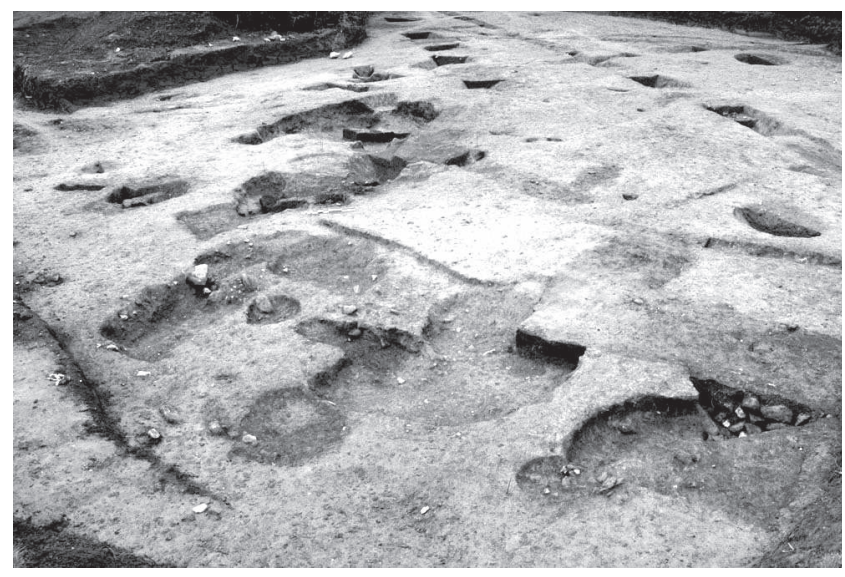

Figure 4 : Vue générale vers l'ouest des vestiges du haut Moyen Âge ; au premier plan, l'imbrication de fosses Us. 03.

Figure 4: The early medieval features looking west; intercutting pits Us. 03 in the foreground.

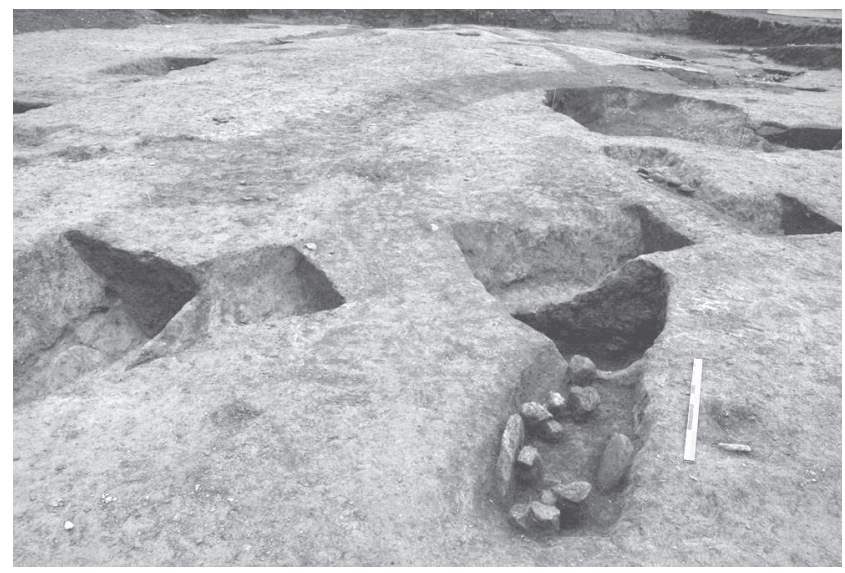

Figure 5 : Vue générale vers l'est des vestiges du haut Moyen Âge ; au premier plan, four S. 52, silo S. 41 et fossé T. 23.

Figure 5: The early medieval features looking east; in the foreground, kiln S. 52, storage pit S. 41 and ditch T. 23.

\section{LES FOSSÉS}

Les fossés sont matérialisés par un tronçon principal orienté ouest/est, dédoublé en deux tracés courbes en direction du sud-est (T. 22 et T. 23). Une petite antenne perpendiculaire (T. 27) complète l'ensemble en direction de l'est.

\section{Le fossé T. 23}

Le fossé T. 23 constitue le segment occidental du dédoublement évoqué plus haut. D'une longueur de $15 \mathrm{~m}$, il est orienté nord-ouest/sud-est (fig. 6). Au sud, il disparaît, tronqué par les perturbations modernes, tandis qu'au nord, 


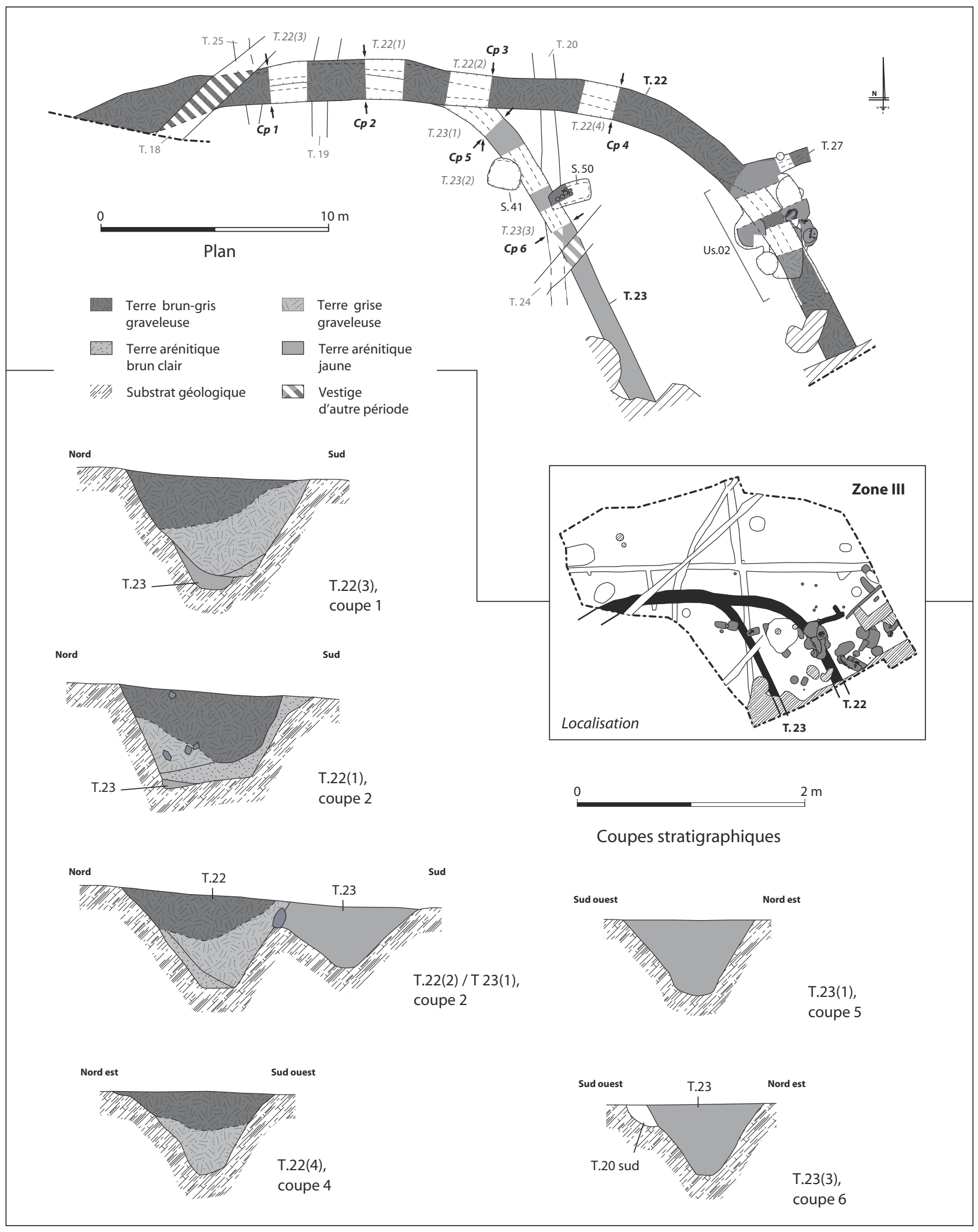

Figure 6: Plan et coupes stratigraphiques des fossés T. 22 et T. 23.

Figure 6: Plans and sections of ditches T. 22 and T. 23. 
il s'incurve en direction du nord-ouest pour rejoindre la branche principale. La fouille montre clairement que le comblement de terre arénitique jaune de T. 23 est recoupé par les terres brun-gris graveleuses du fossé T. 22, à hauteur de leur jonction. Cependant, T. 23 ne ressort pas au-delà, au nord de T. 22.

Trois sondages furent réalisés, là où le tracé de T. 23 est confronté aux structures avoisinantes : à l'intersection T. 22/T. 23, à hauteur de la structure S. 41 et près de la structure $S$. 50, aux recoupements avec les fossés antiques (T. 19, T. 20 et T. 25) ou d'époque moderne (T. 18 et T. 24). La relation entre T. 23 et les structures voisines datées du haut Moyen Âge montre que les comblements des fosses S. 41 et $S .50$ sont postérieurs au fossé (cf. infra). Ces sondages révèlent pour T. 23 un profil en $\mathrm{V}$ bien marqué. Sa largeur est de 1,20 à 1,40 m à l'ouverture, sa profondeur par rapport au niveau actuel du substrat est de 0,55 à $0,65 \mathrm{~m}$.

La fouille de l'intersection de T. 22 et de T. 23 apporte des informations sur le prolongement occidental du tracé de ce dernier. Malgré le creusement de T. 22, le fossé T. 23 apparaît furtivement sous la trace de son successeur, comme plusieurs indices le prouvent. D'une part, un petit canal occupe la partie profonde du profil de T. 22, le long de son flanc septentrional (sondage T. 22[1]) ; il est comblé par le même sédiment arénitique jaune et ce petit canal se recentre ensuite vers l'ouest (sondage T. 22[3]). D'autre part, un léger élargissement localisé de T. 22, à hauteur et à l'ouest de l'intersection, pourrait correspondre à l'ancien flanc nord du creusement de T. 23, curé lors de l'excavation de T. 22; ce dernier reprendrait ainsi, en partie, le tracé de son prédécesseur. La longueur totale observée de T. 23 est de plus de $31 \mathrm{~m}$, selon une trajectoire courbe.

\section{Le fossé T. 22}

Le fossé T. 22 possède également un tracé courbe. Si dans sa portion occidentale, il reprend celui du fossé T. 23, il s'en écarte vers l'est pour englober une surface plus vaste avant de se diriger vers le sud (fig. 6 et 7). La longueur totale observée est de près de $38 \mathrm{~m}$. Au sud, ce fossé disparaît, recoupé par les perturbations modernes, tandis qu'à l'ouest il se prolonge au-delà de la limite de fouille sous l'actuel talus arboré, avant d'être lui aussi sectionné par le décaissement récent du terrain de tennis (fig. 2).

Les six sondages réalisés au sein du fossé $T$. 22 révèlent un profil trapézoïdal à parois en $V$ et large fond plat. Sa largeur à l'ouverture est comprise entre 1,45 et $1,60 \mathrm{~m}$ pour $0,50 \mathrm{~m}$ à la base. Sa profondeur varie entre 0,80 et $1,00 \mathrm{~m}$. Il n'y a qu'à proximité du carrefour T. 22/T. 23 que la largeur de la base atteint $0,80 \mathrm{~m}$. Cet élargissement localisé est consécutif au curage de T. 23 lors du creusement de T. 22 comme si,

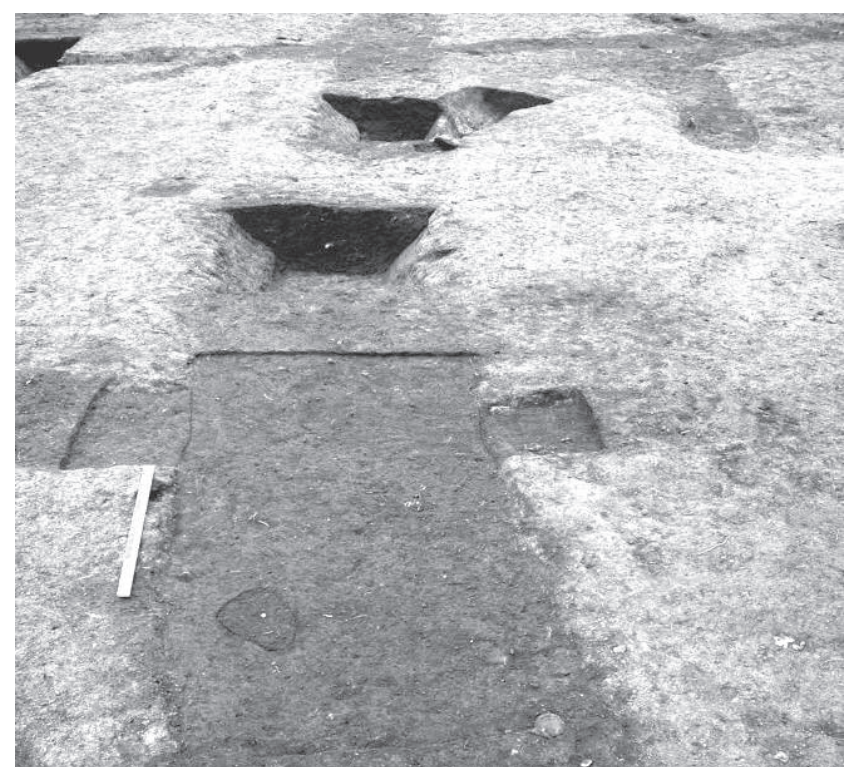

Figure 7 : Vue du fossé T. 22 recoupant des fossés antiques ; au second plan, l'embranchement T. 22 / T. 23.

Figure 7: Ditch T. 22 cutting through Roman ditches; junction of T. $22 / T .3$ in the background.

lors de cette seconde excavation, les ouvriers avaient cherché à obtenir des parois nettes dans le substrat. Un autre élément confirme cette volonté de netteté : sur le flanc méridional du sondage T. 22[1], l'empreinte du tracé de T. 23, filant en direction du sud, perturbait profondément l'intégrité du substrat; cette fenêtre fut obturée, dès le creusement, par la pose de gros blocs de pierre (fig. 8). Ce type d'aménagement ne se retrouvant pas dans les autres sondages, ce placage semble volontaire et très localisé. Par la suite, quelques pierres ont glissé au fond, indice d'une utilisation ouverte du fossé.

Le comblement de T. 22 est constitué à sa base par des couches de ruissellement d'arène jaune, essentiellement le long de son flanc interne méridional (sondages T. 22[1] et [3]) et, dans une moindre mesure, sur son flanc externe septentrional (T. 22[1]). Vient par la suite, une première couche de terre grise graveleuse. Une seconde couche tout aussi graveleuse, mais plutôt brun-gris, clôt le comblement. La limite demeure floue entre ces sédiments; il s'agit davantage d'un lent dégradé, probablement fruit d'une accumulation étalée dans le temps, que de rejets massifs de terre. Par ailleurs, la proximité d'arbres et de leurs racines ne facilite pas la lecture des stratigraphies.

\section{Le fossé T. 27}

Le fossé T. 27 se raccorde au flanc oriental de T. 22 où il ménage une antenne latérale en forme de L. Localisé dans la 


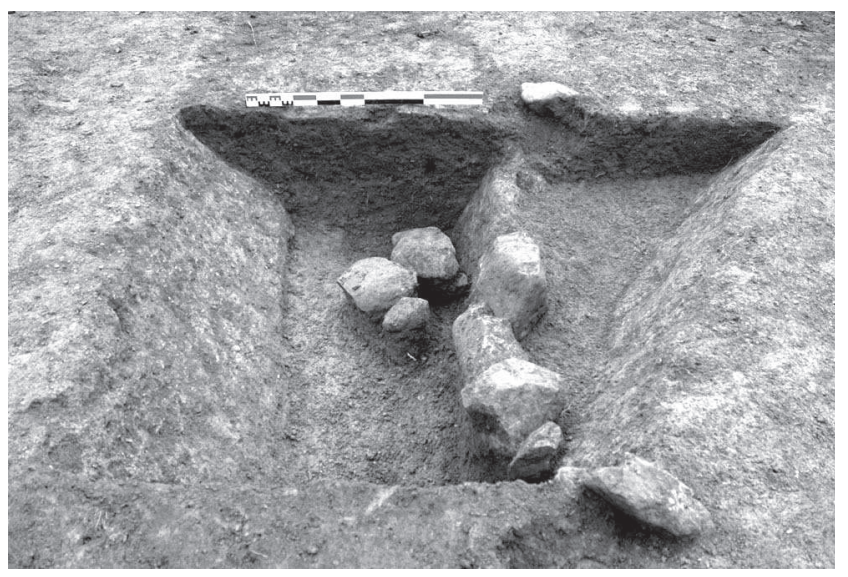

Figure 8 : Vue de l'intersection des tracés des fossés T. 22 (à gauche) et T. 23 (à droite) ainsi que du bourrelet de pierres obturant T. 23 sur le flanc méridional de T. 22.

Figure 8: Crossing point of ditches T. 22 (left) and T. 23 (right), and of the stone feature blocking T. 23 on the south side of T. 22.

partie est du tracé de ce dernier, T. 27 se dirige vers le nordest sur 5,50 m avant d'obliquer brutalement en direction du nord-ouest sur $1,50 \mathrm{~m}$.

Son profil évasé et son fond relativement large rappellent T. 22, mais dans des dimensions plus réduites $(0,85 \mathrm{~m}$ de largeur à l'ouverture pour $0,50 \mathrm{~m}$ de profondeur). Son comblement initial se compose d'une terre arénitique claire se transformant vers la surface en un sédiment arénitique plus gris. Malheureusement, les installations de l'Us. 02 (cf. infra) ont profondément bouleversé ces terres au niveau du raccordement de T. 27 avec T. 22. Malgré tout, si la lecture des couches ne permet pas d'être catégorique, tout porte à privilégier l'hypothèse d'une contemporanéité entre les deux structures.

\section{Le mobilier (fig. 9)}

Les sédiments du fossé T. 23 sont quasiment stériles. Seuls onze tessons de poterie commune grossière, dure et micacée, appartenant à un pot à lèvre rectangulaire éversée, y furent découverts, accompagnés d'un peu de mobilier erratique antique. Le fossé T. 22 livra, essentiellement dans le premier décimètre du niveau supérieur de comblement, trente-huit tessons de poterie commune, pour la plupart gallo-romains. Se distinguent cependant neuf fragments dont la pâte est identique à celle du mobilier de T. 23.

La forme du pot mis au jour au sein de T. 23, avec sa lèvre de section rectangulaire éversée, sa pâte commune grossière à gros grains de quartz et sa technique de finition (lissage de surface tout en laissant des traces de modelage visibles) tendent à dater ce récipient de la fin du haut Moyen Âge. Des

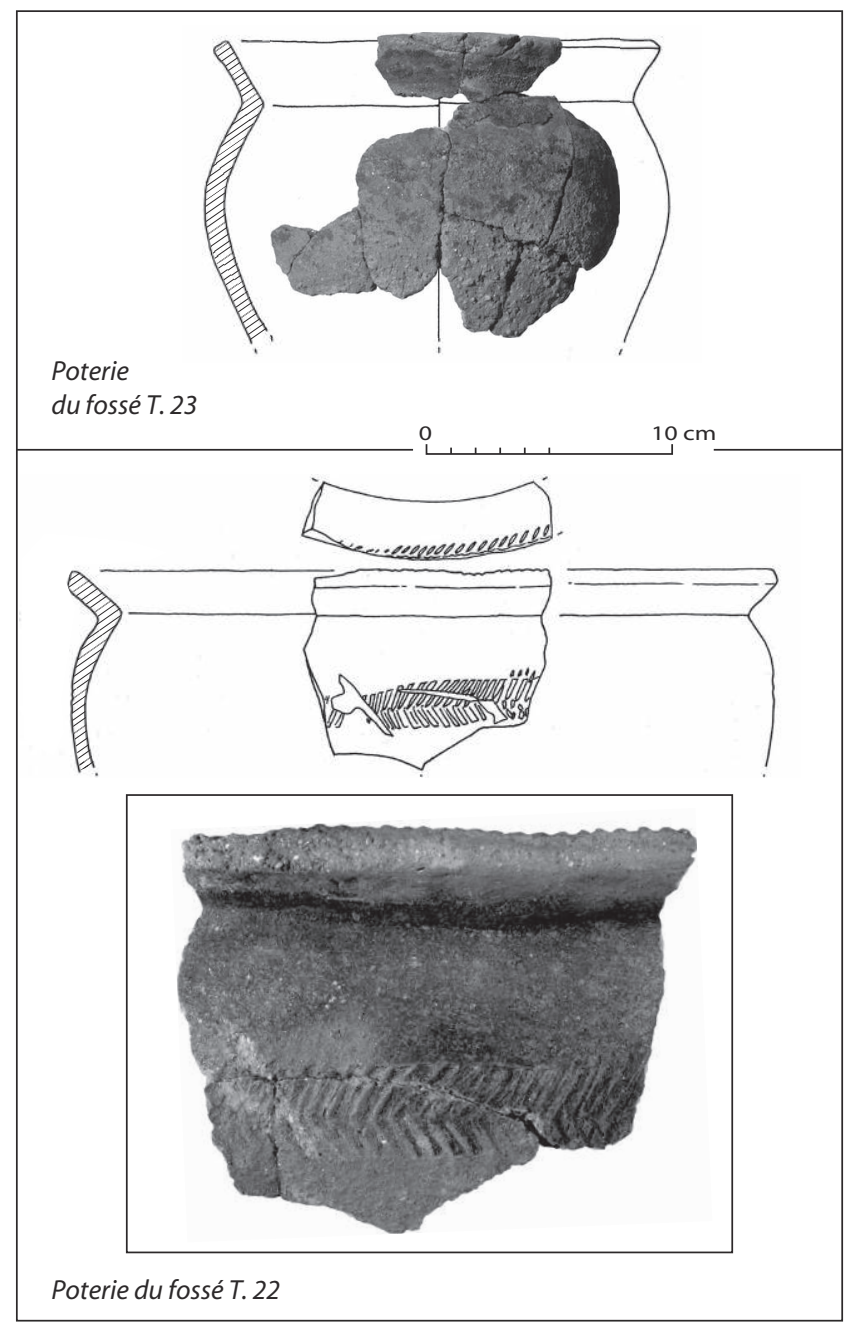

Figure 9 : Poteries issues des fossés. Figure 9: Pottery from the ditches.

comparaisons avec des productions locales de cette période le suggèrent (Villard, 2005b). Parmi les tessons découverts dans T. 22, on remarque un grand fragment de rebord d'un pot ou d'une oule à lèvre rectangulaire éversée. Il est décoré par un ruban à la molette sur le haut de panse et d'incisions en bordure de la lèvre. Le motif figuré sur la panse est double; il se compose d'une rangée de petites stries obliques inclinées à gauche et d'un second registre d'un motif de même type incliné à droite. La superposition des deux rangs engendre un motif cumulé en chevrons; elle montre également que l'on a affaire à deux molettes différentes. Des récipients de ce type sont connus en haute Bretagne au IX ${ }^{e}$ siècle, notamment sur le site d'habitat de Tinténiac (Provost, 1989). 


\section{Interprétation et datation}

Le fossé T. 23 englobe un espace situé à l'emplacement de l'actuel terrain de tennis. Le décaissement de cette partie du site nous prive d'informations quant à la nature ou la fonction de la surface enclose. La stérilité du sédiment de comblement, les parois en $V$ et le fond plat étroit pourraient évoquer une utilisation fermée pour cette structure fossoyée, mais rien ne le prouve.

T. 22 englobe l'espace initial et l'étend en direction de l'est, comme si l'enclos défini par T. 23, devenu exigu, avait nécessité un élargissement. En revanche, si T. 23 pourrait avoir été utilisé fermé, avec une palissade par exemple, cela ne semble pas être le cas de T. 22. La recherche de parois saines et nettes, l'élimination ou l'obturation des zones à sédiments mous parasites, le glissement de certaines pierres plaident davantage en faveur d'un fossé ouvert en avant d'un talus installé au dessus de son flanc interne. Les couches de ruissellement d'arène mises en place au cours de sa phase d'utilisation confirmeraient cette version. La difficulté de lecture des sédiments supérieurs ne permet pas de trancher entre une lente accumulation et un apport massif en fin de fonctionnement, mais le dégradé entre les couches intermédiaires et supérieures privilégie la première solution; les deux phénomènes ont cependant pu se cumuler à la fin de l'histoire de T. 22. Le fossé T. 27 apparaît comme un aménagement latéral, accolé au flanc occidental de l'enclos matérialisé par T. 22 dont il semble contemporain. Il a pu, lui aussi, border un court talus.

La période d'utilisation des fossés est plus délicate à déterminer du fait de la rareté du mobilier. Cependant, l'étude stratigraphique des deux structures indique un réaménagement de l'espace ceint par T. 23 au profit d'une surface limitée par T. 22. La reprise d'une partie du tracé de T. 23 par T. 22 montre une filiation directe entre les deux fossés mais implique un certain laps de temps entre les deux creusements. Une fourchette chronologique incluant le $\mathrm{IX}^{\mathrm{e}}$ et le début du $\mathrm{x}^{\mathrm{e}}$ siècle peut être proposée pour l'utilisation de ces vestiges.

\section{LES STRUCTURES DU SECTEUR ARTISANAL (Us. 02)}

\section{Présentation}

Ce secteur de fouille se situe au-dessus du comblement du fossé T. 22, au sud du carrefour avec T. 27. Il se caractérise, en surface, par un regroupement informe (fig. 10) de nombreuses traces d'activités liées au feu (terres charbonneuses, éléments rubéfiés, scories...). Il s’agit de la seule zone de

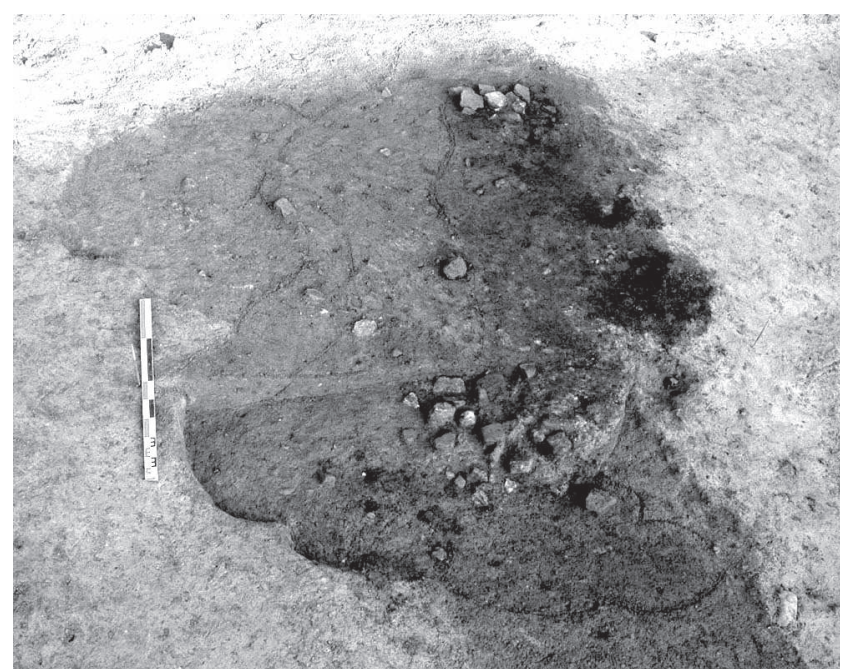

Figure 10 : Vue vers le nord du secteur artisanal Us. 02 en début de fouille.

Figure 10: Workshop area Us. 02 before excavation, looking north.

vestiges stratifiés du site, à la fois installés ou excavés au sommet du fossé et/ou piégés par tassement (fig. 11). Cette partie de la fouille a fait l'objet d'une étude fine; quatre grands horizons ont été repérés, chacun regroupant plusieurs couches, sols ou installations artisanales. Ils matérialisent une évolution stratigraphique autant qu'une succession d'aménagements. Les transitions demeurent cependant parfois floues. Ces horizons sont présentés dans l'ordre de leur mise en place.

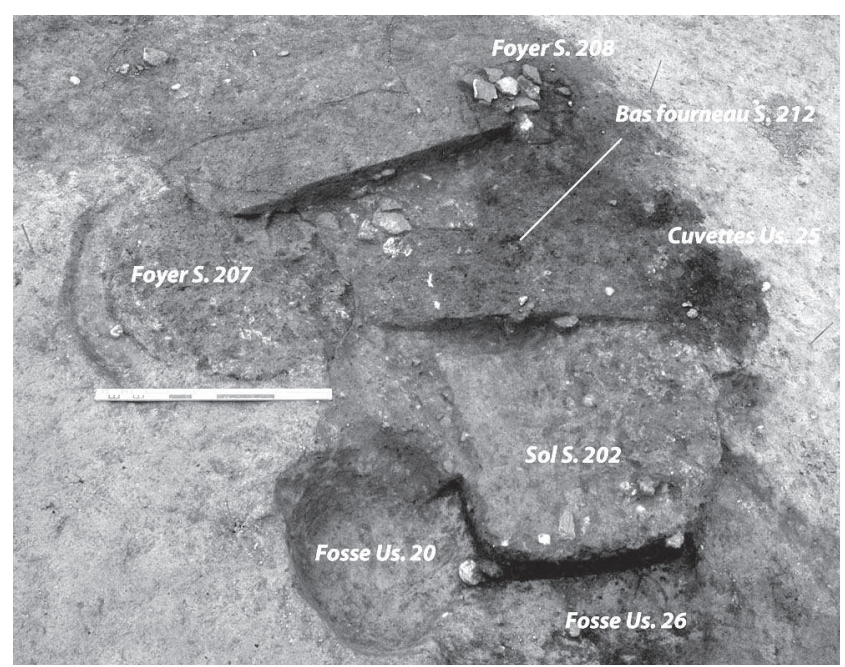

Figure 11 : Vue vers le nord du secteur artisanal Us. 02 en cours de fouille.

Figure 11: Workshop area Us. 02 during excavation, looking north. 


\section{Les structures de l'horizon I}

Les structures de l'horizon I sont les premières manifestations artisanales découvertes dans ce secteur (fig. 11 à 13). Elles sont relativement modestes car les aménagements postérieurs les ont nettement arasées. Il s'agit de deux fosses et de leurs aménagements internes creusés dans le comblement de T. 22 ou le long de son flanc oriental.

\section{La fosse Us. 26 et le niveau S. 215}

La fosse Us. 26 se présente, en plan, sous la forme d'un rectangle aux angles arrondis. Elle est creusée dans les sédiments du fossé T. 22; seul son angle sud-ouest mord dans le flanc de ce dernier. En dépit du bouleversement des installations postérieures, il semble que cette structure ait mesuré à sa base 2,20 $\mathrm{m}$ sur $1,50 \mathrm{~m}$. Son axe longitudinal s'oriente nord/sud; le fond plat se situe à $0,50 \mathrm{~m}$ sous le niveau actuel $\mathrm{du}$ substrat mais sa profondeur totale originelle demeure inconnue en raison de sa position topographique basse.

Cette fosse a été dotée, sur son fond, d'un niveau d'arène induré de 5 à $8 \mathrm{~cm}$ d'épaisseur (S. 215). Ce sol l'isole des sédiments du fossé T. 22 sous-jacent. Il se prolonge également sur les parois, soit sous la forme d'une couche damée rajoutée, soit par le matage ou l'écrasement du substrat géologique. Ce plancher aménagé présente aujourd'hui un plan irrégulier, dû pour partie à la taphonomie. Il est probable qu'à l'origine le fond de la fosse était parfaitement horizontal. Une telle structure, propre et régulière, semble avoir été destinée au recueil ou au stockage d'un produit ou d'un matériau particulier.

\section{La couche S. 203}

Cette couche de terre très noire, charbonneuse, comble la fosse Us. 26. Au cours de la fouille, il fut possible d'observer, au cœur de ce sédiment, la présence de brindilles ou de fragments de branchage parmi les traces de charbons de bois. Malheureusement, ces matériaux, très pulvérulents et dans un mauvais état de conservation, se sont désagrégés rapidement malgré plusieurs tentatives de prélèvement en blocs. La détermination des espèces végétales présentes n’a pu, de ce fait, être réalisée. Par ailleurs, cette couche, limitée par endroits à quelques centimètres d'épaisseur, avait été largement tronquée lors de la mise en place du niveau suivant, S. 213.

\section{La fosse S. 61}

Au nord de l'Us. 26, une seconde fosse a été repérée (S. 61). Elle se situe dans l'angle formé par les fossés T. 22 et T. 27. De plan ovale, ses dimensions sont de 2,20 m par $1,20 \mathrm{~m}$. Son axe longitudinal s'oriente nord-est/sud-ouest, presque parallèlement au flanc externe de T. 22. Elle est comblée par une terre arénitique brune. Sa profondeur maximale, sous le niveau du substrat, atteint $0,60 \mathrm{~m}$. Par endroits, au fond de la fosse, le sédiment géologique semble également avoir été maté ou écrasé.

\section{Datation et interprétation}

Seuls deux tessons de poterie commune grossière, dure et micacée, ont été mis au jour dans la couche S. 203. Le type de production est identique à celui du mobilier des fossés et peut être attribué à la même période, du moins dans la seconde partie de la fourchette compte tenu de la position stratigraphique de ces fosses vis-à-vis de T. 22. La fonction exacte des structures de cet horizon demeure indéterminée. Elle se rattache probablement aux activités de ce secteur, mieux caractérisées dans les niveaux postérieurs.

\section{Les structures de l'horizon II (fig. 11 à 13)}

\section{La couche S. 213}

La couche S. 213 recouvre les fosses de l'horizon précédent. Il s'agit d'une vaste nappe de terre arénitique brune contenant des inclusions d'argile rubéfiée et des traces de charbon de bois. Sa mise en place ne se fit pas sans dégât pour les structures préexistantes puisque la partie septentrionale du comblement S. 203 fut presque entièrement décaissée. Cette couche, couvrant près de $6 \mathrm{~m}^{2}$, s'apparente à une réorganisation de l'espace Us. 02. Ce réaménagement se fit en profondeur, entaillant non seulement les sédiments anciens mais également le substrat au niveau du flanc oriental de T. 22 (fig. 13 , coupe $n^{\circ} 2$ ), preuve d'une extension de l'excavation dans cette direction. Du fait de ce creusement latéral, la mise en place de la couche S. 213 traduit davantage l'aménagement de nouvelles installations qu'un simple abandon de l'horizon précédent.

\section{Le foyer S. 207}

Une plaque foyère circulaire est installée dans une cuvette peu profonde $(0,10 \mathrm{~m})$, au-dessus du flanc sud-ouest du fossé T. 22. Un tiers de la surface de ce foyer mord sur le fossé. À cet endroit, le foyer recouvre la couche S. 213. Cette plaque, de $1,30 \mathrm{~m}$ de diamètre, est constituée de 6 à $8 \mathrm{~cm}$ d'argile rubéfiée, aménagée sur un lit de petits galets. Une couronne d'argile jaunâtre (épaisseur 5 à $15 \mathrm{~cm}$ ) borde la partie occidentale de la plaque sur un tiers de sa circonférence; s'agit-il des restes d'une voûte de four ou d'un simple parement protecteur contre les vents dominants? Ce foyer conserve son horizontalité à l'ouest au-dessus du substrat; à l'est, il s'affaisse au-dessus des sédiments mous pour se désagréger sous la forme d'un épandage d'éléments rubéfiés. 


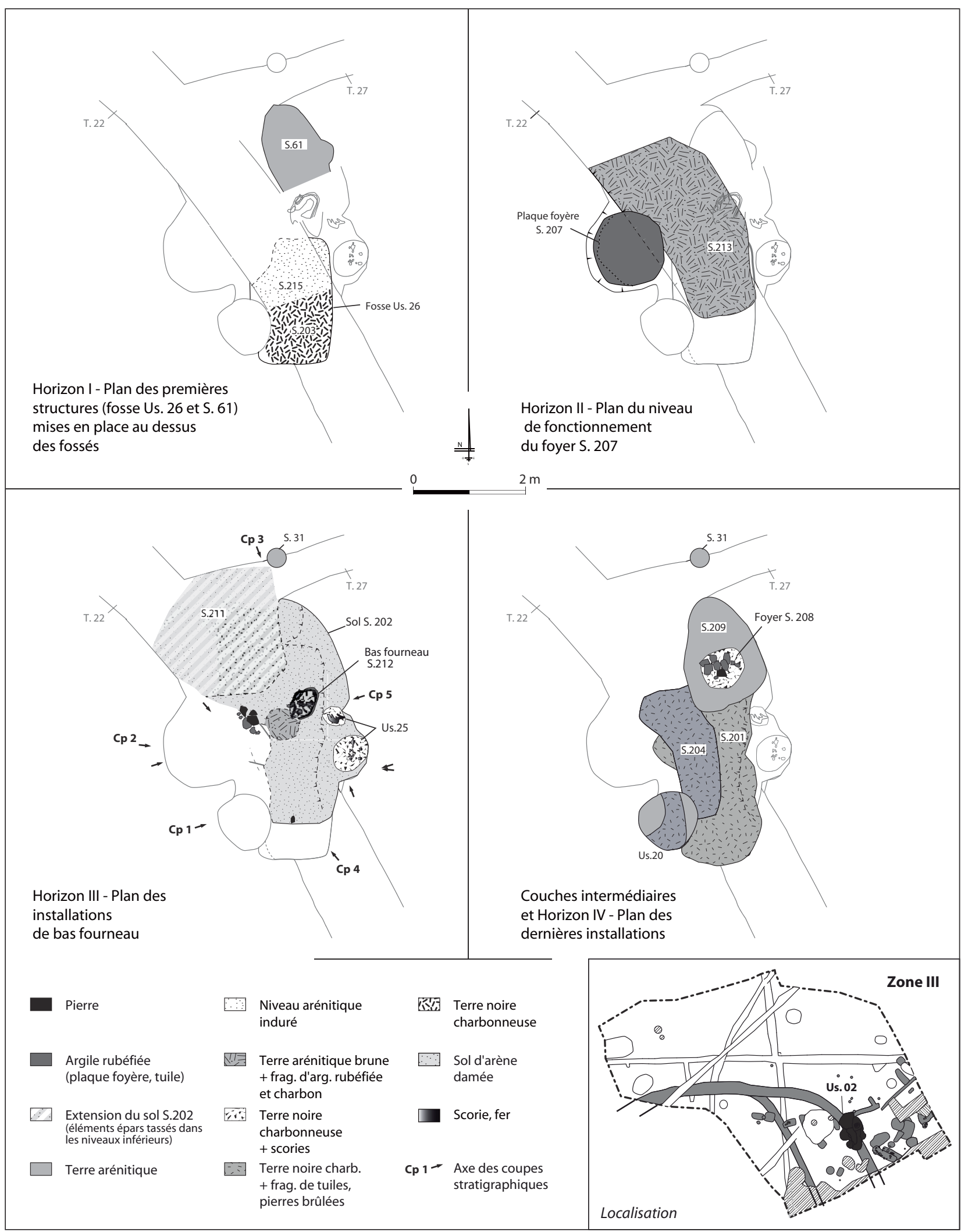

Figure 12 : Plans des structures du secteur artisanal Us. 02.

Figure 12: Plans of features of workshop area Us.02. 


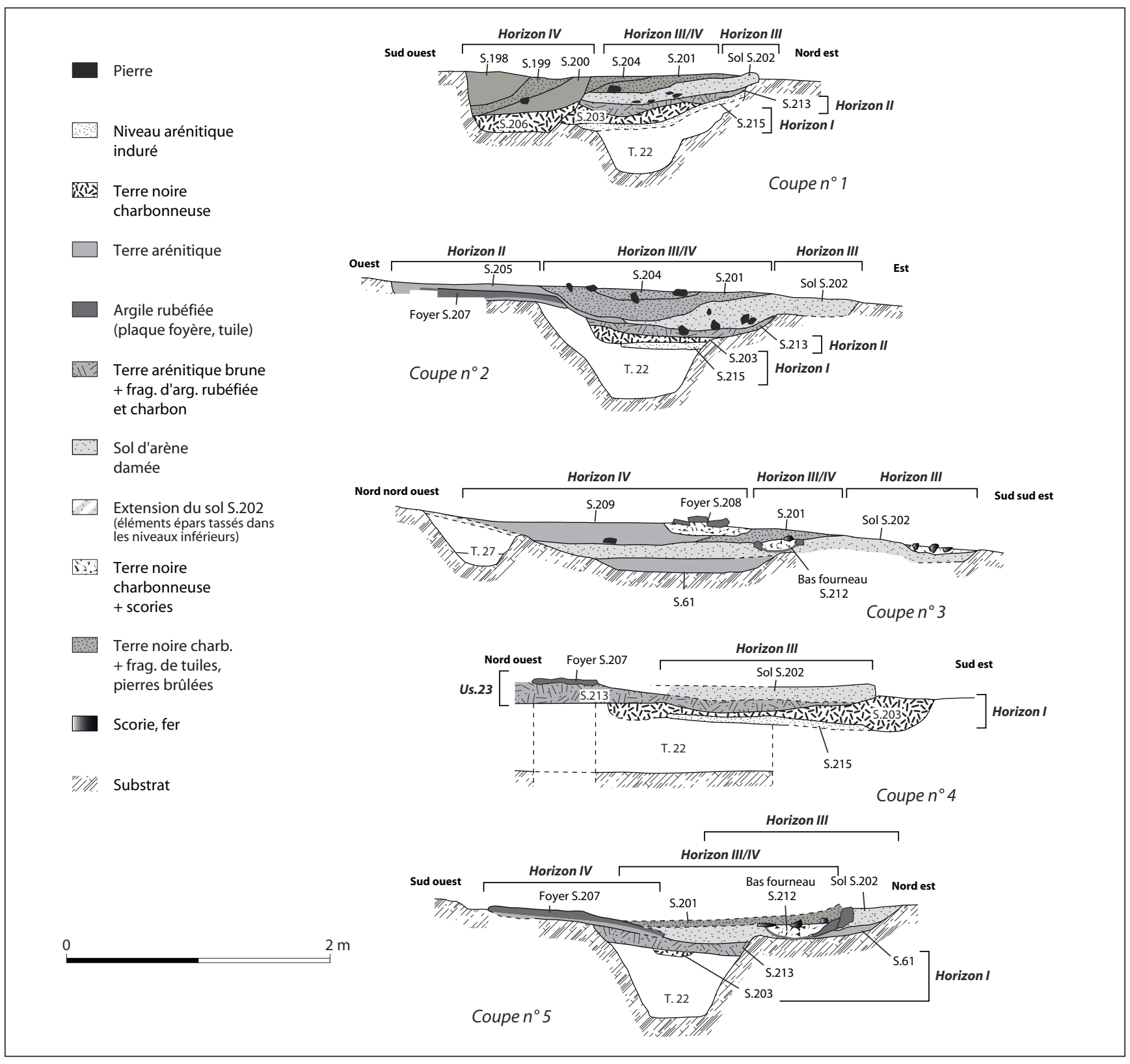

Figure 13 : Coupes stratigraphiques des structures du secteur artisanal Us. 02. Figure 13: Sections of features of workshop area Us. 02.

\section{La couche S. 205}

La couche S. 205 est très localisée. Elle se présente sous la forme d'un fin niveau de terre arénitique jaune recouvrant la sole du foyer S. 207. Il pourrait s'agir de la couche d'abandon de ce dernier.

\section{Datation et interprétation}

Seule la couche S. 213 livra un peu de mobilier. Trentetrois tessons de poterie commune grossière, dure et micacée, furent mis au jour. Parmi ceux-ci, se distinguent plusieurs fragments d'un vase à anse interne renfoncée orné à la molette (cf. infra, fig. 17). Ce décor est constitué de bandes de petits rectangles, irrégulièrement imprimées dans la pâte. Cette association de décors avec des anses internes renfoncées est caractéristique des céramiques quimpéroises des $\mathrm{IX}^{\mathrm{e}}$ $\mathrm{x}^{\mathrm{e}}$ siècles, notamment sur le site de Créac'h-Gwen (Villard, 2005b). Un rebord de vase à lèvre rectangulaire éversée complète ce modeste lot, ainsi que 232 g. d'agglomérat scoriacé. 


\section{Les structures de l'horizon III (fig. 11 à 13)}

Le sol S. 202

Un troisième remaniement est ensuite perceptible. Un sol épais est mis en place; il est constitué d'arène granitique damée et inclut des petites pierres et des fragments d'argile rubéfiée. Ce sol reprend globalement l'espace creusé au début de l'horizon II; cependant, plusieurs indices laissent supposer qu'il s'étendait plus à l'est. Tout d'abord, la coupe stratigraphique $\mathrm{n}^{\circ} 2$ (fig. 13) montre une extension orientale du creusement du substrat par rapport à l'aménagement précédent. Par ailleurs, dès que le sol atteint le niveau du substrat géologique actuel dans cette direction, il empiète sur ce dernier. Il y est ensuite rapidement tronqué par l'érosion naturelle et anthropique. À l'est, il vient mordre sur la limite orientale du foyer S. 207.

Cet aménagement, parfois massif (jusqu’à 0,30 m d'épaisseur), présente une certaine horizontalité dans sa partie orientale. Des états de surface du sol sont nettement visibles (fig. 11). Vers l'ouest, la situation n'est pas aussi claire, son épaisseur pouvant s'affiner jusqu'à seulement $0,05 \mathrm{~m}$. Un pendage général en direction de l'ouest s'observe, mais irrégulièrement. Parfois, cela s'apparente davantage à une rupture bien marquée. L'axe de cette modification topographique est globalement orienté nord-nord-ouest/sudsud-est. La présence du fossé T. 22 sous-jacent pourrait éventuellement expliquer un tassement mais ce ne semble pas être le cas car les couches des horizons I et II, ainsi que la base du sol S. 202, conservent une relative horizontalité. De plus, l'agencement des couches postérieures (cf. infra) ne semble pas l'avoir perturbé. Il semble donc qu'il faille interpréter le pendage de ce sol comme une volonté de créer une structure semi-excavée sur deux niveaux, sans exclure la possibilité de perturbations locales ou de restructurations liées à son utilisation. Vers le nord, une zone matérialisée par des éléments arénitiques jaunes (S. 211), tassés au sommet du comblement de la jonction entre T. 22 et T. 27, pourrait figurer une extension du niveau S. 202, alors fortement dégradé et dont il ne subsisterait plus que la base. Cela porterait la surface couverte par cet ensemble à environ $10 \mathrm{~m}^{2}$.

Le démontage et la fouille de ce niveau livrèrent dix tessons de poterie commune grossière, dure et micacée dont un fragment de rebord à anse renfoncée.

\section{Les installations métallurgiques}

Sur le sol S. 202, plusieurs aménagements liés à des activités métallurgiques ont été découverts.

- Le bas-fourneau S. 212 (fig. 14).

Au centre de l'espace S. 202, à proximité de la rupture de pente de ce sol, un aménagement particulier a été repéré.
Il se présente sous la forme d'une cuvette oblongue de 0,50 par $0,70 \mathrm{~m}$, dont l'axe longitudinal s'oriente nord-est/ sud-ouest. Celle-ci est creusée à même le sol S. 202. Ses parois et son fond sont totalement rubéfiés et son pourtour est souligné d'un bourrelet d'argile rougie, large de $5 \mathrm{~cm}$. Le flanc nord-ouest s'agrémente d'une pierre placée de chant ainsi que d'un bloc de matière vitrifiée incrusté dans le bourrelet argileux périphérique. Pierre et bloc vitrifié sont distants de $6 \mathrm{~cm}$. Au sud-ouest, dans le prolongement de son axe longitudinal, la cuvette semble s'ouvrir en direction de la partie basse du sol. Face à cette ouverture, en contrebas, une seconde cuvette, elle aussi excavée dans S. 202, remet au jour les sédiments sous-jacents de l'horizon II (S. 213). La cuvette principale est comblée par une terre noire très charbonneuse celle-ci formant par endroits une véritable croûte vitrifiée sur le flanc. Parmi ces terres, se trouvent $2,32 \mathrm{~kg}$ de scories légères ou d'agglomérat d'éléments minéraux, dont une scorie coulée d'une vingtaine de centimètres de long, découverte au niveau de l'ouverture (fig. 15). Elles ne réagissent pas à l'aimantation. La cuvette secondaire basse contient également quelques restes scoriacés et des blocs d'argile rubéfiée.

Cet ensemble est représentatif de ce que l'on connaît des bas-fourneaux, destinés à la réduction du minerai de fer, sur les sites archéologiques. Ces bas-fourneaux portent le minerai, grillé au préalable, à des températures suffisantes pour que la gangue s'écoule vers bas ou à l'extérieur de la structure afin d'extraire une portion variable du fer contenu dans l'oxyde du minerai (Mangin et al., 2000). Il ne s'agit pas ici de liquéfier directement le métal, l’opération nécessiterait des températures trop élevées. La plupart des éléments caractéristiques de ce processus de réduction sont ici présents (fig. 16). La cuvette principale devait constituer la base d'une cheminée subcylindrique montée à son aplomb. Le bourrelet rubéfié mis au jour correspondrait au vestige d'une telle superstructure. Une fois mis en chauffe, la cheminée est chargée, par le haut, de couches alternées de charbon de bois et de minerai. Les croûtes charbonneuses et les scories légères ou coulées mises au jour coöncident avec cette étape accompagnée d'une production de déchets quelquefois évacués par une ouverture à la base (d'où probablement la cuvette secondaire en avant et en contrebas). Cependant, le charbon de bois ne permet pas d'atteindre une température suffisante sans un apport d'oxygène important et régulier par ventilation forcée (soufflet et tuyère). La pierre de chant et l'élément vitrifié observé sur le flanc de la structure pourraient correspondre à l'emplacement d'une telle d'arrivée d'air, à la base du bas-fourneau (renseignements Dominique Vuaillat). 


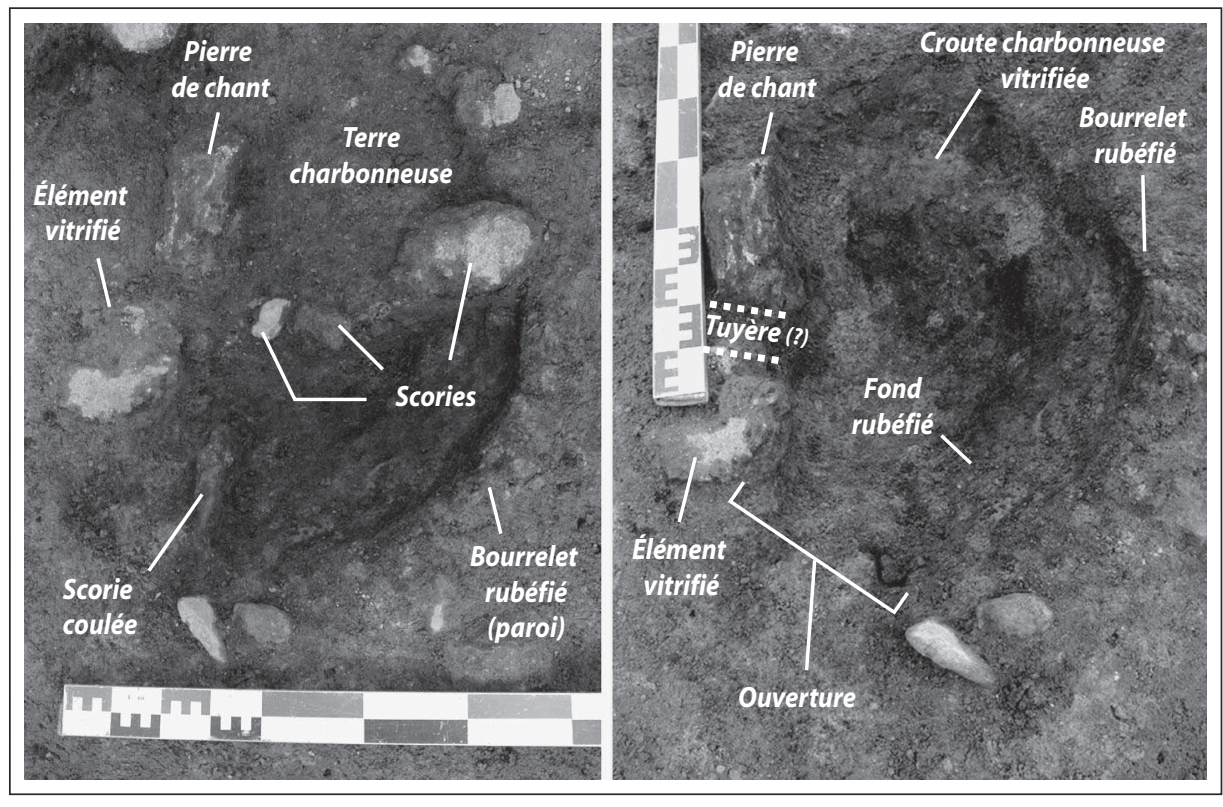

Figure 14 : Vues de détail du bas fourneau S. 212 (Horizon III), en cours et en fin de fouille.

Figure 14: Detail views of furnace S.212 (Level III), during and after excavation.

\section{- Les cuvettes Us. 25}

Au sud-est de ce bas-fourneau, se trouvent deux fonds de cuvettes légèrement imprimés dans la partie supérieure du sol S. 202 (moins de 0,10 $\mathrm{m}$ de profondeur), en limite orientale de ce dernier. Leur paroi n'est pas rubéfiée. Ces cuvettes contiennent une terre charbonneuse, des concentrations de scories légères ou coulées et des agglomérats d'éléments minéraux très oxydés et pulvérulents pour un poids total de $2,17 \mathrm{~kg}$ (fig. 15). Compte tenu de l'absence totale de rubéfaction sur les parois des cuvettes et de l'absence d'indices d'aménagements périphériques, l'hypothèse de fonds de structures de bas-fourneaux ne parait pas envisageable. Il pourrait s'agir de cuvettes d'écoulement secondaire, destinées à recevoir les déchets d'éventuels bas-fourneaux situés plus à l'est, là où le sol S. 202 a aujourd'hui disparu, mais nulle trace ne permet de l'affirmer. Il pourrait également s'agir de simples structures de stockage temporaire de déchets de réduction. À moins que l'on ait affaire à une première phase de dégrossissage, étape suivante dans la chaîne métallurgique, l'épuration du massiau de fer obtenu lors de la réduction (cf. infra).

\section{Les couches intermédiaires entre les horizons III et IV}

Le sol S. 202 et ses installations métallurgiques sont, par la suite, couverts de deux couches de sédiments dont l'interprétation, ainsi que le rattachement aux horizons III ou IV, sont délicats. Ces deux épandages marquent la fin de l'utilisation des installations de réduction de l'horizon III, mais il peut également s'agir de niveaux de remblais destinés à asseoir le suivant.
La couche S. 201 est matérialisée par une terre noire charbonneuse, contenant quelques fragments de tuiles et des pierres brûlées. Elle recouvre le bas-fourneau S. 212, mord sur la cuvette septentrionale de l'Us. 25 et, vers le sud et l'ouest, comble la partie basse du sol. La fouille de cette couche livra vingt tessons de poterie commune grossière de la fin du haut Moyen Âge, quelques tessons erratiques gallo-romains et $3,5 \mathrm{~kg}$ de fragments de tuiles. À ce mobilier céramique, il convient d'ajouter $183 \mathrm{~g}$. de scories légères et 317 g. de scories coulées (fig. 15).

Un second niveau de terre de même nature, mais davantage chargé en débris rubéfiés (S. 204/210), recouvre la partie occidentale de la couche S. 201, au-dessus de la partie la plus basse de S. 202. Sept tessons de poterie commune, dure et micacée, dont un rebord de pot à lèvre rectangulaire éversée et un fragment de plat rectangulaire de facture grossière furent mis au jour dans cette couche (fig. 17). Ce type de récipient est jusqu'ici inédit à Quimper. Là encore, 184 g. de scories complètent le mobilier.

\section{Les structures de l'horizon IV (fig. 12 et 13)}

\section{La couche S. 209}

La couche S. 209 est localisée au nord-est du secteur Us. 02. Plus qu'une couche, il s'agit d'une terre arénitique grise et fine comblant une dépression ovoïde, ménagée dans les sédiments antérieurs. Six tessons de poterie commune grossière, dure et micacée, ainsi que $475 \mathrm{~g}$. de scories (fig. 15) et des fragments de tuiles y furent découverts. 


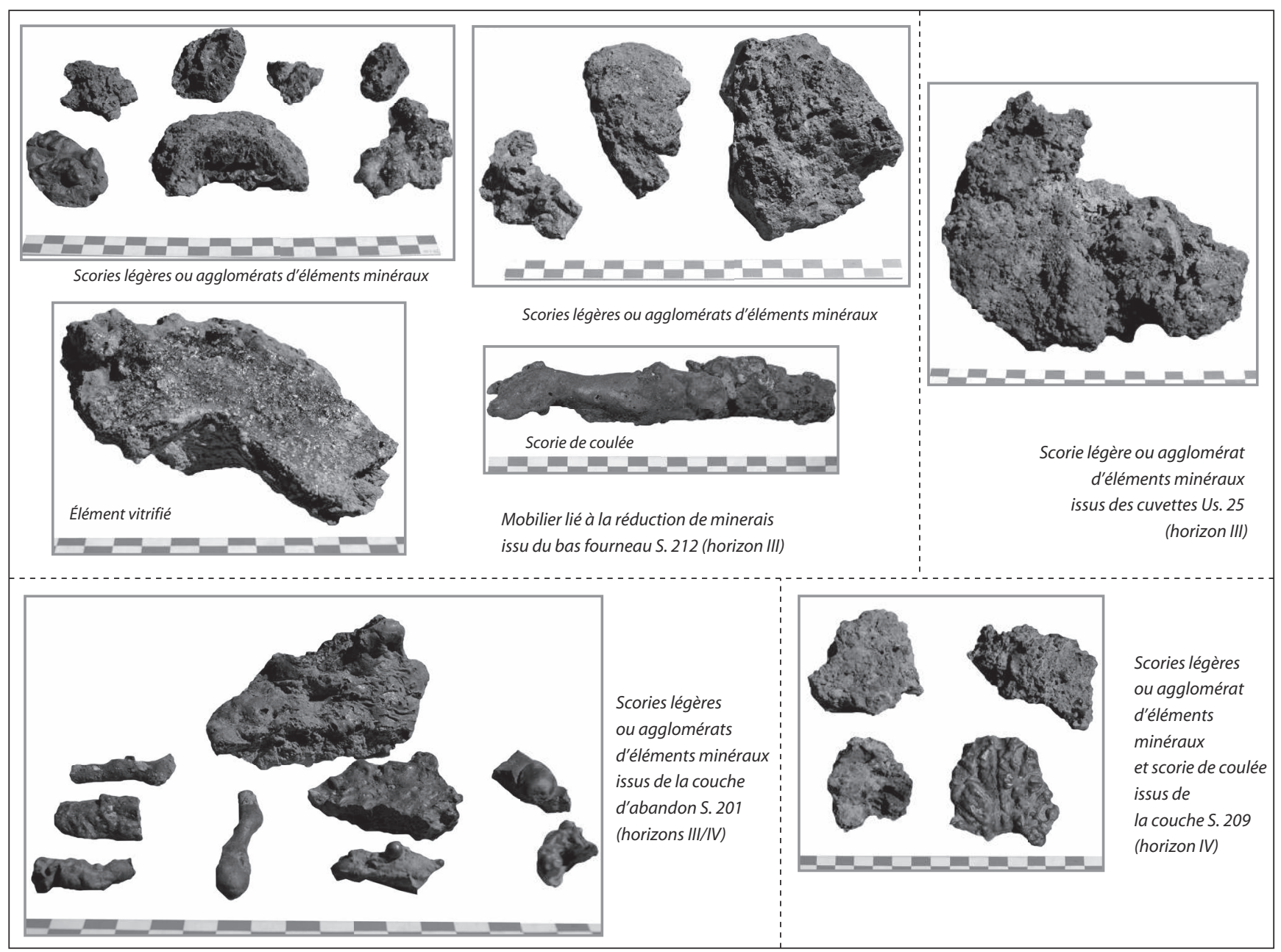

Figure 15: Scories et éléments liés à la métallurgie du fer (secteur artisanal, Us. 02). Figure 15: Slags and other remains from iron smelting (workshop area, Us. 02).

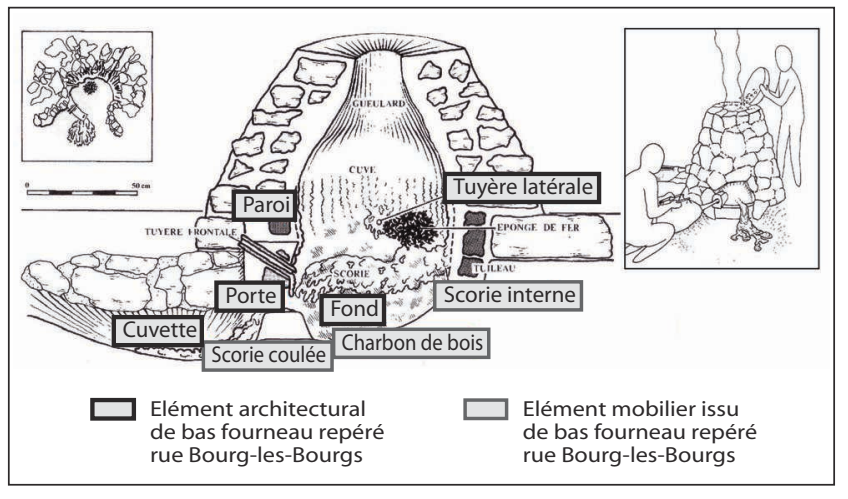

Figure 16 : Reconstitution idéale d'un bas fourneau d'après l'exemple des Boulies dans le Jura suisse (Eschenlhor et Serneels, 1991).

Figure 16: Reconstruction of a furnace after the example of Les Boulies (Swiss Jura) (from Eschenlhor \& Serneels, 1991).

\section{Le foyer S. 208}

Le foyer S. 208 est installé au centre de la couche S. 209. Il est constitué d'une cuvette de $0,80 \mathrm{~m}$ de diamètre pour $0,12 \mathrm{~m}$ de profondeur, comblée par de la terre noire charbonneuse et des scories $(90 \mathrm{~g})$. Au sommet de ce remplissage, sept fragments de tuiles et une pierre plate brûlée étaient disposés à plat. Cette structure rappelle les petits foyers artisanaux des $\mathrm{XI}^{\mathrm{e}}-\mathrm{XII}^{\mathrm{e}}$ siècles mis au jour à Quimper sur le site du Moustoir 2 (Le Bihan et Villard, 2005). Ce foyer clôt l'empilement stratigraphique visible dans la partie septentrionale du secteur Us. 02. À ce stade, les structures affleurent à un niveau légèrement supérieur au substrat. Il est probable que l'érosion, pour beaucoup anthropique dans ce secteur méridional de la zone III, nous prive d'informations complémentaires. 


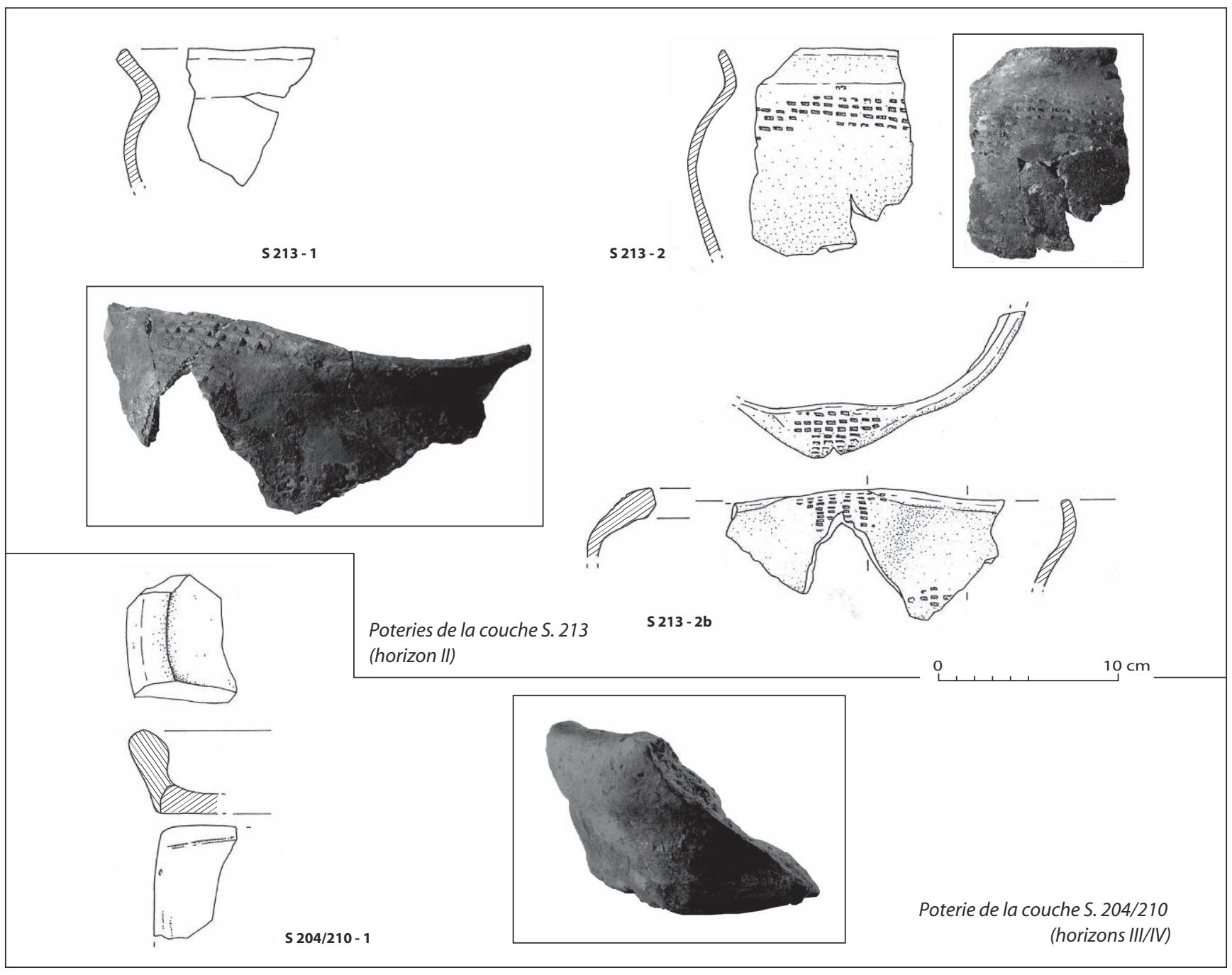

Figure 17 : Poteries issues du secteur artisanal Us. 02.

Figure 17: Pottery from the workshop area Us. 02.

\section{La fosse Us. 20}

La fosse Us. 20, située plus au sud, s'inscrit elle aussi dans une phase terminale de l'histoire de ce secteur. Il s'agit d'une fosse subcylindrique à fond plat, d'un diamètre de près d'un mètre pour une profondeur de $0,50 \mathrm{~m}$. Son comblement se compose de quatre couches disposées selon un pendage orienté vers le sud-ouest. La première (S. 206) est constituée d'une terre très noire et charbonneuse. Viennent par la suite la terre arénitique gris clair S. 200 puis la terre grise chargée d'argile rubéfiée S. 199. Enfin, la terre arénitique brun jaune S. 198 clôt la structure. Seuls trois tessons de poterie commune grossière, dure et micacée, furent exhumés en compagnie de nombreux fragment d'argile rubéfiée (éléments de four?).

\section{Datation et interprétation}

\section{Datation}

Le secteur Us. 02 se caractérise par la concentration de nombreuses structures liées aux arts du feu et plus particulièrement à la métallurgie. Ces activités semblent assez bien calées dans le temps par la fréquence des tessons de poterie commune à pâte grossière, dure et micacée, caractéristique des productions locales de la fin du haut Moyen Âge. Quelques éléments distinctifs, tels que les anses internes renfoncées, les décors imprimés à la molette ou les rebords éversés de section rectangulaire sont comparables aux récipients des sites quimpérois des $\mathrm{IX}^{\mathrm{e}}-\mathrm{X}^{\mathrm{e}}$ siècles de Créac'hGwen ou de Quistinidal (Villard, 2005b). Ces types de 
vases sont concentrés dans la couche S. 213 de l'horizon II (fig. 17). Le seul autre élément céramique identifiable est le petit plat rectangulaire mais il n'a pas d'équivalent connu. Il occupe une place relativement tardive de la stratigraphie (fin de l'horizon III). La pâte grossière dans laquelle il est réalisé pourrait être comparée à des productions recensées au Moustoir 2 jusqu'au milieu du XI ${ }^{\mathrm{e}}$ siècle (Villard, 2005b). Enfin, ce secteur est installé au dessus du comblement du fossé T. 22 dont la date d'utilisation proposée couvre le $\mathrm{IX}^{\mathrm{e}}$ siècle et le début du $\mathrm{X}^{\mathrm{e}}$. La période de fonctionnement suggérée pour ces installations artisanales serait davantage centrée sur le $\mathrm{x}^{\mathrm{e}}$ siècle.

\section{Interprétation}

Dans le secteur Us. 02, nous avons affaire, successivement, à une fosse aménagée pour du stockage, à une plaque foyère, à un sol aménagé avec au moins une structure de bas-fourneau, à des cuvettes de stockage de scories et à un petit foyer de type artisanal. Une question se pose à propos de la nature de ces vestiges : s'agit il d'un unique atelier occasionnel où l'on a pratiqué successivement les diverses étapes d'une transformation du minerai, ou bien d'un secteur artisanal plus complexe et durable, où plusieurs activités métallurgiques ont été mises en œuvre?

L'analyse de détail de cette stratigraphie n'est pas incompatible avec l'hypothèse d'un unique atelier. Des entretiens avec Dominique Vuaillat, qui a réalisé des expérimentations de réduction, livrent des informations intéressantes. Reprenons les étapes nécessaires aux opérations de réduction de minerais (Mangin et al., 2000). Une fois le minerai extrait et trié, il est amené sur les lieux de transformation et y est stocké. Le creusement initial Us. 26 avec ses parois et son fond aménagé, ainsi que la fosse S. 61, auraient pu servir à ce stockage. L'étape suivante de la chaîne opératoire, le grillage, est un traitement thermique préliminaire du minerai destiné à fragiliser la roche afin de la concasser plus facilement, tout en éliminant sous forme de gaz l'eau et certains éléments chimiques. Cela ne nécessite pas obligatoirement d'importantes installations : "Il suffit de jeter le minerai dans un feu de bois pendant quelques heures "(Mangin, 2004). À Boécourt dans le Jura Suisse, les structures de grillage, attestées par des analyses chimiques, sont de simples foyers ouverts à même le sol (Eschenlohr et Serneels, 1991). Les éléments nécessaires sont donc du charbon de bois (là encore la fosse Us. 26, avec son comblement charbonneux, aurait pu servir à ce stockage) et un foyer adapté au volume de minerai à griller, ceci pouvant se faire par petites quantités. La plaque foyère S. 207, avec ses $1,30 \mathrm{~m}$ de diamètre, serait suffisante et l'amorce d'une possible paroi protectrice, ceinturant le côté ouest du foyer sur un tiers de sa circonférence, correspondrait à des structures de grillage connues, notam- ment en Suisse. Cette méthode peut se combiner avec des traitements simples tels que l'exposition du minerai durant un laps de temps assez longs aux intempéries (pluie et gel) afin de faciliter, lors des étapes ultérieures, la concentration du minerai. Ce dernier ainsi conditionné serait prêt pour l'opération de réduction dans le bas-fourneau avec sa production de déchets (scories légères et coulées). L’horizon III trouverait, à ce stade, sa raison d'être. Par la suite, le massiau de fer obtenu, appelé aussi éponge ou loupe, est dégrossi et épuré afin de séparer le métal des derniers résidus scoriacés. Ce dégrossissage ne livre généralement que quelques scories légères du même type que celles issues du bas-fourneau (cf. le contenu des cuvettes Us. 25 ?). Enfin, l'épuration ellemême se fait par martelage du massiau réchauffé dans un foyer de forge jusqu'à obtention d'un lingot ou barre. Le foyer S. 208 pourrait-il s'apparenter à ce type de structure de combustion?

Il est remarquable de constater que chacun des horizons repérés lors de la fouille peut correspondre à une étape du travail de transformation du minerai en métal, de la matière brute au produit semi-fini. L'hypothèse est séduisante, mais la situation n'est-elle pas trop belle?

Dans ce cas, nous aurions affaire à un seul atelier réalisant successivement ces étapes. Pour ce faire, si l'on s'en tient aux observations archéologiques, à chacune de ces phases, le lieu aurait subi des modifications profondes avec recreusements, apports et/ou étalages de sédiments... Cela semble complexe d'autant que l'on n'observe qu'un seul bas-fourneau de dimensions réduites. Il n'a pas produit d'importantes quantités de fer (probablement quelques kilogrammes) car on sait que, pour récupérer le massiau en fin de réduction, la cheminée doit être cassée, la structure étant à usage unique. Il devient alors plus difficile de voir dans ces vestiges le résultat d'une unique chaîne opératoire complète. Il est intéressant de noter que l'ensemble des opérations a pu être réalisée sur le site. Cependant, il semble plus raisonnable de voir dans les structures du secteur Us. 02, la concentration en un même lieu de ces activités au cours d'une longue période, durant laquelle les remaniements successifs ont épargné tantôt une fosse, tantôt un foyer ou un bas-fourneau. Ainsi, si le foyer S. 207 avec son muret protecteur a pu griller du minerai, il a tout aussi bien pu servir de sole de forge, un rempart de protection se retrouvant également dans de telles installations (Mangin, 2004, p. 190, fig. 6). En revanche, pour ce qui est de l'activité de forge, aucune battiture n'a été mise au jour dans le secteur. Les différents remaniements médiévaux et l'érosion anthropique récente sont-ils la cause de cette absence? Compte tenu des infrastructures présentes, le forgeage fut certainement pratiqué sur le site.

La stratigraphie et les réaménagements donnent donc le sentiment d'une certaine durée pour ces activités artisanales. 
Cependant, le mobilier mis au jour n'est pas suffisant pour la préciser : l'activité a pu aussi bien s'étendre au cours du $\mathrm{x}^{\mathrm{e}}$ siècle ou ne fonctionner que quelques années durant cette époque.

\section{LES STRUCTURES DE STOCKAGE}

Deux structures de stockage (S. 41 et S. 51) sont attestées sur le site. D'autres fosses, qui pourraient s'intégrer à cette catégorie mais sans éléments probants, sont présentées plus loin (cf. infra, $\$$ 6.). Ce problème sera rediscuté.

\section{Les structures}

L'excavation S. 41 empiète sur le flanc occidental du fossé T. 23 (fig. 18 et 19). Il s'agit d'une structure fossoyée à plan quadrangulaire, aux angles arrondis, mesurant 1,50 par $1,30 \mathrm{~m}$. Son axe longitudinal est orienté ouestnord-ouest/est-sud-est. Ses parois sont globalement verticales et son fond plat est situé à $1,25 \mathrm{~m}$ sous le niveau actuel du substrat. La partie basse des flancs méridionaux et septentrionaux présente une paroi concave. Cependant, l'épais sédiment géologique (arène et argile) tapissant le fond, ainsi que la légère remontée de celui-ci vers l'angle sud-ouest, montrent qu'il s'agit en fait d'un effondrement tardif des parois, peu avant le rebouchage de l'excavation par des couches massives de terres arénitiques brun-jaune et brun-gris-jaune. Ces couches supérieures empiètent nettement sur le tracé du fossé T. 23. Le creusement originel de S. 41, débordant lui aussi franchement sur la trajectoire du fossé, confirme que cette structure fut mise en place et utilisée après l'abandon de ce fossé. La régularité de la forme générale de la structure, parallélépipédique, est frappante. Elle semble avoir fonctionné ouverte jusqu'au moment de l'effondrement des parois. Aucune trace d'aménagement interne particulier ou de couverture n'est observée.

Une seconde structure quadrangulaire (S. 51) a été mise au jour au sud-est de la précédente (fig. 3 et 20). Elle mesure $1,15 \mathrm{~m}$ de côté pour une profondeur de $0,95 \mathrm{~m}$. Ses parois sont subverticales et son fond est plat. Elle s'oriente selon un axe longitudinal nord-ouest/sud-est et est comblée par deux couches massives disposées à l'horizontale. La première, une terre sombre, sableuse et charbonneuse, est recouverte d'une couche de terre brune. Là encore, il semble que la mise en place de ces sédiments se soit faite lors de l'abandon de la structure. Aucune trace d'aménagement interne particulier n'a été observée et aucun mobilier mis au jour. Cette fosse est recoupée dans sa partie septentrionale par une carrière datée de la fin du Moyen Âge.

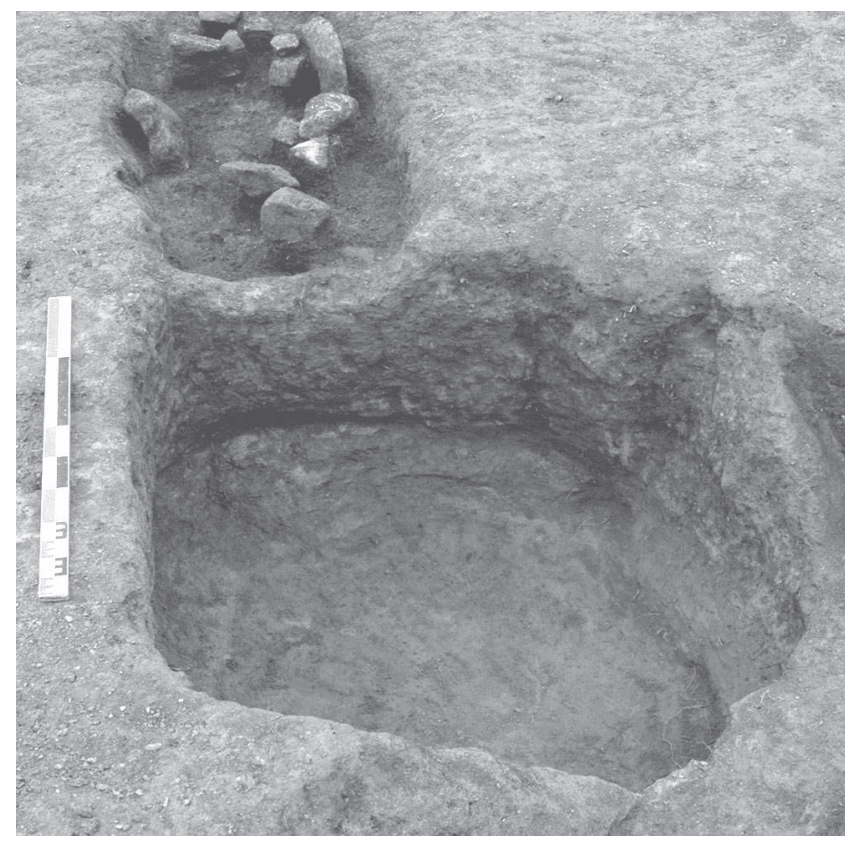

Figure 18 : Vue vers l'ouest du silo S. 41 ; au second plan, la structure de séchage $S .52$.

Figure 18: Storage pit S. 41 looking west; in the background, corndrying kiln S. 52.

\section{Le mobilier}

La structure S. 41 livra quelques tessons antiques et un grand fragment de rebord d'un large récipient à anse interne renforcée décorée à la molette (fig. 21). Les motifs imprimés sont de deux sortes : des petits rectangles accolés verticalement, figurant des lignes sur la paroi externe de la panse, au niveau de l'épaule et des lignes de petits triangles localisées exclusivement sur la partie sommitale, au dessus de l'anse. Ce vase présente par ailleurs deux indices d'utilisation : une perforation réalisée après cuisson, à hauteur du renflement de l'anse et une usure sur la face interne, dans le creux de l'anse, avec traces d'oxydes de fer. Ce type de récipient rappelle celui mis au jour parmi les sédiments de l'horizon II du secteur Us. 02 et daté des $I^{\mathrm{e}}-\mathrm{X}^{\mathrm{e}}$ siècles.

\section{Datation et interprétation}

La datation proposée pour cet unique élément mobilier est confirmée par quelques comparaisons locales. Sur les sites quimpérois de Créac'h-Gwen ou Keradennec, ce type de récipient est également datable des $\mathrm{IX}^{\mathrm{e}}$ et $\mathrm{X}^{\mathrm{e}}$ siècles (Villard, 2005b). À Keradennec, une fosse parallélépipédique semblable, elle-même inscrite dans un espace rectangulaire légèrement excavé avec solin de pierre et contenant aussi un vase à anse interne renfoncé, fut mise au jour et interprétée 


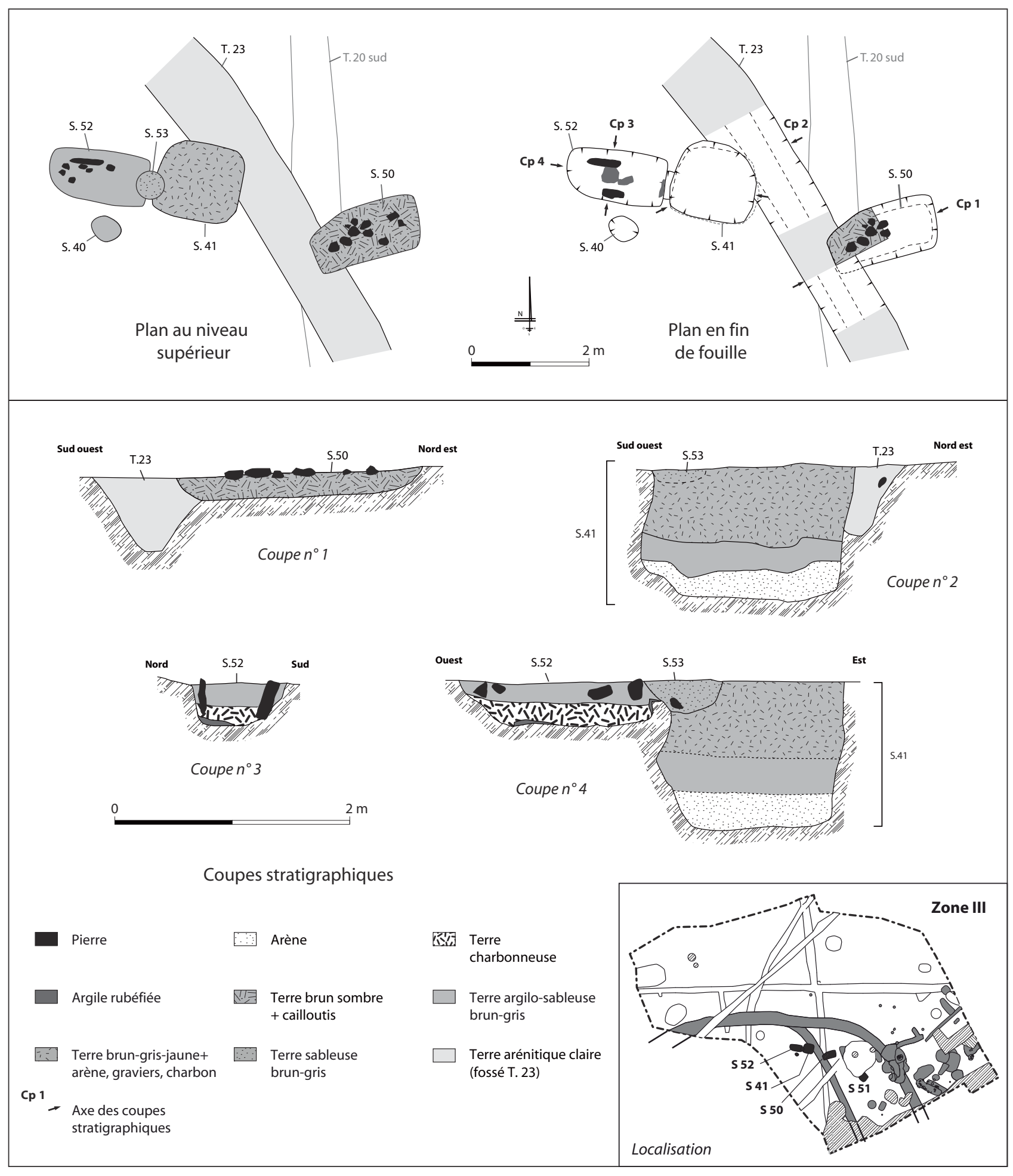

Figure 19 : Plan et coupes stratigraphiques des structures S. 40, S. 41, S. 50, S. 52 et S. 53.

Figure 19: Plan and sections of features S. 40, S. 41, S. 50, S. 52 and S. 53. 


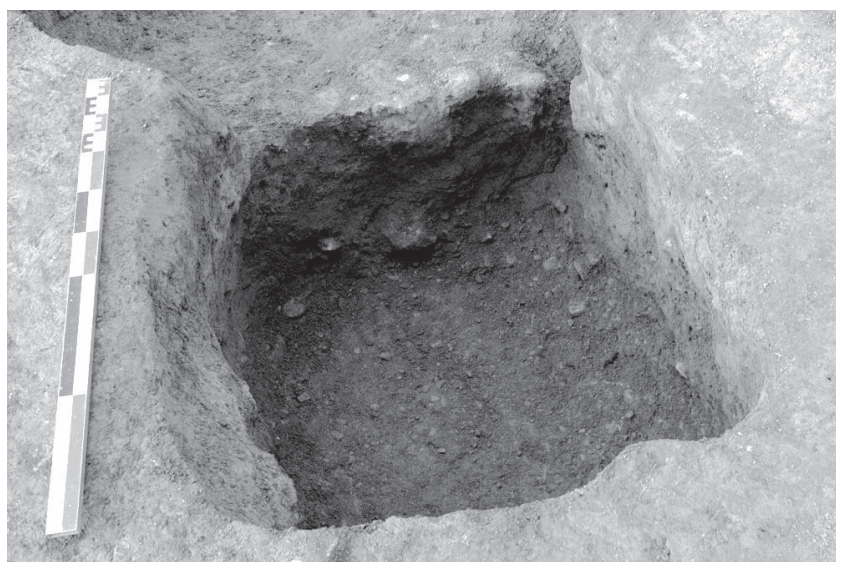

Figure 20 : Vue vers le nord-ouest du silo S. 51.

Figure 20: Storage pit S. 51 looking north-west.

comme le vestige probable d'un silo ou d'une cave de maison. Ce type de structure est également présent sur un autre site des environs des $\mathrm{X}^{\mathrm{e}}$ et $\mathrm{XI}^{\mathrm{e}}$ siècles, au Corniguel 2 (Le Bihan et Villard, 2005). Rue Bourg-les-Bourgs, la chronologie relative place ces silos entre l'abandon du fossé T. 23 (pour S. 41) et la carrière du bas Moyen Âge (pour S. 51).

Aucune autre structure n'est directement associée à ces fosses et leurs dimensions sont plus modestes que celle de Keradennec. La capacité de S. 41 est d'au moins $2,5 \mathrm{~m}^{3}$, tandis que celle de $S$. 51 n'est que de $1,25 \mathrm{~m}^{3}$, soit la moitié. Le terme de silo semble plus judicieux pour qualifier ces fosses que celui de caves. Leur utilisation pour le stockage des récoltes semble devoir être retenue. Ces structures sont fréquentes sur les sites de cette époque, aussi bien en Bretagne (Catteddu et al., in Catteddu, 2001, p. 218) qu'en France septentrionale (Catteddu, 2009, p. 56).

\section{LES STRUCTURES DE COMBUSTION}

En plus des vestiges artisanaux du secteur Us. 02 (cf. supra), quatre structures en creux (S. 52, 300, 301 et 307) présentent des traces de rubéfaction plus ou moins marquées.

\section{Description}

La structure S. 52 est presque accolée au flanc ouest du silo S. 41, parfaitement alignée dans le même axe longitudinal (fig. 19 et 22). Oblongue, elle mesure $1,70 \mathrm{~m}$ de long et $0,90 \mathrm{~m}$ de large pour une profondeur de $0,35 \mathrm{~m}$. Son profil transversal est en $U$ à fond relativement plat. L'ensemble de la structure est en forme de baignoire excavée dans le substrat. Sa base et ses flancs présentent des traces de rubé-

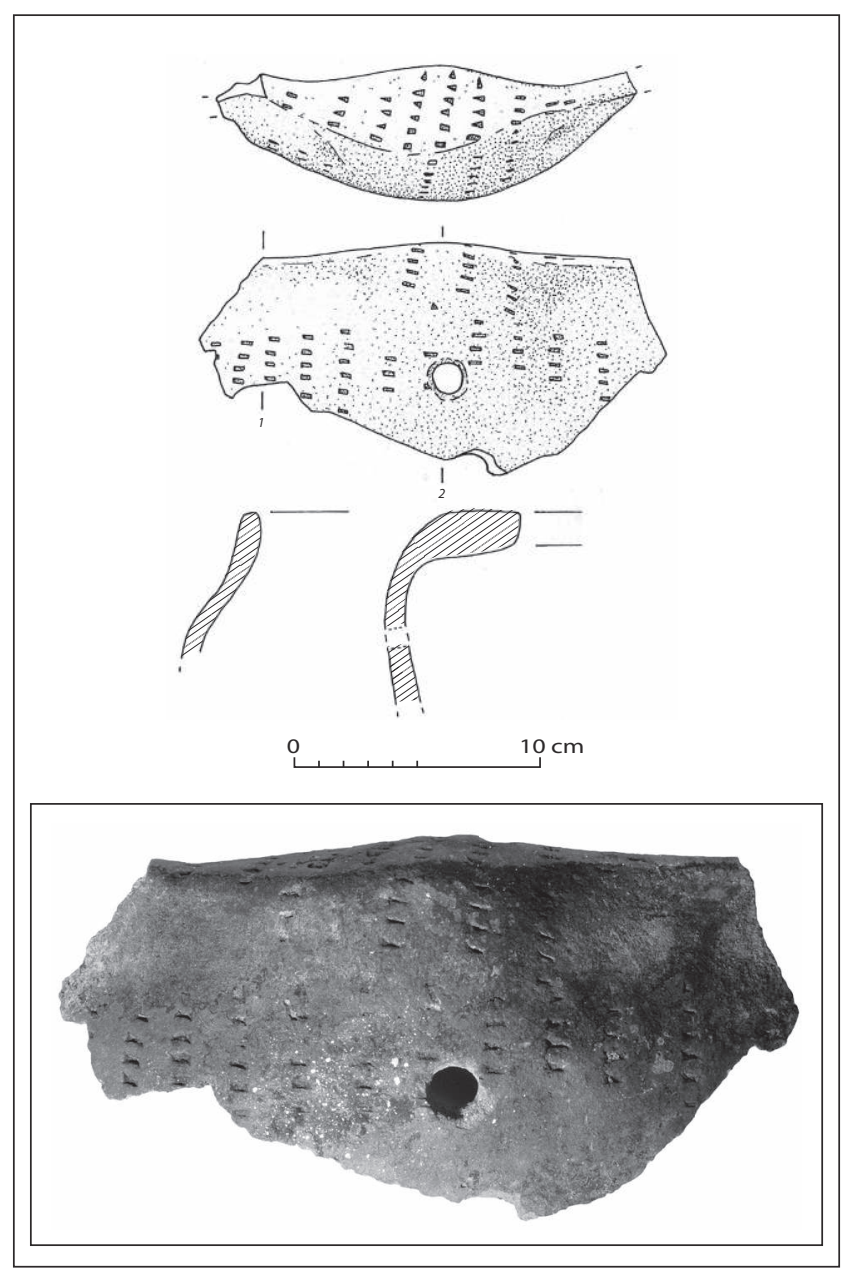

Figure 21 : Poterie issue du silo S. 41.

Figure 21: Pottery from the storage pit S. 41.

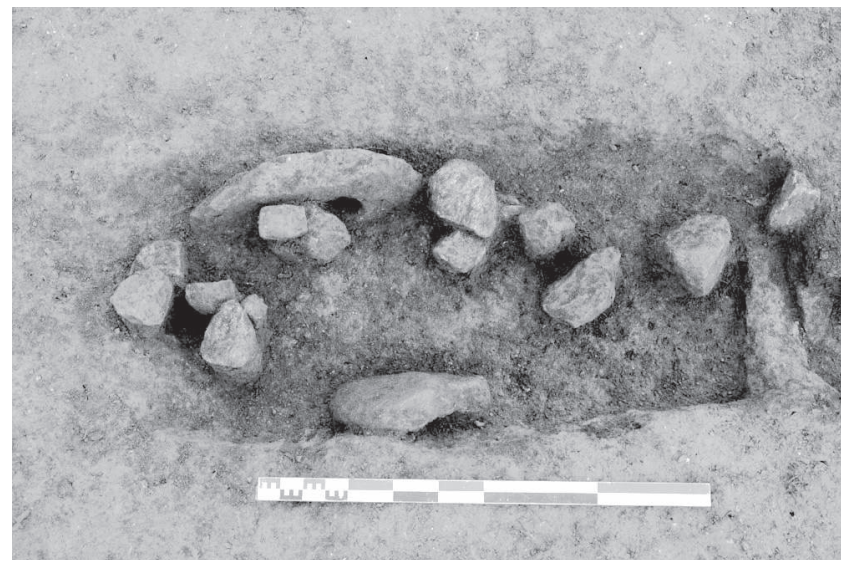

Figure 22 : Vue de détail du four à grain S. 52. Figure 22: Detail of the corn drying kiln S. 52. 
faction. Deux dalles de granite placées de chant, en vis-à-vis le long des parois septentrionale et méridionale, ont également subi l'épreuve de la chaleur sur leur face interne. L'une d'entre elles présente une perforation centrale cylindrique (diamètre $11 \mathrm{~cm}$ ). Une des faces est plane, au grain lissé ou usé et, à sa périphérie, cette surface s'incurve en rebord de cuvette avant d'être brisée. Il s'agit d'un fragment de meule recyclé; difficilement datable, il peut aussi bien être médiéval qu'antique. Plaquées contre les parois, ces deux dalles sont recouvertes par une couche de terre charbonneuse de $0,25 \mathrm{~m}$ d'épaisseur qui tapisse le fond de la structure. Ces vestiges semblent relever de la phase d'utilisation de S. 52 . Ces éléments furent par la suite noyés par une couche de terre argilo-sableuse contenant des blocs de pierres brûlées répartis en deux groupes : une ligne parallèle au flanc septentrional et un amas superposé ou éboulé au niveau de l'extrémité occidentale. Cette seconde étape pourrait correspondre à l'abandon de la structure et au rejet ou destruction d'aménagements périphériques en pierre, compléments des dalles de chant. La structure S. 52 est séparée du silo S. 41 par un bourrelet de substrat, large de 0,25 m. Les deux comblements ne se recoupent pas et ne livrent pas leur chronologie relative, d'autant moins que la petite structure isolée S. 53, postérieure, perturbe le point de jonction.

La structure S. 307 a été mise au jour à l'est de la précédente (fig. 23), au centre de l'imbrication de fosses du secteur Us. 03 (angle sud-est de la zone III). Elle est également de plan subrectangulaire, en baignoire. Ses dimensions sont de 1,80 par 0,80 m, pour une profondeur maximale de $0,40 \mathrm{~m}$, l’axe longitudinal étant orienté nord-est/sud-ouest. Son profil transversal est en $U$ tandis que, longitudinalement, son plancher s'incline en pente douce vers le nord-est. Les parois sont rubéfiées, ainsi que le fond de la partie basse. Cette surface rougie est recouverte par une mince pellicule de terre noire charbonneuse. La structure est ensuite comblée par de la terre brun-noir incluant des traces de charbon de bois. Cet aménagement est un des plus récents du secteur puisque son comblement recoupe les sédiments des fosses antérieures S. 305 et S. 309 (cf. infra).

La structure S. 300 se situe au sud-ouest, dans de prolongement de S. 307 (fig. 23). Il s'agit d'une petite fosse circulaire de $0,85 \mathrm{~m}$ de diamètre pour $0,18 \mathrm{~m}$ de profondeur dont les parois sont rubéfiées. Elle est comblée en son centre par une couche de terre noire charbonneuse disposée en tas. Celle-ci a ensuite été recouverte par une terre arénitique brun-clair.

L'aménagement S. 301 n'est pas à proprement parler une structure de combustion car il ne présente pas de parois rubéfiées (fig. 23). Il se caractérise davantage par le rejet ou l'installation de fragments de four ou de foyer au sein de son comblement. La structure se présente sous la forme d'une tranchée, longue d'au moins 2,90 $\mathrm{m}$ pour $0,80 \mathrm{~m}$ de large, peu profonde (entre 0,15 et $0,20 \mathrm{~m}$ ). Son axe longitudinal est orienté nord-ouest/sud-est. Vers le nord-ouest, l'extrémité de l'aménagement est atteinte, tandis qu'au sud-est des perturbations modernes interrompent son tracé. Comblée par une terre arénitique brun-clair, la partie supérieure du remplissage présente, au niveau du substrat, deux concentrations de blocs d'argile rubéfiée et de fragments de tuiles $(1,1 \mathrm{~kg})$. L'ensemble le plus septentrional, de plan subcirculaire, semble matérialiser une surface, mais il est bien difficile d'apprécier dans quelle mesure cet effet de surface correspond à une réalité ou s'il découle de l'érosion de la partie supérieure des vestiges. Quoiqu'il en soit, il demeure possible que cette concentration ait servi de base à un foyer. Cette tranchée est recoupée sur son flanc occidental par une autre structure parallèle, S. 303 (cf. infra).

\section{Mobilier et datation}

Là encore, le mobilier n'est guère abondant. La structure S. 52 livra quatre tessons de poterie commune dont un fragment d'anse interne renfoncée, et S. 307 un seul tesson de poterie similaire associé à un fragment de sole ou paroi de four. Aucun tesson ne fut découvert dans la tranchée S. 301. En revanche, un grand fragment de pot ou oule en poterie grossière, dure et micacée, à la surface craquelée fut mis au jour dans le comblement charbonneux de la petite fosse S. 300 (fig. 24); la lèvre, à section rectangulaire, est éversée et la surface externe est couverte d'une croûte de suie.

Le mobilier mis au jour s'insère dans la fourchette chronologique de la fin du haut Moyen Âge. Le fragment d'anse interne renfoncé est typique de la céramique du site. Le pot à lèvre éversée trouve des équivalents à Créach-Gwen et à Keradennec entre le $\mathrm{IX}^{\mathrm{e}}$ et le début du XI ${ }^{\mathrm{e}}$ siècle (Villard, 2005b).

La fosse S. 307 est datable des environs de la fin du $\mathrm{x}^{\mathrm{e}}$ et/ ou du $\mathrm{XI}^{\mathrm{e}}$ siècle par la chronologie relative (S. 305, antérieure, livre des tessons du $\mathrm{X}^{\mathrm{e}}$-début XI ${ }^{\mathrm{e}}$ siècle; cf. infra).

\section{Interprétation}

La structure S. 52, avec sa forme de baignoire aux parois rubéfiées et renforcées d'agencements latéraux de dalles ou pierres placées de chant, évoque sans nul doute des aménagements de fours, plus particulièrement, des fours à sécher le grain. Des structures identiques sont connues à Quimper sur les sites de Kerlaéron, de Créac’h-Gwen, du Moustoir 1 ou du Moustoir 2 (Le Bihan et, Villard, 2005). Ces structures rubéfiées ne sont que la partie profonde d'aménagements plus importants destinés à conserver les grains par séchage tout en conservant leurs propriétés germinatives (tempé- 


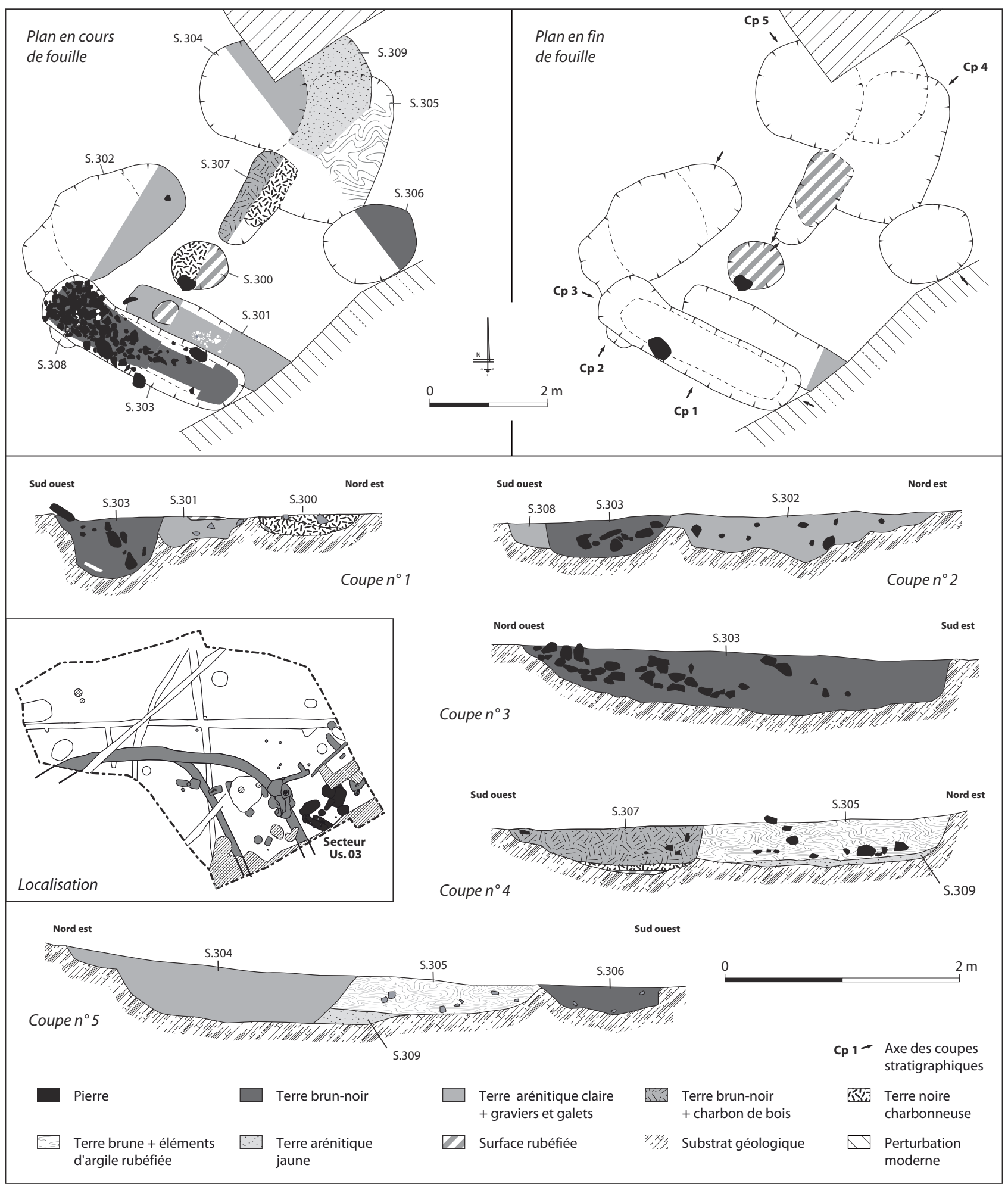

Figure 23 : Plans et coupes stratigraphiques des fosses du secteur Us. 03.

Figure 23: Plans and sections of area Us. 03 pits. 


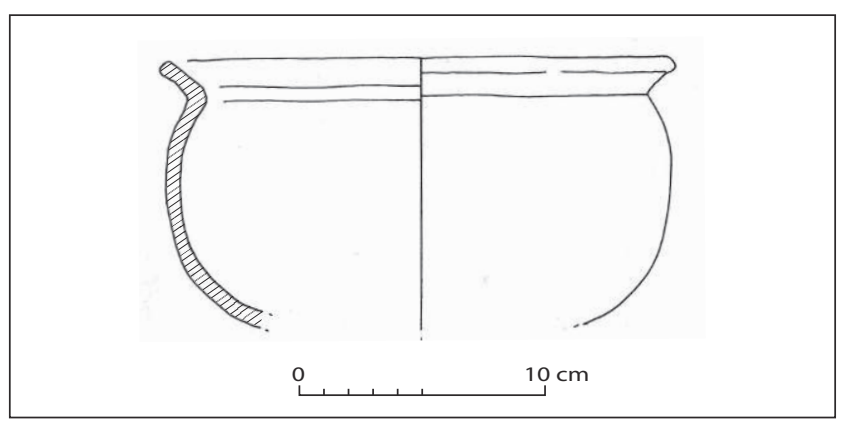

Figure 24 : Poterie issue de la structure de combustion S. 300. Figure 24: Pottery from the hearth or oven S. 300.

rature inférieure à $40^{\circ}$ ). Ces fosses soumettaient les grains à la chaleur sans toutefois les griller. Ces derniers, séparés du contact du feu ou des braises, devaient être disposés au dessus sur des aménagements aériens à structure légère, aujourd'hui disparus. Ce type de vestiges est fréquemment repéré en fouille en France septentrionale.

Il est intéressant de noter l'extrême proximité de ce four et de la structure de stockage S. 41, ainsi que leur parfait alignement. S'il est établi que tous deux furent utilisés à la fin du haut Moyen Âge, ont-ils fonctionné conjointement? La présence d'un fragment de meule réutilisé pour l'aménagement du four renforce également la vocation agricole de l'établissement. Ce serait là un bel exemple d'ensemble complet de structures liées au traitement des récoltes (fours à sécher le grain), au stockage (S. 41) et à la transformation (meule). Dans l'espoir de retrouver quelques restes végétaux, un échantillon de vingt litres de terre fut prélevé dans la couche charbonneuse profonde de S. 52. Le tamisage fin (inférieur à $1 \mathrm{~mm}$ ) et le flottage des refus de tamis ne révélèrent aucun élément végétal. La même opération fut effectuée dans la couche profonde de comblement de la structure de stockage $S$. 51 sans plus de résultats. Il est vrai que, dans ce dernier cas, ces terres charbonneuses étaient davantage issues de la phase d'abandon que de celle de son utilisation. D'une morphologie similaire, la fosse S. 307 a pu fonctionner de la même manière que la structure $S .52$, pour le séchage du grain, mais aucun indice ne le confirme. Plus généralement, ces vestiges s'inscrivent dans la catégorie des tranchées-foyers, fréquents sur des sites armoricains de ces périodes (Le Bihan et Villard, 2005; Catteddu et al., in Catteddu, 2001, p. 217), sites qui, bien souvent, livrent des restes de céréales (Provost, 1989).

La structure en cuvette S. 300 évoque davantage un aménagement de foyer ou de four. La présence du grand fragment de pot à cuire, avec ses dépôts de suie, évoquerait une utilisation comme foyer domestique. Cependant, sa proximité avec la tranchée $S .307$ suggérerait une utilisation concomitante : S. 300 a pu servir à préparer les braises déposées par la suite dans la tranchée S. 307 pour sécher le grain.

Il demeure plus délicat d'interpréter la tranchée S. 301. Si elle s'insère dans le cadre de l'établissement, sa fonction demeure incertaine. Elle a pu, à un moment, accueillir un petit foyer mais l'origine et les raisons du creusement de la tranchée initiale sont inconnues. Par ailleurs, son interruption vers le sud-est ne permet pas de savoir s'il s'agit d'un aménagement en tranchée sur quelques mètres destiné à une utilisation spécifique, d'un partage de l'espace ou de l'extrémité d'un fossé.

\section{LES FOSSES}

Une série de fosses, de tailles, de formes et de natures différentes fut mise au jour sur toute la partie méridionale de la zone III, avec une concentration notable au sud-est (secteur Us. 03).

\section{La fosse S. 303}

La fosse S. 303 est une tranchée subrectangulaire orientée nord-ouest/sud-est (fig. 23 et 25), recoupant le flanc occidental de la structure S. 301 (cf. supra). Elle mesure 3,60 $\mathrm{m}$ de long pour une largeur moyenne de $0,90 \mathrm{~m}$ et s'élargit légèrement à son extrémité septentrionale. Son profil transversal est en $U$ avec des flancs taillés proprement dans le substrat. Son fond est arrondi. La moitié méridionale présente, longitudinalement, un fond relativement plat (profondeur moyenne de $0,50 \mathrm{~m}$ ) qui remonte en pente douce vers le nord-ouest, réduisant alors la profondeur à $0,20 \mathrm{~m}$. Des pierres émergent en surface à l'extrémité septentrionale et le long du flanc sud-ouest. Une fouille en paliers des sédiments (terre brun-noir) a permis de dégager un empierrement dense, mêlé à de nombreux fragments de tuiles $(9,5 \mathrm{~kg})$, se développant vers le bas de la fosse. Aucune organisation des pierres n'apparaît. En fait, l'empierrement s'incline vers le sud-est, conformément au pendage du fond de la moitié nord de la structure; il s'agit davantage d'un rejet massif de blocs de pierres lors du comblement de la fosse que d'un aménagement interne structuré. Certains blocs sont de belle taille tandis que d'autres présentent des faces brûlées. Le reste de la fosse est rempli de la même terre brun-noir, mêlée aux pierres. Outre la tranchée S. 301, S. 303 recoupe également la petite structure S. 308 et la fosse S. 302.

Vingt-cinq tessons de poterie commune grossière, à la surface craquelée, y furent mis au jour. Parmi ceux-ci, il est possible d'identifier un rebord à chanfrein interne et un fragment de bord à anse renfoncée. Ce mobilier est associé 


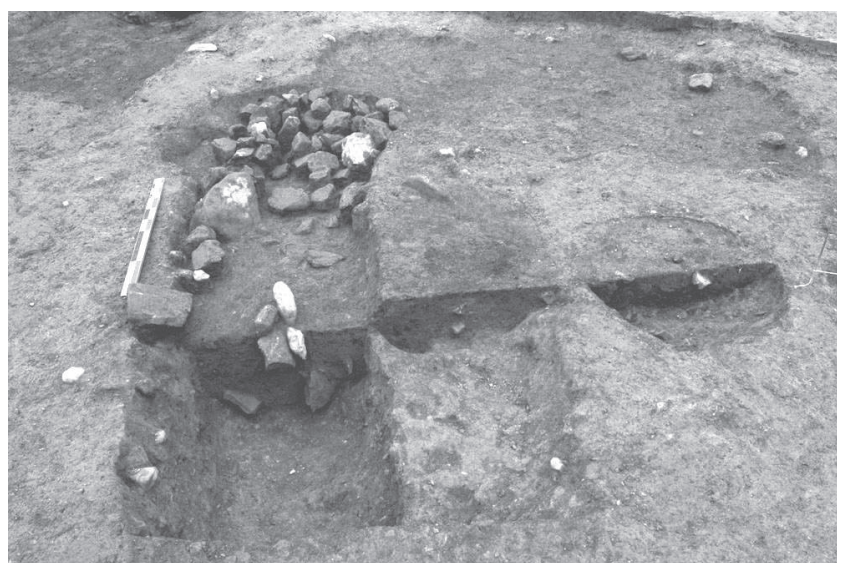

Figure 25 : Vue vers le nord-ouest des fosses S. 303, S. 301 et S. 300 (de gauche à droite).

Figure 25: Pits S. 303, S. 301 and S. 300 (from left to right), looking to the north-west.

à quelques fragments de poterie gallo-romaine erratique. Un fragment de pierre à aiguiser fut également découvert parmi l'empierrement. L'anse renfoncée est datable des $\mathrm{IX}^{\mathrm{e}}-\mathrm{X}^{\mathrm{e}}$ siècles tandis que le rebord à chanfrein interne est plutôt typique des productions des $\mathrm{x}^{\mathrm{e}}$-XI ${ }^{\mathrm{e}}$ siècles (Villard, 2005b). Compte tenu de ce mobilier et de la position relative de cette structure vis-à-vis de ses voisines, la seconde fourchette semble la plus appropriée pour dater son fonctionnement.

Le mode d'utilisation d'une telle structure demeure mystérieux. Qu'elle ait accueilli un rejet massif de matériaux supposerait, en toute logique, qu'elle fonctionnait ouverte. Les parois soigneusement taillées confirmeraient ce point de vue. Dès lors, qu'elle fut son utilisation? Le stockage? Elle pourrait se rapprocher, par la fonction, de la tranchée S. 301, voisine et antérieure, mais celle-ci ne livre pas plus d'informations. Les dimensions de S. 303 l'apparenteraient aux tranchées-foyers, fréquentes à cette époque aussi bien à Quimper (Créac'h-Gwen) qu'en Ille-et-Vilaine (Catteddu et al., in Catteddu, 2001 ; Provost, 1989). Mais, ici, aucune trace de rubéfaction n'est observée. La structure n’aurait-elle pas servi? Le comblement indique la présence à proximité d'aménagements en pierre détruits mais sans qu'il soit possible d'en déterminer la nature. Ceux-ci auraient pu tout aussi bien se situer dans l'environnement de la structure que participer d'un aménagement lié à son fonctionnement, périphérique ou en élévation.

\section{Les fosses d'extraction}

\section{Description}

Trois fosses, S. 302, S. 304 et S. 306, sont interprétées comme des fosses d'extraction par leurs caractères morpho- logiques. Toutes sont situées dans le secteur Us. 03, où elles s'imbriquent avec d'autres structures en creux (fig. 23 et 26).

S. 302 est, stratigraphiquement parlant, la plus ancienne des trois puisqu'elle est, dans sa partie occidentale, recoupée par S. 303. Informe et étirée sur un axe longitudinal nordest/sud-ouest, elle mesure $3,00 \mathrm{~m}$ sur $1,50 \mathrm{~m}$. Sa profondeur maximum, au centre, est de $0,40 \mathrm{~m}$. Son fond est très irrégulier et marqué de cicatrices d'arrachement. Creusée dans un substrat d'argile graveleuse, elle est comblée d'un sédiment arénitique brun clair relativement homogène mais chargé de petites pierres et de galets.

La fosse S. 304 se situe plus à l'est où elle est partiellement recoupée par l'angle d'une perturbation moderne. Il s'agit d'une excavation circulaire de $1,90 \mathrm{~m}$ de diamètre et profonde de 0,60 m. Le fond, globalement incliné vers le sud, est irrégulier. Elle est comblée par une terre arénitique claire chargée de graviers et petits galets. Ce creusement entaille les sédiments des fosses antérieures S. 305 et S. 309.

La situation stratigraphique de la fosse S. 306 est assez proche puisqu'elle aussi est postérieure à $\mathrm{S}$. 305. De plan circulaire (diamètre $1,40 \mathrm{~m}$ ), elle est creusé sur $0,25 \mathrm{~m}$ de profondeur et remplie de terre brun-noir.

\section{Le mobilier}

Les trois fosses livrèrent un mobilier relativement abondant. Si les poteries mises au jour sont toujours réalisées en pâte commune grossière, dure et micacée, à la surface craquelée, quelques particularités typologiques sont présentes. Parmi les tessons de la fosse S. 302, figure un grand fragment d'un pot à cuire à lèvre rectangulaire éversée, chan-

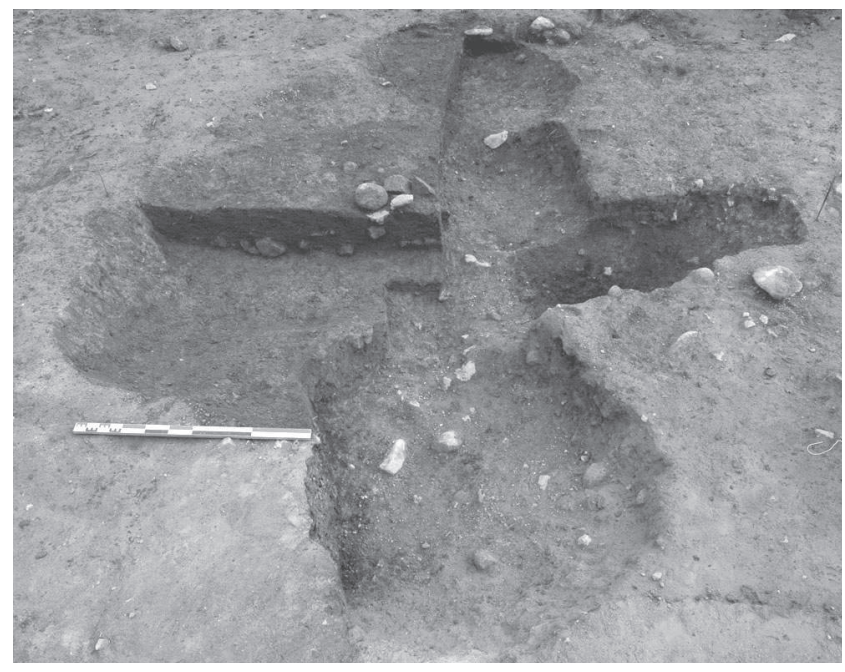

Figure 26 : Vue vers le sud des fosses de la partie orientale du secteur Us. 03 (S. 304, S. 305, S. 306, S. 307 et S. 309).

Figure 26: Pits of the eastern area Us. 03 (S. 304, S. 305, S. 306, S. 307 and S. 309), looking south. 
frein interne et petite anse en ruban entre la lèvre et le col (fig. 27). Ces caractéristiques se retrouvent également sur plusieurs pots de la fosse S. 304. L'un d'entre eux, malgré sa petite anse, ne possède pas de chanfrein interne. Un autre rebord à large lèvre éversée à l'horizontale et anse en ruban ornée d'incisions a été découvert dans S. 302. Il est réalisé dans une pâte plus dure, sonore et de couleur beige.

\section{Datation et interprétation}

Le chanfrein interne, observé sur la plupart des récipients à anse(s), est un critère local présent sur les poteries produites au $\mathrm{X}^{\mathrm{e}}$ siècle et au début du $\mathrm{XI}^{\mathrm{e}}$ (Villard, 2005b). Le chanfrein interne au niveau du col apparaît à Créac'h-Gwen (Menez et Batt, 1988) dans la dernière phase d'occupation de ce site, et il est présent au Moustoir 2 jusqu'au milieu du XI ${ }^{\mathrm{e}}$ siècle (Le Bihan et Villard, 2005). Ce caractère n'est pas exclusivement local puisqu'il se retrouve ailleurs en Bretagne : à Tinténiac en Ille-et-Vilaine (Provost, 1989) ou à
Saint-Urnel en Plomeur dans le Finistère (Giot et Monnier, 1978). Le petit vase à anses, sans chanfrein, de la fosse S. 304 ne dépareille pas la série car des récipients identiques sont recensés à Quimper (Créac'h-Gwen et Quistinidal) pour les $\mathrm{IX}^{\mathrm{e}}-\mathrm{X}^{\mathrm{e}}$ siècles. Le mobilier situerait le creusement de ces fosses autour $\mathrm{du} \mathrm{x}^{\mathrm{e}}$ siècle, peut-être à une date relativement avancée dans ce siècle.

L'irrégularité du plan de la fosse S. 302, ainsi que celle de son fond, évoquent un creusement lié à la recherche de matériaux. Le substrat argileux pourrait expliquer cette excavation, de même que les galets, présents dans l'argile naturelle et rejetés dans le comblement. La situation est identique pour S. 304 et $S$. 306, avec leurs fonds d'où émergent nombres de blocs de pierres et galets du substrat. En revanche, la sélection des matériaux extraits ne devait pas toujours répondre à de grandes exigences car, dans le cas de S. 304, une grande partie de son emprise recoupe les comblements des structures antérieures. L'utilisation des

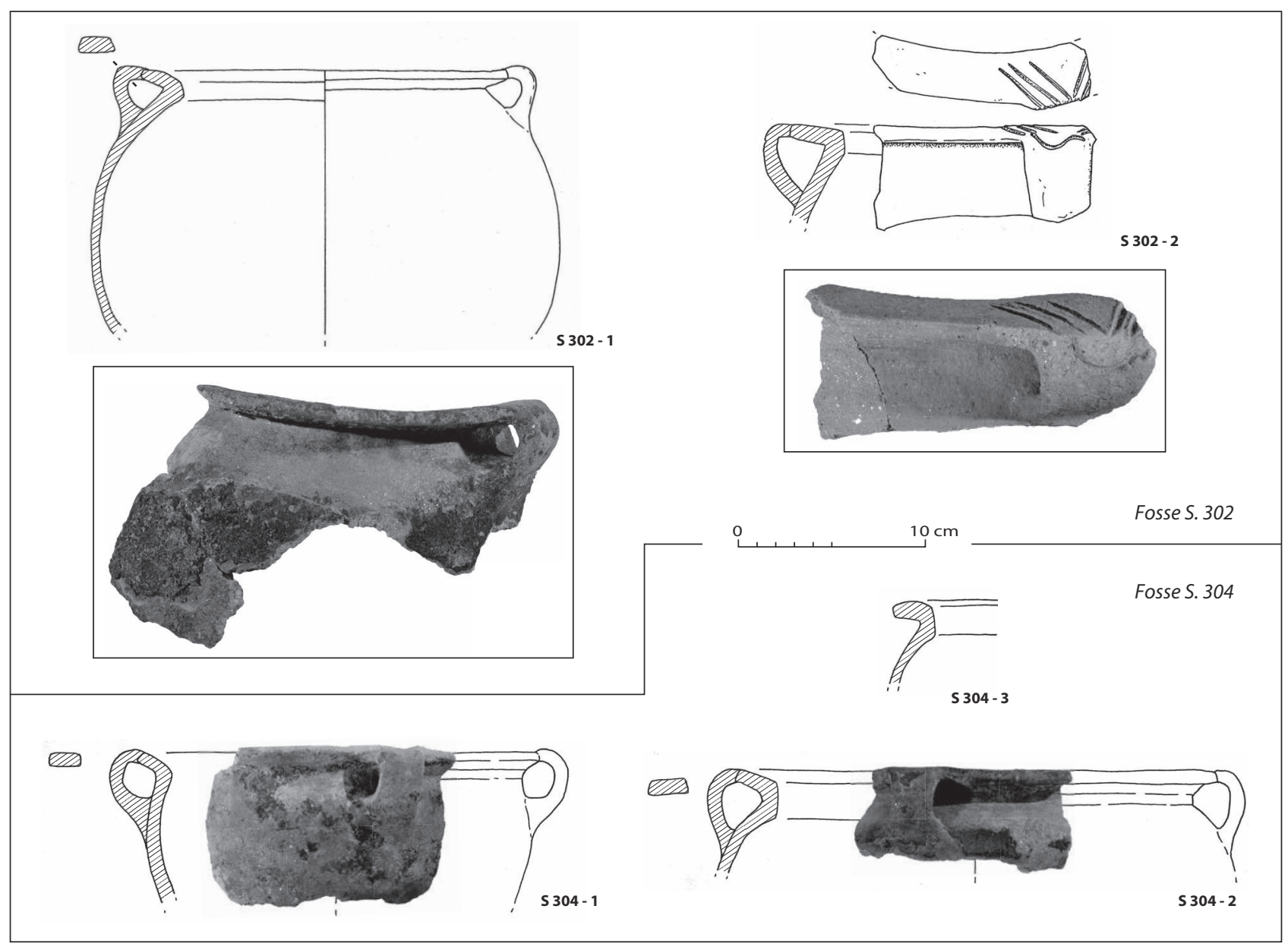

Figure 27 : Poteries issues des fosses d'extraction. Figure 27: Pottery from the clay pits. 
sédiments extraits est inconnue. Peut-être ont-ils servi à réaliser des sols, du même type que ceux de l'ensemble artisanal Us. 02?

\section{Les autres fosses}

En plus de celles citées précédemment, une dizaine de fosses de tailles et de formes différentes ont été mises au jour dans cette partie méridionale de la zone III. Leur interprétation est généralement délicate voire impossible, mais elles livrent un mobilier similaire aux autres structures en creux. Elles peuvent être regroupées en trois catégories.

\section{Les fosses à plan subrectangulaire}

Elles sont au nombre de quatre et sont généralement d'assez grande taille (fig. 3, 19 et 23).

La fosse S. 50 est localisée au sud-est du silo S. 41. Comme ce dernier, elle recoupe le tracé du fossé T. 23. L'étude en surface montrait déjà clairement que le comblement de terre brune, sombre, argilo-sableuse et chargée de cailloutis de cette fosse recoupait les sédiments du fossé. Orientée ouestsud-ouest/est-nord-est sur son axe longitudinal, elle mesure $1,90 \mathrm{~m}$ sur $0,90 \mathrm{~m}$. Son fond plat est situé à $0,20 \mathrm{~m}$ sous le niveau actuel du substrat. Quelques pierres plates sont disposées, sans véritable organisation, au sommet du comblement. Il est bien difficile de se prononcer sur la fonction de cette structure. La couverture de pierres plates pourrait évoquer des structures analogues mises au jour sur le site carolingien de La Chapelle-Saint-Aubert en Ille-et-Vilaine (Hurtin, in Catteddu, 2001, p. 177). Mais, dans ce cas, aucune proposition d'un quelconque mode de fonctionnement n'est formulée.

La fosse S. 305 est localisée dans le secteur Us. 03. Son axe longitudinal est orienté nord-nord-est/sud-sud-ouest. Elle mesure 3,70 m sur, approximativement, 1,70 m pour une profondeur de $0,32 \mathrm{~m}$. Elle est retaillée par la structure de combustion S. 307 ainsi que les fosses d'extraction S. 304 et S. 306, mais recoupe la fosse S. 309 (cf. infra). Son comblement se compose d'une terre brune chargée de résidus d'argile rubéfiée et de quelques petites pierres. La particularité de cette structure est de livrer un mobilier relativement abondant (fig. 28) : trente-sept tessons de poterie commune grossière, dure et micacée, à la surface craquelée, parmi lesquels six rebords de vases à chanfrein interne ( $\mathrm{x}^{\mathrm{e}}$ siècle et première moitié $\left.\mathrm{du} \mathrm{XI}^{\mathrm{e}}\right)$. L'utilisation d'une telle fosse demeure énigmatique; son comblement indique la présence de structures de combustions proches mais pas sa fonction.

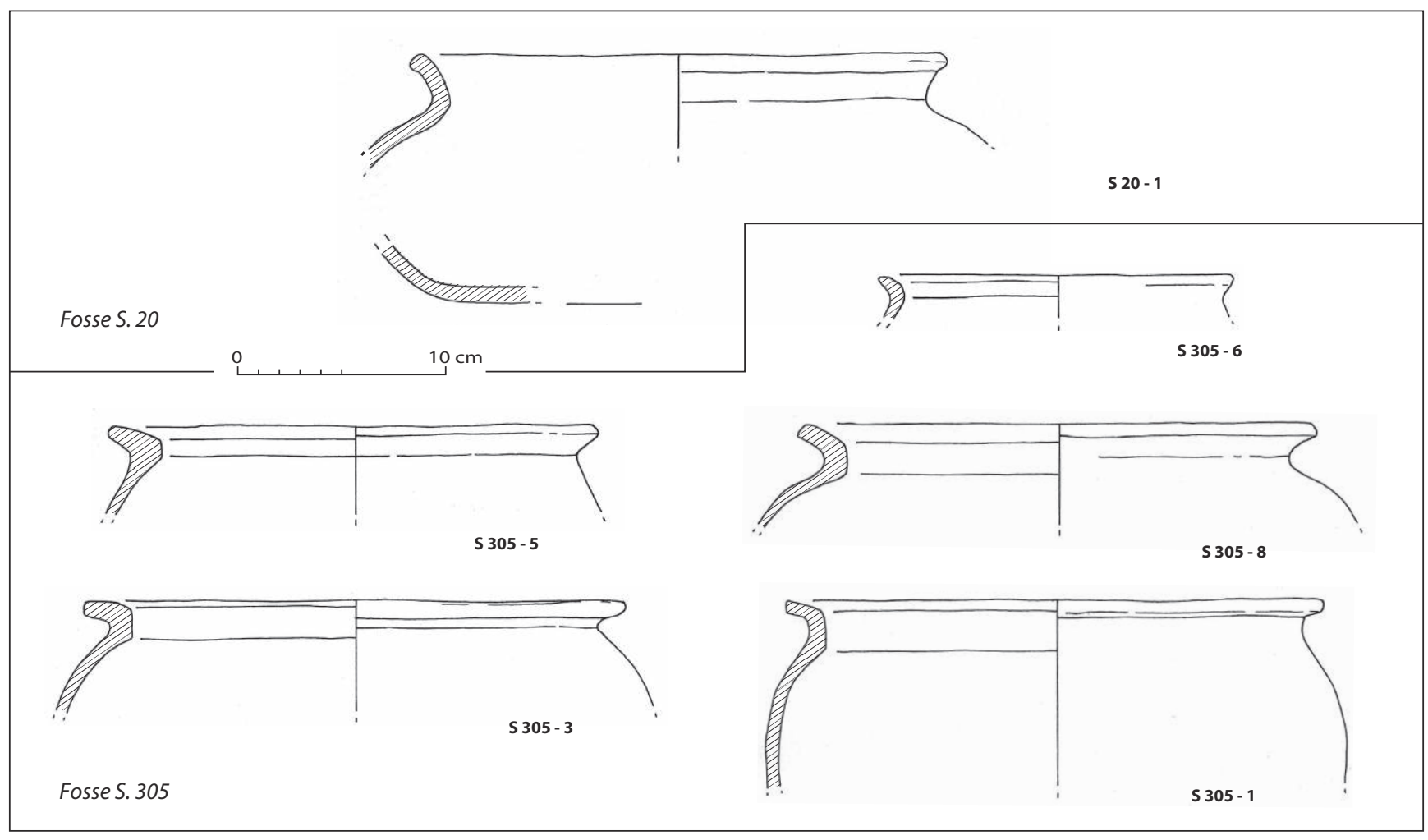

Figure 28 : Poteries issues des autres fosses.

Figure 28: Pottery from other pits. 
La fosse S. 26 est située au nord des précédentes (fig. 3). Orientée nord-ouest/sud-est, elle mesure 2,50 m sur 1,00 m pour $0,12 \mathrm{~m}$ de profondeur. Elle n'a été étudiée que partiellement, au contact du petit fossé T. 28 qu'elle recoupe (cf. infra). Elle est comblée par une terre brune, sombre, argilo-sableuse, chargée en cailloutis. Aucune interprétation n'est proposée; sa forme, son type de comblement et sa localisation incitent cependant à la raccorder à l'occupation du haut Moyen Âge.

La fosse S. 45 est localisée entre les fossés T. 22 et T. 23 (fig. 3). De dimensions plus modeste $(1,25 \times 0,85 \mathrm{~m}$, profondeur $0,12 \mathrm{~m}$ ), elle est orienté nord-est/sud-ouest. Elle a livré deux tessons de poterie commune grossière, dure et micacée, permettant de la rattacher au site de la fin du haut Moyen Âge.

\section{Les fosses à plan circulaire}

Trois petites fosses circulaires ont été identifiées (fig. 3).

S. 46 est une dépression d'environ $0,22 \mathrm{~m}$ de profondeur pour un diamètre de $1,10 \mathrm{~m}$. Elle livre quelques petits tessons de poterie commune du haut Moyen Âge associée à quelques tessons antiques.

La fosse S. 308 est observée le long du flanc sud-ouest de la fosse-tranchée S. 303 qui la recoupe nettement. Ses dimensions sont inconnues, mais elle livre malgré tout un petit fragment de rebord à anse interne renfoncée.

La petite fosse circulaire S. 20 est mise au jour en limite orientale de la zone III, où elle recoupe la fosse S. 62 (fig. 29). D'un diamètre d'environ $0,70 \mathrm{~m}$, elle est comblée par une terre brun-gris sombre et des petites pierres. Cette fosse livre un ensemble de vingt-cinq tessons de poterie commune grossière micacée appartenant à un vase à lèvre éversée de section rectangulaire et fond légèrement bombé (fig. 28). Ce vase serait datable des $\mathrm{IX}^{\mathrm{e}}-\mathrm{X}^{\mathrm{e}}$ siècles, par comparaison avec les poteries quimpéroises de Créac'h-Gwen ou de Quistinidal (Villard, 2005b).

\section{Des fosses partiellement étudiées}

Restent quatre structures qui n'ont été que partiellement appréhendées par la fouille, soit du fait de leur localisation en limite de sondage, soit du fait de leur recoupement par des structures postérieures (fig. 3 et 23).

La fosse S. 62 se situe près de l'angle sud-est de la zone III, en limite de fouille. Cette structure, qui devait s'étendre plus à l'est, est par ailleurs largement entaillée dans sa partie septentrionale par des perturbations modernes (fig. 29). Sa forme exacte ne peut être définie. Dans sa partie profonde, elle marque le substrat d'une empreinte subcirculaire légèrement plus encaissée $(0,45 \mathrm{~m})$ que dans son extension orientale. Elle est comblée par une terre arénitique grise, fine, chargée de petits graviers et de traces de charbon de

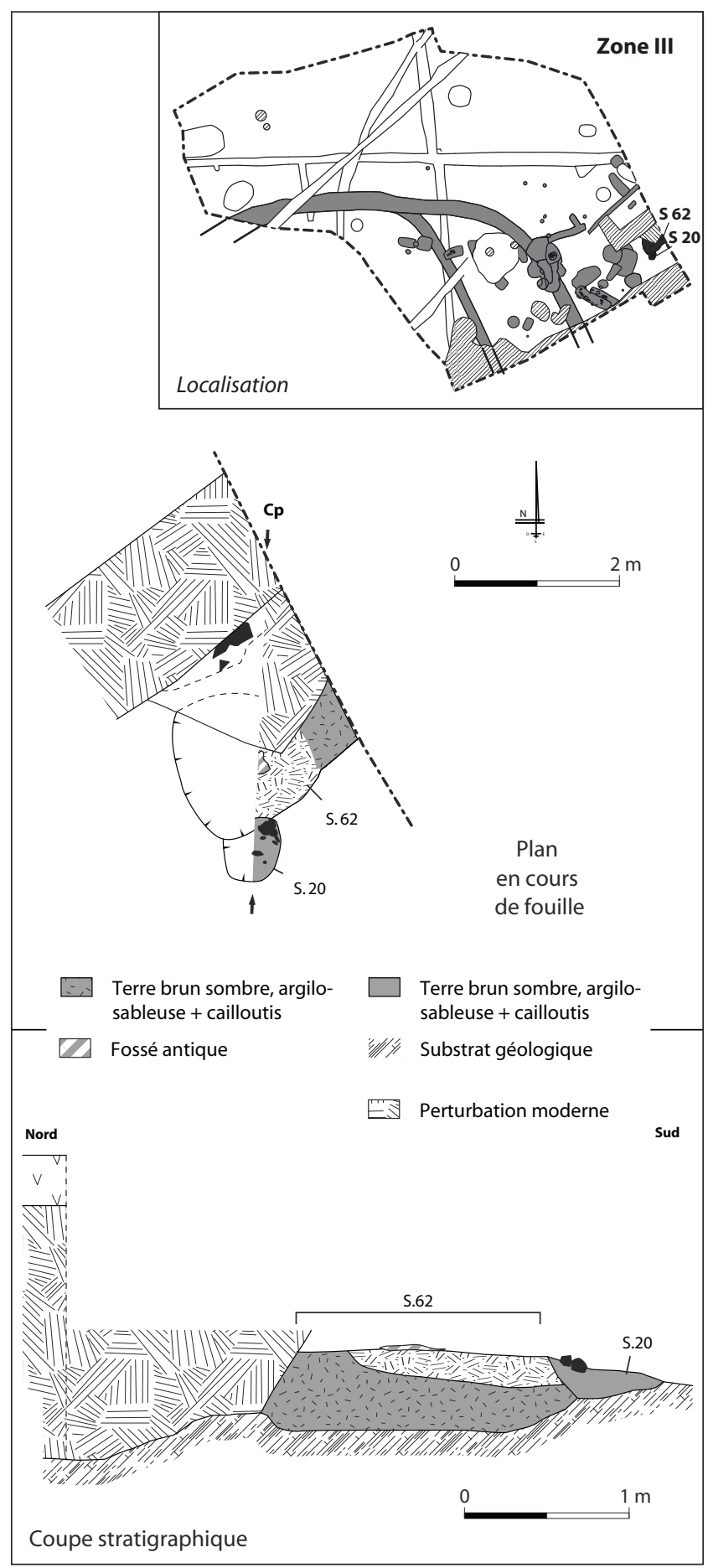

Figure 29: Plan et coupe stratigraphique des fosses S. 20 et S. 62. Figure 29: Plan and sections of pits S. 20 and S. 62.

bois. Au sommet de ce comblement, un banc d'argile jaune compacte scelle ce remplissage et, à la surface de celui-ci, une petite zone rubéfiée apparaît. Il n'est pas possible d'attribuer une fonction à cette fosse S. 62 tant elle est perturbée. Cependant, cette rubéfaction supérieure n'est pas sans 
rappeler le cas de la fosse $S .301$, pour laquelle l'hypothèse d'un aménagement de foyer à une étape tardive de l'histoire de la structure a été évoquée. S. 62 ne livre pas de mobilier mais elle est recoupée par la fosse circulaire S. 20, datée des $\mathrm{IX}^{\mathrm{e}}-\mathrm{X}^{\mathrm{e}}$ siècles.

La fosse S. 309 constitue l'étape la plus ancienne, en termes de chronologie relative, des fosses du secteur Us. 03 (fig. 23). Son comblement de terre jaune arénitique apparaît localement sous les remplissages des fosses S. 304 et S. 305, ainsi qu'au nord de cette dernière. D'après son empreinte partielle, conservé localement dans le substrat, la forme du creusement devait être subcirculaire.

La fosse S. 66 a été localisée le long du flanc occidental du fossé T. 22, face à son antenne latérale T. 27. Elle est partiellement détruite par le creusement de la carrière du bas Moyen Âge. De plan ovale (1,75 m par 0,75 m), elle s'enfonce à $0,35 \mathrm{~m}$ dans le substrat. Elle est comblée d'une terre arénitique gris-jaune.

\section{Datation, interprétation}

Toutes ces structures appartiennent à l'établissement de la fin du haut Moyen Âge aussi bien par le mobilier qu'elles livrent que par leur position stratigraphique. Leur fonction, (stockage, soutien d'éléments architecturaux?) demeure indéterminable.

\section{QUELQUES STRUCTURES ISOLÉES}

Quelques structures isolées ou particulières restent à décrire pour compléter le panorama des vestiges.

\section{Le fossé T. 28}

Le petit fossé T. 28 se situe à l'est de la zone III. Orienté nord-est/sud-ouest, il a été suivi sur une longueur de $6,50 \mathrm{~m}$ (fig. 3). Au sud-ouest, il disparaît, victime de l'érosion, tandis que, de l'autre côté, il se prolonge au-delà de la limite de fouille. Son profil en $\mathrm{U}$ est profond de $0,15 \mathrm{~m}$ pour une largeur de $0,35 \mathrm{~m}$. Antérieur à la fosse $\mathrm{S}$. 26, il ne livre qu'un tesson de poterie commune grossière, dure et micacée. Cette structure semble avoir servi au cloisonnement de l'espace (support d'une petite palissade?) à un moment de l'histoire du site; peut-être en association avec le fossé T. 27 ou pour border l'ensemble fossoyé Us. 03.

\section{Des trous de poteaux}

Quelques trous de poteaux ont été découverts en différents endroits du site. Ils demeurent malheureusement trop rares et dispersés pour traduire une quelconque organisation (fig. 3). Il s'agit des structures S. 27 à S. 32, S. 38, S. 39, S. 40, S. 45 et S. 53. Toutes sont comblées par une terre arénitique brun-gris et leur diamètre avoisine les $0,30 \mathrm{~m}$ pour une profondeur moyenne de $0,20 \mathrm{~m}$. Trois tessons de poterie commune grossière ont été découverts dans le trou S. 53, dont un fragment décoré à la molette. Un fragment de rebord avec amorce d'une anse renfoncée a été mis au jour dans le trou S. 38. Le mobilier exhumé, ainsi que le recoupement du fossé T. 27 par S. 31, placent certaines de ces structures individuelles à une date avancée de l'occupation de la fin du haut Moyen Âge. Cependant, rien ne prouve que toutes soient contemporaines. Par ailleurs, leur fonction est difficilement déterminable (support de charpente pour bâtiments, piquets de clôture, autre?).

\section{La structure S. 60}

\section{Description et mobilier}

La structure S. 60 est localisée près de la limite orientale de la zone III, mordant largement sur le tracé d'un fossé galloromain (fig. 30). Mesurant 1,10 m de côté, cette excavation quadrangulaire s'enfonce profondément dans le substrat, en deçà des sédiments du fossé antique. Compte tenu de l'exiguiité de la structure et de sa localisation au pied du talus arboré bordant le chemin traversant le parc, la fouille complète de la structure n'a pu être réalisée. Une profondeur de $1,80 \mathrm{~m}$ a néanmoins été atteinte en la fouillant par moitié et un sondage complémentaire réalisé à l'aide d'un jalon laisse supposer que la structure descend encore de plus de $0,60 \mathrm{~m}$, soit un total de 2,40 m au minimum. Dans le premier mètre, la structure traverse un banc naturel d'arène granitique avant de rencontrer le substrat argileux. Elle est comblée par une terre brune, sombre, argilo-sableuse, assez caillouteuse.

Neuf tessons de poterie commune grossière, dure et micacée, furent mis au jour, en association avec plusieurs tessons antiques erratiques. À ce mobilier céramique, il convient d'ajouter 202 g de scories légères. Parmi les tessons, se distingue une lèvre éversée à l'horizontale, de section rectangulaire.

\section{Datation, interprétation}

Le mobilier gallo-romain semble erratique et provient du recreusement du fossé antique. Le reste des tessons date la structure de la fin du haut Moyen Âge, sans plus de précision.

L'aspect quadrangulaire de l'excavation évoque les structures de stockages S. 41 et S. 51 (cf. supra), mais celles-ci ne sont pas aussi profondes et le rapport emprise au sol/ profondeur n'est pas le même; cette fonction ne semble pas devoir être nécessairement retenue. Le type de substrat traversé suggère d'autres hypothèses. L'argile présente en pro- 


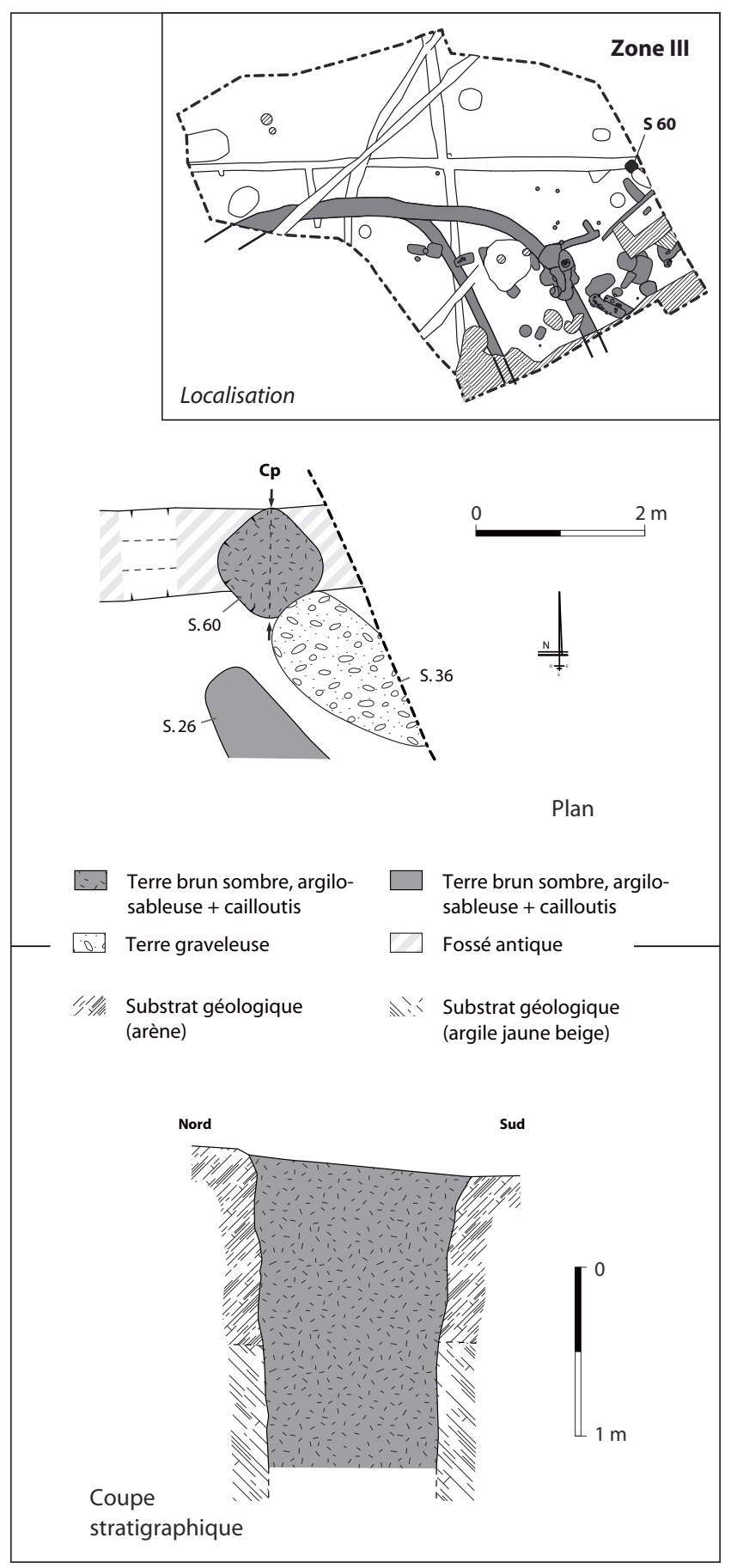

Figure 30 : Plan et coupe stratigraphique de la structure S. 60. Figure 30: Plan and section of feature S. 60.

fondeur est de bonne qualité; elle peut être utilisée comme matériau de construction, voire entrer dans la composition de productions céramiques. Ce type d'excavation en puits, pour extraire de la matière première rappellerait ainsi une structure de même nature fouillée au Corniguel 2 (Le Bihan et Villard, 2005). Il s'agissait là d'une recherche de pierres dans un filon granitique diaclasé. Une seconde hypothèse, toujours liée à la présence d'argile, serait celle d'un puits. En effet, un forage bien entretenu dans ce type de substrat, en pied de coteau arénitique aux propriétés drainantes, en ferait une bonne structure de recueil et de stockage d'eau.

\section{Conclusions}

Les vestiges évoqués ici couvrent une surface somme toute restreinte, moins de $600 \mathrm{~m}^{2}$. Cet espace livre, malgré tout, une forte densité de vestiges et des traces d'une activité relativement intense. Malheureusement, l'opération archéologique n'a permis d'ouvrir qu'une fenêtre restreinte sur une occupation plus vaste. L'absence de vestiges du haut Moyen Âge au nord de l'axe gallo-romain T. 21 (fig. 3), situe le cœur de l'établissement plus au sud, en direction de la rue Bourgles-Bourgs. Les vestiges mis au jour sont divers puisque se côtoient des fossés d'enclos, des fours à grains, des silos, des fosses d'extraction de matériaux, des installations métallurgiques, des trous de poteaux... Tous ces indices traduisent des activités variées aussi bien artisanales qu'agricoles.

\section{La datation et le mobilier}

Les indices permettant de dater cet établissement sont peu abondants et ne sont basés que sur des éléments de mobilier céramique. Le travail de synthèse réalisé à propos de ce type de mobilier pour l'époque médiévale, à Quimper, permet de mieux appréhender les vases et de les dater (Villard, 2005b).

Mis à part les tessons erratiques antiques, le lot de mobilier issu des vestiges de l'établissement forme un groupe très homogène. La pâte est souvent très chargée en dégraissant à base de grains de quartz, très anguleux et abondants. Ils peuvent, à l'occasion, s'accompagner de nodules rougeâtres ou blanchâtres. D'autres critères communs sont observables sur ces productions : une surface craquelée, des parois simplement lissées marquées de fines stries, un lissage rapide qui ne gomme pas les irrégularités de montage (colombins) ou les stigmates du modelage. Les pâtes sont généralement brunes ou brun-gris sombre à l'extérieur et grises à beiges à l'intérieur. Ces productions sont majoritaires, quand elles ne sont pas exclusives, sur les sites quimpérois attribués à la fin du haut Moyen Âge, essentiellement entre les $\mathrm{IX}^{\mathrm{e}}$ et $\mathrm{X}^{\mathrm{e}}$ siècles.

La morphologie des vases présente elle aussi certaines caractéristiques. Les anses internes renfoncées, formées par un épaississement local de la lèvre rabattu vers l'intérieur, constituent un mode de préhension typique des récipients de cette époque; de même pour les décors à la molette qui peuvent néanmoins être un peu plus anciens (entre le VIII ${ }^{\mathrm{e}}$ et le $\mathrm{x}^{\mathrm{e}}$ siècle). L'association de ces deux critères, morpho- 
logique et décoratif, est par ailleurs fréquente ainsi que le montrent les exemplaires de Créac'h-Gwen.

En ce qui concerne les pots à cuire ou les oules aux lèvres à section rectangulaire éversée à $45^{\circ}$ et aux parois convexes, ils sont également datés, à Quimper, des $\mathrm{IX}^{\mathrm{e}}-\mathrm{X}^{\mathrm{e}}$ siècles. Certains sont agrémentés d'une petite anse en ruban reliant la lèvre et le col. Ils présentent fréquemment d'abondantes traces de suie.

En revanche, d'autres vases à lèvre rectangulaire éversée entre $45^{\circ}$ et l'horizontale, à chanfrein interne vertical ou légèrement oblique, réalisés dans des pâtes semblables ou plus micacées, sont également recensés. Ils possèdent fréquemment une anse en ruban. Ce chanfrein est un caractère morphologique un peu plus tardif : il apparaît plutôt entre le $\mathrm{X}^{\mathrm{e}}$ et le début du XI ${ }^{\mathrm{e}}$ siècle à Créac'h-Gwen, au Moustoir 2, à Keradennec et au Corniguel 2. À Saint-Urnel en Plomeur (Finistère), sa date est validée par la numismatique et des datations ${ }^{14} \mathrm{C}$ (Giot et Monnier, 1978). Par ailleurs, il n'est pas observé de poteries à pâte onctueuse, ou à surfaces onctueuses pour les plus précoces, parmi le mobilier de l'occupation de la fin du haut Moyen Âge. Ce type de production n'apparaît à Quimper qu'au cours du $\mathrm{XI}^{\mathrm{e}}$ siècle (Le Moustoir 2, place Laënnec), de même qu'à Saint-Urnel.

Tous ces éléments intègrent l'occupation du site au sein d'une fourchette chronologique allant du $\mathrm{Ix}^{\mathrm{e}}$ siècle au milieu du $\mathrm{XI}^{\mathrm{e}}$ (fig. 31). La stratigraphie de certains secteurs de fouille a par ailleurs montré de multiples recoupements de structures, fruits de réaménagements ou d'activités renouvelées; cela confère également au site une certaine durée. L'analyse de la répartition des différents mobiliers ainsi que la chronologie relative entre les structures permet d'établir l'évolution chronologique et spatiale des vestiges. Plusieurs étapes de mise en place et de développement de l'établissement se distinguent.

\section{L'histoire du site}

Rue Bourg-les-Bourgs, l'élément médiéval le plus ancien est le fossé T. 23 qui matérialise un premier enclos (fig. 32-1). Malheureusement, l'implantation des zones étudiées fait que seul un quart de son tracé est observé. De taille relativement modeste, la surface enclose est estimée à $2000 \mathrm{~m}^{2}$, en se basant sur un hypothétique tracé circulaire de ce fossé. Ce type d'enclos curviligne est relativement fréquent à cette époque dans le nord-ouest de la France (Catteddu et NissenJaubert, in Demoule, 2004, p. 159). Aucun vestige lié à son occupation n'est observé, l'épicentre de l'établissement se situant au-delà de la limite de fouille. L'hypothèse d'une palissade installée dans le fossé a été évoquée, mais rien n'est sûr. Quelques structures extérieures pourraient se rattacher à cette phase sans qu'il soit possible de les définir.

La seconde étape voit un élargissement de l'enclos initial, tout au moins en direction de l'est. Le creusement du fossé T. 22 conserve la limite septentrionale de la phase 1 mais

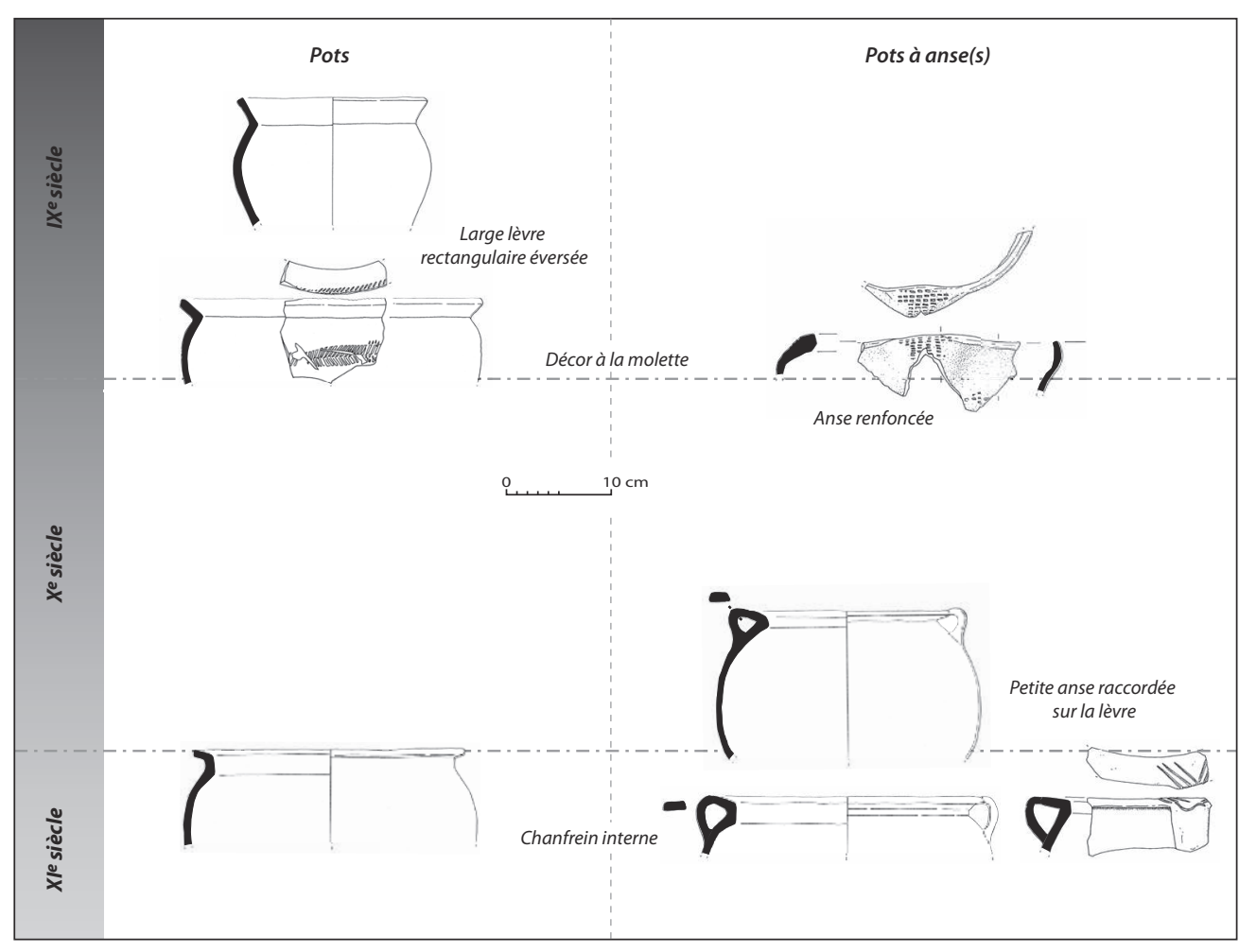

Figure 31 : Tableau d'évolution des formes de poteries. Figure 31: Table of the morphological evolution of the pottery. 


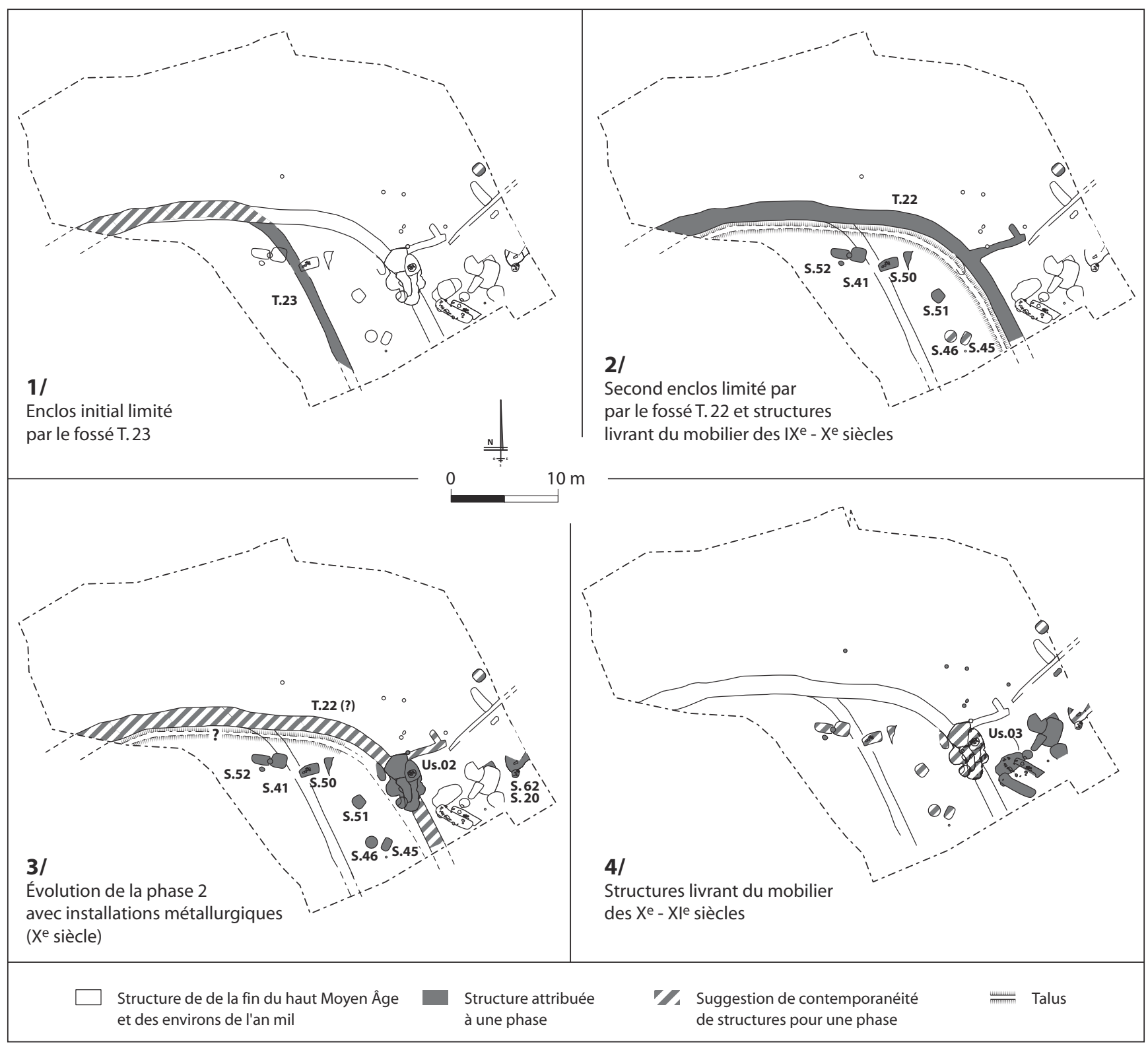

Figure 32 : Proposition d'évolution et d'organisation spatiale des vestiges ( $\mathrm{IX}^{\mathrm{e}}$-milieu XI ${ }^{\mathrm{e}}$ siècle).

Figure 32: Proposed chronology and spatial organisation of excavated remains (9th to mid-11th century).

s'en écarte vers l'est pour cerner une surface plus importante (fig. 32-2), mais on ne sait si cet élargissement fut également réalisé en direction du sud et de l'ouest. Cette mise en place s'accompagne de l'édification d'un talus bordant le flanc interne du fossé, mais ce talus pouvait déjà exister au nord selon l'hypothèse retenue pour l'utilisation de T. 23. Des aménagements périphériques devaient exister extérieurement, à l'est, limités par le petit fossé T. 27 et peut-être au-delà (T. 28). À l'intérieur, plusieurs structures peuvent fonctionner avec ces installations; il s'agit des silos S. 41 et S. 51, du four à grain S. 52 et de quelques fosses
(S. 45, S. 46 et S. 50). Hormis le fait de se situer au sein de l'emprise de T. 22, ces structures se caractérisent également par la céramique qu'elles livrent : les décors à la molette, les anses internes renfoncées ou les pots à lèvre rectangulaire éversée, qui forment un lot cohérent pour la période des $\mathrm{IX}^{\mathrm{e}}-\mathrm{X}^{\mathrm{e}}$ siècles. Cette fourchette chronologique intégrerait ces deux premières phases. L'évolution spatiale pourrait résulter d'un accroissement du nombre d'habitants et/ou de leur potentiel économique.

Cette seconde phase connaît ensuite de nouveaux bouleversements sans qu'il soit tout à fait possible de définir s'ils 
furent profonds ou résultèrent d'une évolution progressive. À ce stade, le fossé T. 22 est entièrement ou en partie comblé. Au sommet de ce remplissage s'installent les activités métallurgiques de l'Us. 02 (fig. 32-3). Si le fossé est remblayé, le talus peut, quant à lui, demeurer en partie fonctionnel. C'est possible au nord mais pas à l'est où, localement, les structures artisanales empiètent sur le flanc interne de T. 22 (foyer S. 207, fosses Us. 26 ou Us. 20). En tous cas, la mise en place de ces structures dans l'ancien angle de T. 22 et T. 27, n'est pas anodine. Elle semble démontrer que le paysage était encore marqué par ces précédents aménagements. Le mobilier mis au jour date ces activités d'une période proche de la précédente. Compte tenu de la stratigraphie, il convient de retenir une date plus récente dans cette fourchette chronologique (probablement au $\mathrm{x}^{\mathrm{e}}$ siècle). Les fours et silos précités, situés dans l'espace intérieur, peuvent soit encore fonctionner, soit, pour certains, être installés dans ce second temps.

L'ultime phase est surtout perceptible par le mobilier. Au sein des fosses du secteur Us. 03, situées nettement hors de l'espace anciennement clos par T. 22, un nouveau type de céramique fait son apparition : les récipients à chanfrein interne et/ou petites anses en ruban. Ils ne sont mis au jour que dans ces structures au sud-est de la fouille (fig. 32-4). Certaines d'entre elles recoupent des vestiges plus anciens livrant des fragments d'anse renfoncée. En l'absence totale de tessons en poterie onctueuse ou à surface onctueuse associés à ces formes, comme cela était le cas sur l'occupation médiévale du Moustoir 2, abandonnée au milieu du $\mathrm{XI}^{\mathrm{e}}$ siècle (cf. supra), il semble qu'il faille de préférence dater ces structures d'une période comprise entre la fin du $\mathrm{x}^{\mathrm{e}}$ siècle et le début $\mathrm{du} \mathrm{XI}^{\mathrm{e}}$. Le site poursuivrait ainsi son extension vers le sud-est, à moins qu'il ne s'agisse d'un décalage plus global de l'établissement dans cette direction. Ce dernier serait, à ce moment là, plus ouvert, talus et fossés ayant alors disparu, tout au moins dans cette partie accessible du site.

La période de fonctionnement du site, centrée sur l'époque carolingienne, est chronologiquement parlant déconnectée des autres occupations du secteur. Les vestiges gallo-romains étudiés rue Bourg-les-Bourgs ne vont pas au-delà du $\mathrm{II}^{\mathrm{e}}$ siècle et, à Roz-Avel, les derniers niveaux archéologiques sont datés aux alentours de 275 de notre ère. Entre la fin de cet établissement antique et l'installation des structures de la phase 1 , vers le $\mathrm{IX}^{\mathrm{e}}$ siècle, ont ne sait rien de l'histoire de ce secteur de Quimper. De même, après le XI ${ }^{e}$ siècle, un nouveau vide est observé; d'après les vestiges mis au jour, les occupations suivantes n'interviennent pas avant la fin du Moyen Âge et le début de l'époque moderne ( $\mathrm{xIV}^{\mathrm{e}}-\mathrm{XVII}^{\mathrm{e}}$ siècles).

\section{Les activités}

En ce qui concerne les traces d'activités observées sur le site, plusieurs réflexions peuvent être faites. Les lieux de stockage (silo ou cave), les fours à sécher le grain, les multiples fosses sont des éléments récurrents sur les sites ruraux de la fin du haut Moyen Âge. Malheureusement, si dans certains cas ces installations ont une durée de vie limitée (Provost, 1989), dans d'autres il est prouvé qu'elles ont été construites pour servir plus longtemps. À titre d'exemple, le four à grain du Moustoir 1 présentait de nombreuses traces de réfection et de réaménagement; la structure excavée du Corniguel 2 (cave?) fut sûrement aménagée avec soin, avec un plancher et des parois boisées (Le Bihan et Villard, 2005). Faute d'éléments précis, il est difficile de se prononcer quant à la durée de fonctionnement des structures mises au jour rue Bourgles-Bourgs.

Pour ce qui est des activités métallurgiques, il est intéressant de noter leur présence sur la plupart des sites quimpérois de la fin du haut Moyen Âge. Tous ne sont cependant pas strictement contemporains (entre le $\mathrm{IX}^{\mathrm{e}}$ et le $\mathrm{XII}^{\mathrm{e}}$ siècle). Des forges sont attestées à Créac'h-Gwen et peut-être à Keradennec, des petits foyers artisanaux le sont également au Moustoir 2. Le travail du fer est également recensé sur d'autres sites armoricains au Teilleul, à La Talvassais (Catteddu et al., in Catteddu, 2001) ou normands (Carpentier, 1999). En règle générale, " on savait un peu partout réduire le minerai en fonction des besoins, au moyen de bas fourneaux " (Catteddu et Nissen-Jaubert, in Demoule, 2004, p. 169). Leur fréquence est plus importante que sur les sites ruraux antiques ou laténiens. Si l'absence ou la légèreté des vestiges sur les sites gaulois a pu suggérer l'hypothèse de forgerons itinérants, à la fin du haut Moyen Âge, les infrastructures ne manquent pas. Les installations de l'Us. 02 et ses réaménagements montrent plutôt le travail d'un artisan fixe rue Bourg-les-Bourgs; il ne semble pas raisonnable d'envisager de modifier ou refaire en profondeur de tels aménagements au gré du passage de spécialistes itinérants. L'exemple du Lac de Paladru (Isère) montre des installations fixes caractérisées par "des fortes épaisseurs d'argile et de galets isolant foyers et forges du substrat " (Colardelle et Verdel, 1993). Cette description rappelle, par bien des aspects, le cas de l'Us. 02 et du sol S. 202. Par ailleurs, le regroupement des différentes étapes de travail du fer en un même lieu (grillage, réduction, forge) est assez fréquent durant l'époque carolingienne sur des sites $\mathrm{du}$ nord de la France, en Alsace, dans l'Eure ou dans le Calvados (Carpentier, 1999). Malgré tout, la taille des bas-fourneaux induit ici, en ce qui concerne l'étape de réduction, des productions modestes. Il semble s'agir surtout de quantités liées à des besoins locaux. Sur le site, la quantité de scories mise 
au jour, tous types confondus, est d'un peu plus de six kilogrammes et elles sont à $95 \%$ concentrées dans le secteur Us. 02. Ces vestiges ne sont que des déchets de réduction ne contenant plus de fer exploitable (pas de réaction à l'aimant).

De même, le travail de forge devait répondre à des besoins de fabrication et de réparation d'outils ou d'objets potentiellement propres à l'établissement, à partir du produit semifini issu des bas-fourneaux. Malheureusement, la fouille de la rue Bourg-les-Bourgs n'a livré aucun objet en fer provenant de ces installations. Seule la pierre à aiguiser découverte dans la fosse S. 303 évoque cet outillage.

Reste la question de l'origine du minerai. Le Massif armoricain n'est pas avare en fer. Les éléments de quartz, présents dans de nombreux agglomérats scoriacés, supposent une origine granitique de ce minerai, mais pas exclusive. Sans analyses métallographiques, il est difficile d'être plus précis sur la provenance. Les gisements de fer les plus proches actuellement référencés sont situés dans la presqu'île de Crozon, à une quarantaine de kilomètres ${ }^{1}$. Cependant, la fréquence des installations de bas-fourneaux et de forges sur les sites quimpérois de cette époque, leur dispersion sur le territoire et les faibles quantités produites par chacune de ces structures de réduction supposent une certaine facilité d'accès aux matières premières. Un approvisionnement local semble devoir être privilégié. Certaines techniques d'exploitation et de traitement pouvaient éventuellement concentrer un minerai à faible teneur naturelle pour en améliorer le rendement (Mangin, 2004, p. 33-47). Ce problème n'est pas résolu et il se pose dans les mêmes termes à Quimper pour les quelques vestiges antiques de réduction, sans plus de réponses (Le Bihan et Villard, en préparation).

Enfin, la multiplicité et la variété des diverses fosses et creusements sont des critères fréquents sur les sites de cette période. Il est souvent difficile d'interpréter de telles excavations. Si certaines présentent des caractères permettant de les assimiler à des lieux de stockage ou à des aménagements de fours, d'autres sont plus avares en indices. Ainsi, par exemple, l'imbrication des creusements du secteur Us. 03 ne traduit ni une organisation, ni une accumulation de structures identiques. Les fosses les plus irrégulières peuvent correspondre à une recherche de matériaux de construction (arène, argile). Quant aux plus régulières, à paroi taillée soigneusement dans le substrat, sont-elles à rattacher aux profondes structures de stockage parallélépipédiques S. 41 et S. 51 ? Elles se présentent sous différentes formes : des fosses subrectangulaires à fond plat ou des creusements en tranchée, également à fond plat ou en légère pente.

1. [www.bretagne-environnement.org/Sous-sol/Les-ressources-souterraines/ L-inventaire-minier].
Au-delà de leur morphologie, les recoupements stratigraphiques induisent une chronologie relative de ces creusements. Ainsi, la structure S. 41, interprétée comme un silo, est liée à une phase précoce de l'établissement (Ix siècle), tandis que les fosses de l'Us. 03, plus modestes et moins profondes, se rattachent à une occupation plus tardive $\left(\mathrm{x}^{\mathrm{e}}\right.$ début $\mathrm{XI}^{\mathrm{e}}$ siècle). S'agit-il là d'une évolution des modes de stockage? Rien n'est sûr car le silo S. 51 n'est pas daté avec autant de précision et, par comparaison, la structure quadrangulaire (cave) du site du Corniguel 2, avec ses poteries à chanfrein, serait davantage contemporaine des fosses de l'Us. 03. En ce qui concerne les autres creusements, l'incertitude demeure, tant les formes et les comblements varient. Des conditions de stockage dans un environnement géologique sain sont acceptables mais que penser de structures telles que S. 303, S. 304 ou S. 305, recreusées dans d'anciens comblements, eux-mêmes accumulés dans un substrat argileux? L'humidité ne devait guère y être propice à la conservation. Cette réflexion est également valable pour le silo S. 41 dont le flanc oriental est partiellement constitué des sédiments de comblement de l'ancien fossé T. 23 qu'il recoupe. La question des conditions d'utilisation de ce type de structures a déjà été posée à Quimper, dans le cas des fosses de stockage du site de Kerbabic au bas Moyen Âge. Si conservation il y eut dans ces fosses, on ne peut probablement y voir que des aménagements temporaires, ouverts, semi-enterrés. Des structures de ce type, destinées à d'autres produits que les grains ou encore à la fermentation de plantes fourragères, sont connues (Catteddu et al., in Catteddu, 2001). Elles seraient alors plus à mettre en relation avec les batteries de fosses subrectangulaires précitées de Quimper - Kerbabic (Le Bihan et Villard, 2005). La multiplicité des types de creusements serait ainsi due à la variété des types de produits stockés et la taille liée aux quantités, plutôt qu'à des modes de stockage spécifiques à chacune des phases d'occupation. L'étude générale des sites d'époque carolingienne montre une abondance de structures de stockage et révèle une production agricole active et variée (Catteddu et Nissen-Jaubert in Demoule, 2004).

Quoiqu'il en soit, la découverte d'un ou plusieurs fours à sécher le grain confirme la vocation agricole de l'établissement. Elle implique, de fait, la nécessité de stocker et transformer ces récoltes.

En résumé, les vestiges mis au jour ici confirment la présence, au sein de l'établissement de la fin du haut Moyen Âge, de plusieurs activités : métallurgie du fer, agriculture avec traitement et stockage... Ce site présente toutes les caractéristiques des établissements ruraux de cette époque. Des comparaisons ont été établies avec des sites quimpérois contemporains, elles sont également possible non seulement avec plusieurs établissement armoricains analogues 
tels que ceux de Tinténiac (Provost, 1989), de Montours ou de La Chapelle-Saint-Aubert (Catteddu et al., in Catteddu, 2001), mais également de France septentrionale. Tous montrent l'image, non pas de sites axés sur une seule activité, mais de lieux où l'on produit et transforme, aussi bien dans le domaine agricole que dans celui de l'artisanat (poterie, métallurgie), au gré des besoins de la communauté. À l'intérieur des enclos, " les bâtiments et les activités évoluent librement " (Catteddu et Nissen-Jaubert in Demoule, 2004, p. 159). Notre manque de vision générale de l'établissement de la rue Bourg-les-Bourgs ne permet d'appréhender ni sa structuration interne, ni le nombre de ses habitants. Au vu des deux silos et des installations métallurgiques, aux productions somme toute modestes, il semble raisonnable d'y voir un regroupement de quelques familles plus qu'un véritable village. L'estimation de la surface de l'établissement de la première phase plaiderait en ce sens (cf. supra). Cependant, l'accroissement progressif de l'espace enclos au fil de l'histoire du site, ainsi que sa vision partielle, ne permettent pas d'être catégorique. D'une ferme, il a pu évoluer en hameau. Les indices sur les habitations sont rares. Quelques trous de poteaux dispersés sont attestés mais rien n'assure leur appartenance à des bâtiments. De fait, la vie quotidienne de ces habitants apparait ici plus au travers des activités artisanales que par les activités domestiques. La zone fouillée correspondrait-elle à un secteur spécifique de l'établissement? C'est peu probable, tant les activités, à la fois agricoles et artisanales, semblent imbriquées. Cependant, la question de la durée de fonctionnement des structures n'a pas été résolue. Toutes ne sont pas obligatoirement strictement contemporaines, au sein d'une même phase d'occupation. Quoiqu'il en soit, le secteur habité n'est pas réellement appréhendé par la fouille, seule la céramique et quelques tuiles suggèrent leur présence non loin; cela indique cependant une distinction spatiale entre lieu de vie et lieu de travail. Si le site carolingien de Naveil (Loir-et-Cher) montre une certaine sectorisation entre espaces d'habitat et de stockage (Chaudriller, 2009), pour les exemples précités ce n’est pas un règle.

\section{Le site et l'Histoire}

À l'image du reste de l'Armorique, la période allant de la fin de l'Antiquité à celle du haut Moyen Âge demeure floue aussi bien rue Bourg-les-Bourgs qu’à Quimper en général. Du premier établissement médiéval (phase 1), on ne sait pratiquement rien. En revanche, sa date est intéressante puisqu'elle correspond également aux premières occupations médiévales recensées sur la commune : Quistinidal, Créac'hGwen, Keradennec (Le Bihan et Villard, 2005). Mis à part le cas unique et particulier de Kerlaéron ( $\mathrm{viI}^{\mathrm{e}}$ siècle), ces sites des $\mathrm{IX}^{\mathrm{e}}-\mathrm{X}^{\mathrm{e}}$ siècles, sont les plus anciennes manifestations archéologiques postérieures à l'époque romaine autour du bassin de l'Odet (fig. 1).

Le lieu d'implantation de l'établissement étudié ici est remarquable d'un point de vue topographique : l'espace ceint par les enclos successifs est installé sur un replat à mipente, face à la ria de l'Odet. Contrairement aux occupations antiques (parcellaire et habitat) qui colonisent l'intégralité des terres, faisant parfois fi des contraintes géographiques, le choix de l'assise de l'habitat de la fin du haut Moyen Âge semble avoir répondu à certaines préoccupations. Il convient cependant de se méfier, tant l'érosion et les aménagements récents sur la partie basse du terrain ont pu modifier la topographie. La moindre profondeur du fossé T. 22 vers le sud peut indiquer la perte des niveaux supérieurs à cet endroit et donc, de ce fait, induire un replat aujourd'hui moins marqué. Il demeure difficile de se prononcer sur la topographie réelle de cette époque. Il semble, malgré tout, que cet effet de terrasse se prolonge plus généralement vers l'est. Il a donc pu favoriser l'implantation de l'établissement. L'extension du site, au cours de son évolution, reste cantonnée à ce replat. Par ailleurs, le lien entre ce lieu et la rivière ne doit pas être négligé. Lors de l'installation au $\mathrm{Ix}^{\mathrm{e}}$ siècle, les effets de la régression marine des $\mathrm{V}^{\mathrm{e}}$-VIII ${ }^{\mathrm{e}}$ siècles devaient encore se faire sentir, dégageant des espaces utiles en contrebas du site, plus importants que durant l'époque gallo-romaine (Le Bihan et Villard, 2005). Le retour à la situation antique autour de l'année $1000 \mathrm{a}$ pu également avoir des conséquences sur l'évolution de l'établissement en réduisant ces terres basses.

Celui-ci croît ou se modifie à un rythme relativement soutenu : modification du tracé de l'enclos, creusements multiples de fosses, réfections d'installations artisanales (cf. supra). Cette image est conforme à celle des sites contemporains quimpérois ou bien d'Ille-et-Vilaine : des petits établissements ruraux dont le fonctionnement diffère peu de celui des fermes gauloises ou des exploitations rurales gallo-romaines. On y vit regroupé en communautés plus ou moins grandes, on y produit selon ses besoins (nourriture, outils). Rien n'est figé, les remaniements se succèdent souvent. Les constructions sont en bois et en terre, plus sur sablières basses que sur poteaux en ce qui concerne Quimper (Keradennec par exemple). La pierre est rarement utilisée, éventuellement pour des solins ou quelques aménagements particuliers et localisés (fours). Parmi les nombreux fragments de tuiles découverts, parfois en réutilisation, comme bases de foyers, dans les structures artisanales, quelques tuiles particulières sont identifiées. Elles se caractérisent par une épaisseur plus faible $(2 \mathrm{~cm})$ que les tegulae récupérées parmi les vestiges antiques. Elles sont fabriquées dans une pâte d'aspect général brunâtre, chargée en dégraissant de quartz. De forme quadrangulaire, elles présentent un rebord obtenu par simple pliage de la pâte à $90^{\circ}$. Elles rappellent les tuiles 
médiévales découvertes dans les niveaux de la place Laënnec à partir du XI ${ }^{\mathrm{e}}$ siècle (Le Bihan et Villard, 2005). Il est difficile de savoir si, à l'origine, ces tuiles couvraient des édifices légers à proximité du site ou des bâtiments plus importants ailleurs sur le territoire. Des échanges existent sans doute entre tous les sites quimpérois de cette époque sans que l'on connaisse la nature exacte de ces liens, économiques ou hiérarchiques. Une impression d'autonomie se dégage malgré tout de ces établissements. Sans parler d'autarcie complète, une sorte d'autosuffisance semble caractériser la plupart des sites de la fin du haut Moyen Âge en raison de leurs activités diversifiées et ce, aussi bien au niveau régional (Catteddu et al., in Catteddu, 2001; Le Bihan et Villard, 2005) que sur l'ensemble du domaine carolingien (Carpentier, 1999; Cuisenier, Guadagnin, 1988; Colardelle, Verdel, 1993).

En revanche, si de nombreux noyaux de peuplement, datés des alentours des $\mathrm{IX}^{\mathrm{e}}-\mathrm{XI}^{\mathrm{e}}$ siècles, sont aujourd'hui bien repérés par l'archéologie, leur environnement l'est moins. À Quimper, l'archéologie révèle soit des sites d'habitat (Bourg-les-Bourgs, Créach-Gwen, Keradennec, Le Corniguel 2, Le Moustoir 2), soit des éléments de parcellaire (Kervouyec, Quistinidal) mais ces deux types de sites ne sont pas directement associés (fig. 1). Les habitats se présentent comme des lieux de concentration d'activités, parfois clos (palissade, fossé et/ou talus), au mieux agrémentés de petits enclos périphériques accolés (Bourg-les-Bourgs, Le Moustoir 2) mais sans preuves d'existence d'un réseau parcellaire attenant tel que cela s'observe fréquemment autour des fermes laténiennes ou gallo-romaines. Cela impliquerait un paysage environnant plus ouvert, sans système d'enclos ou de cloisonnement à fondations profondes, un paysage échappant à l'œil de l'archéologue. Des systèmes légers de clôture ou des haies ont cependant pu exister sans pour autant laisser de traces. Ici, le parcellaire antique lié à la villa de Roz-Avel n'apparaît plus; seuls les cheminements peuvent perdurer. Malgré tout, si ce paysage totalement ouvert a pu exister à la fin du haut Moyen Âge, il n'est pas général. Les parcellaires quimpérois précités le prouvent, de même que certains sites d'Ille-et-Vilaine. Ces derniers révèlent des habitats intégrés dans un paysage structuré (Catteddu et al., in Catteddu, 2001, p. 221-224). Il ne semble pas y avoir de règle, tout au moins perceptible. Des différences microrégionales peuvent également exister.

Les modifications internes de l'établissement de la rue Bourg-les-Bourgs le font durer jusqu'au début du XI ${ }^{\mathrm{e}}$ siècle. À cette époque, le paysage quimpérois s'est modifié. Au $\mathrm{IX}^{\mathrm{e}}$ siècle, le site pouvait s'apparenter à un simple établissement rural. La ville antique de Locmaria avait périclité au début $\mathrm{du}_{\mathrm{IV}}^{\mathrm{e}}$ siècle et l'on ne sait que peu de choses de l'éventuelle continuité d'un habitat groupé dans le secteur (Le Bihan et Villard, 2005). Ensuite, au cours de son occu- pation, les habitants du site de Bourg-les-Bourgs ont été les témoins d'au moins deux événements majeurs de l'histoire locale : la fondation de l'église épiscopale de Locmaria autour du IXe siècle (Le Bihan et Villard, 2007), sur l'autre rive de l'Odet; la création de la ville de Quimper intra-muros, au confluent de l'Odet et du Frout, à la fin du $\mathrm{x}^{\mathrm{e}}$ siècle (Le Bihan et Villard, 2005).

Dans quelle mesure les habitants du site participèrent-ils à ces évènements? Leur simple présence dans une couronne relativement proche de ces lieux, leurs activités économiques et/ou leurs besoins spirituels et religieux associés à ceux de l'ensemble des établissements voisins furent-il des facteurs propices à ces choix? Il est bien difficile de le dire. Par ailleurs, faute d'une vision globale de l'établissement, il est délicat d'en déterminer le statut politique et/ou hiérarchique, de même que ses relations avec les autres sites contemporains du bassin de l'Odet. Son occupation durant une période charnière, entre la fin de l'époque carolingienne et le début de l'époque féodale, avec les changements sociaux que cela induit, n'aide pas à la réflexion. La disparition du site vers le milieu du $\mathrm{XI}^{\mathrm{e}}$ siècle est-elle à rechercher dans cette évolution de la société, dans une réorganisation territoriale après la création de la ville ou dans d'autres raisons indéterminées? Si, à Quistinidal, la fondation de la ville entraine une modification du réseau routier et de ses occupations proches, pour les autres sites ruraux (Créach-Gwen, Keradennec, Le Corniguel 2) leur abandon à cette même période demeure inexpliqué. Ces quelques questions à propos de la structure de la société rurale de la fin du premier millénaire échappent, en partie, aux filtres de l'archéologie. Les réponses ne se trouvent guère plus dans les textes, souvent peu diserts sur la vie quotidienne des campagnes.

\section{Bibliographie}

Carpentier, V., 1999 - Une occupation du haut Moyen Âge dans le bocage normand à Saint-Ouen-des-Besaces (Calvados), Revue archéologique de l'ouest, 16, p. 209-226.

Catteddu, I. (dir.), 2001 - Les habitats carolingiens de Montours et La Chapelle-Saint-Aubert (Ille-et-Vilaine), Paris, Maison des Sciences de l'Homme (DAF 89), 235 p.

Catteddu, I., 2009 - Archéologie médiévale en France, Le premier Moyen Âge ( $V^{e}-X I^{e}$ siècles), Paris, La Découverte/INRAP, $177 \mathrm{p}$.

Catteddu, I., Ruas, M.-P., Pradat, B. et Marguerie, D., 2001 Synthèse in Catteddu (dir.), 2001, op. cit., p 211-225.

Catteddu, I. et Nissen-Jaubert, A., 2004 - Héritages antiques et temps nouveaux, le haut Moyen Âge, in Demoule, 2004, op. cit., p. 155-169. 
Chaudriller, S., 2009 - Un habitat médiéval à Naveil (Loiret-Cher), [http://www.inrap.frlarcheologie-preventive/Sitesarcheologiques/p-2767-Un-habitat-medieval-a-Naveil.htm].

Colardelle, M. et Verdel, E., 1993 - Chevaliers-paysans de l'an mil, au lac de Paladru, Paris, éditions Errance/Musée dauphinois, $119 \mathrm{p}$.

Cuisenier, J. et Guadagnin, R., 1988 - Un village au temps de Charlemagne: moines et paysans de l'abbaye de Saint-Denis du VII siècle à l'An Mil (catalogue d'exposition), Paris, Musée des ATP, $357 \mathrm{p}$.

Demoule J.-P. (dir.), 2004 - La France archéologique. Vingt ans d'aménagements et de découvertes, Paris, éditions Hazan, 255 p.

Eschenlohr, L. et Serneels, V., 1991 - Les bas fourneaux mérovingiens de Boécourt, les Boulies (Jura Suisse), Porentruy, Cahiers d'Archéologie jurassienne (3), 143 p.

Giot, P.-R. et Monnier, J.-L., 1978 - Les oratoires des anciens bretons de Saint-Urnel ou Saint-Saturnin en Plomeur (Finistère). Archéologie médiévale, 8, p. 55-93.

Hurtin, S., 2001 - La Chapelle-Saint-Aubert/La Chaîne, in Catteddu, I. (dir.), 2001, op. cit., p 169-186.

Le Bihan, J.-P., 1986 - Aux origines de Quimper, Ville de Quimper/Ministère de la Culture, $60 \mathrm{p}$.

Le Bihan, J.-P. et Villard, J.-F., 2005 - Archéologie de Quimper : matériaux pour servir l'Histoire; tome 1, De la chute de l'Empire romain à la fin du Moyen Âge, éditions Centre de Recherche archéologique du Finistère/Cloître, Saint-Thonan, 459 p.

Le Bihan, J.-P. et Villard, J.-F., 2007 - Vestiges médiévaux et modernes place Bérardier à Quimper (DFS de diagnostic archéologique), Rennes, SRA de Bretagne.

Le Bihan, J.-P. et Villard, J.-F., en préparation - Archéologie de Quimper: matériaux pour servir l'Histoire; tome 2, Au temps de l'Empire romain, éditions Centre de Recherche archéologique du Finistère/Cloître, Saint-Thonan.

Mangin, M., Fluzin, Ph., Courtadon, J.-L. et Fontaine, M.-J., 2000 - Forgerons et paysans des campagnes d'Alésia (Haut-
Auxois, Côte-d'Or), Ir siècle avant-VIII siècle après J.-C. Paris, CNRS éditions, $508 \mathrm{p}$.

Mangin, M., 2004 - Le fer, Paris, éditions Errance, 239 p.

Menez, Y. et BatT, M., 1988 - L'habitat du haut Moyen Âge de Créac'h-Gwen à Quimper (Finistère). Revue archéologique de l'Ouest, 5, p. 123-140.

Provost, A., 1989 - Fosses néolithiques et village carolingien à La Cocherais en Tinténiac (Ille-et-Vilaine) (rapport de fouille), Rennes, SRA de Bretagne.

Roy, E., 2004 - Sondages archéologiques systématiques avant l'implantation de nouvelles constructions au 22 rue Bourg-les-Bourgs à Quimper dans le Finistère (DFS de diagnostic archéologique), Rennes, SRA de Bretagne.

SANQUER, R., 1975 - Chronique d'archéologie antique et médiévale, Bulletin de la Société archéologique du Finistère, 103, p. 87-88.

SANQUER, R., 1976 - Chronique d'archéologie antique et médiévale, Bulletin de la Société archéologique du Finistère, 104, p. 63-64.

SANQUer, R., 1977a - Chronique d'archéologie antique et médiévale, Bulletin de la Société archéologique du Finistère, 105, p. 68-70.

SANQUER, R., 1977b - Informations archéologiques, circonscription de Bretagne (Quimper Roz-Avel, p. 363-367), Gallia, 35-2, p. 335-367.

VillaRD, J.-F., 2005a - Les vestiges antiques et médiévaux du 22 de la rue Bourg-les-Bourgs à Quimper : établissements périurbains et ruraux de l'époque gallo-romaine, carolingienne tardive et du bas Moyen Âge (DFS de fouille complémentaire), Rennes, SRA de Bretagne.

VillaRD, J.-F., 2005b - La poterie : typologie et chronologie, in Le Bihan, J.- P. et Villard, J.-F., 2005, op. cit., p. 358-389. 